\title{
Implications of surgical and endoscopic interventions in the upper GI tract (with focus on management of GERD and Weight Control
}

Citation for published version (APA):

van Rijn, S. (2018). Implications of surgical and endoscopic interventions in the upper Gl tract (with focus on management of GERD and Weight Control. [Doctoral Thesis, Maastricht University]. Maastricht University. https://doi.org/10.26481/dis.20180321sr

Document status and date:

Published: 01/01/2018

DOI:

10.26481/dis.20180321sr

Document Version:

Publisher's PDF, also known as Version of record

Please check the document version of this publication:

- A submitted manuscript is the version of the article upon submission and before peer-review. There can be important differences between the submitted version and the official published version of record.

People interested in the research are advised to contact the author for the final version of the publication, or visit the DOI to the publisher's website.

- The final author version and the galley proof are versions of the publication after peer review.

- The final published version features the final layout of the paper including the volume, issue and page numbers.

Link to publication

\footnotetext{
General rights rights.

- You may freely distribute the URL identifying the publication in the public portal. please follow below link for the End User Agreement:

www.umlib.nl/taverne-license

Take down policy

If you believe that this document breaches copyright please contact us at:

repository@maastrichtuniversity.nl

providing details and we will investigate your claim.
}

Copyright and moral rights for the publications made accessible in the public portal are retained by the authors and/or other copyright owners and it is a condition of accessing publications that users recognise and abide by the legal requirements associated with these

- Users may download and print one copy of any publication from the public portal for the purpose of private study or research.

- You may not further distribute the material or use it for any profit-making activity or commercial gain

If the publication is distributed under the terms of Article $25 \mathrm{fa}$ of the Dutch Copyright Act, indicated by the "Taverne" license above, 


\section{Implications of surgical and endoscopic interventions in the upper GI tract}

(with focus on management of GERD and Weight Control) 
(C) S. van Rijn, Maastricht 2018

All rights reserved. No parts of this book may be reproduced or transmitted in any form or by any means, without prior permission in writing by the author, or when appropriate, by the publishers of the publications

Layout: Tiny Wouters

Cover design: Stefan Habets | www.stefanhabets.nl

Print: Gildeprint Drukkerijen

ISBN: 978-94-6233-887-6

Printing of this thesis was financially supported by Maastricht University and Catharina Hospital Eindhoven. 


\title{
Implications of surgical and endoscopic
} interventions in the upper GI tract

\section{(with focus on management of GERD and Weight Control)}

\author{
PROEFSCHRIFT \\ ter verkrijging van de graad van doctor aan de Universiteit Maastricht, \\ op gezag van de Rector Magnificus, Prof. dr. Rianne M. Letschert, \\ volgens het besluit van het College van Decanen, \\ in het openbaar te verdedigen \\ op woensdag 21 maart 2018 om 14.00 uur
}

door

Selwyn van Rijn 


\section{Promotoren}

Prof. dr. N.D. Bouvy

Prof. dr. A.A.M. Masclee

\section{Beoordelingscommissie}

Prof. dr. E.E. Blaak (voorzitter)

Prof. dr. M.A. Cuesta

Prof. dr. A.J.P.M. Smout

Prof. dr. L. P.S. Stassen

Dr. J.W. Straathof 


\section{Contents}

$\begin{array}{lll}\text { Chapter } 1 \quad \text { General Introduction } & 7\end{array}$

Part I Surgical complications of antireflux surgery with emphasis on $\quad 19$ vagus nerve injury

Chapter 2 Effect of vagus nerve injury on the outcome of antireflux surgery: an extensive review of literature

Chapter 3 Effect of vagus nerve integrity on short and long-term efficacy of antireflux surgery

Part II Safety and efficacy of new minimal invasive endoscopic and surgical techniques in the treatment of obesity

Chapter 4 Structural Endoscopic Techniques to treat obesity: a review

Chapter 5 Multicenter, phase 1, open prospective trial in gastric electrical stimulation for the treatment of obesity: first in human results with the Exilis system

Chapter 6 The effect of 6 and 12 months duodenal-jejunal bypass liner treatment on obesity and type 2 diabetes: a cross-over cohort study.

Chapter 7 Effect of the EndoBarrier device: a 4 year follow-up of a multicentre randomized clinical trial

Chapter 8 General discussion

Part III Addendum

Valorisation addendum

Samenvatting

List of publications

About the author

Dankwoord 



\section{Chapter 1}

General introduction 



\section{Surgery for gastroesophageal reflux disease}

\section{Epidemiology of gastroesophageal reflux disease and its treatment options}

Over the last decades gastroesophageal reflux disease (GERD) has become a serious health burden with high prevalences among the population ranging from $18-28 \%$ in North America and $9-26 \%$ in Europe. ${ }^{1-3}$ GERD has now reached first position with respect to frequency of gastrointestinal diagnoses in the US. The costs of proton pump inhibitor (PPI) usage for acid related disorders amount up to 10 billon dollars yearly. ${ }^{4}$ Despite the fact that surgery has proven to be more effective than medical treatment for GERD, medical therapy with PPIs remains the treatment of choice. ${ }^{5}$ According to recently published guidelines by the EAES, surgery for GERD is only indicated for patients needing increasing doses of PPI because of persisting symptoms, who require life long medical treatment, or who are refractory to medical treatment with PPI. ${ }^{6} \mathrm{PPI}$ use is considered safe, although risk of pneumonia, intestinal infections, hip fractures and deficiency of vitamin B12, iron and other micronutrients is slightly increased in long term PPI users. ${ }^{7-11}$ In addition recent studies have pointed to changes in intestinal microbial composition during PPI use. ${ }^{12}$

The first antireflux procedure was described by Nissen in $1956 .{ }^{13}$ For seven years this was the primary procedure for antireflux surgery (ARS). In 1963 this changed when Toupet described another approach for ARS. ${ }^{14}$ During these procedures the esophageal hiatus is reduced to its normal size and the gastric fundus of the stomach is partially 270 degrees (Toupet) or totally 360 degrees (Nissen) wrapped around the lower end of the esophagus thereby reinforcing the mechanical barrier of the lower esophageal sphincter. ${ }^{13,14}$

The Laparoscopic Nissen fundoplication (LNF) and laparoscopic Toupet fundoplication (LTF) are the most commonly employed surgical techniques to treat GERD. ARS has proven to be effective in the treatment of GERD on both short and long term followup. $^{15-23}$

\section{Complications after ARS with emphasis on vagus nerve injury}

Despite the adequate results seen after ARS, peri- and postoperative complications occur. Specific postoperative symptoms consist of dysphagia, diarrhea, gas bloating syndrome, vomiting or inability to vomit, inability to belch and other gas related symptoms, heartburn and reflux recurrence. Specific peri-operative complications for LNF and LTF consist of vagus nerve injury, vascular injuries, pneumothorax, pneumomediastinum and gastrointestinal tract perforations. ${ }^{24,25}$

Vagus nerve injury is a feared complication. Up till now the effect of vagus nerve injury has primarily been evaluated by the presence of accompanying symptoms (nausea, vomiting and diarrhea) as seen after vagotomy. ${ }^{26-28}$ At present, objective tests are available to quantify vagus nerve integrity by the response of plasma 
pancreatic polypeptide secretion to insulin-induced hypoglycemia or to sham feeding. ${ }^{29,30}$ Two previous studies assessing vagus nerve integrity after ARS using this technique have shown a prevalence of vagus nerve injury ranging from $10-40 \% .{ }^{31,32}$ In these studies no significant differences were seen regarding the postoperative outcome of ARS between patients with and without vagus nerve injury. However the number of patients evaluated in those studies was small and only short-term followup was available. Therefore the true prevalence of vagus nerve injury after ARS and its effect on the outcome of ARS remain unknown. In this thesis our aim was to obtain more detailed insight in the long-term consequences of vagal nerve injury after ARS.

\section{Gastroesophageal reflux disease and obesity}

Weight gain and overweight are important risk factors for the development of GERD. A higher intra-abdominal pressure, higher prevalence of hiatal hernia and increased transient LES relaxations (TLESR's) seen in the obese population cause obese patients to be at higher risk of developing GERD. ${ }^{33}$ An increase in Body Mass Index (BMI) is associated with an increase in esophageal acid exposure time and severity of GERD. ${ }^{34-36}$ Most important, central adiposity has been associated with increased risk of developing esophagitis, Barrett's esophagus and esophageal cancer. ${ }^{37}$

A recent longitudinal study of 15295 subjects showed that weight loss in subjects with general or abdominal obesity led to improvement of GERD symptoms. ${ }^{38}$

In the rapidly growing obese population who also suffer from GERD symptoms, weight loss interventions come to play an even more important role and will also help to control reflux symptoms.

\section{Surgery for the treatment of morbid obesity}

\section{Epidemiology and consequences of obesity}

Obesity has become a global burden. Since 1980 the prevalence of obesity has more than doubled worldwide. Now 1.9 billion people are overweight and over 600 million people are obese which accounts for $13 \%$ of the overall population worldwide. ${ }^{39}$ The disease has not only become a social burden but also has a considerable economic impact. Yearly national medical care costs in the USA related to obesity have been estimated to be around 210 billion USD, which would account for approximately $20 \%$ of the total annual US healthcare expenditures. ${ }^{40}$

Obesity is defined as an excessive fat accumulation that may impair health and is divided into three classes according to the body mass index (BMI); class $1 \mathrm{BMI}$ $30-35 \mathrm{~kg} / \mathrm{m}^{2}$, class $2 \mathrm{BMI} 35-40 \mathrm{~kg} / \mathrm{m}^{2}$, class $3 \mathrm{BMI} \geq 40 \mathrm{~kg} / \mathrm{m}^{2} .39$

It has been documented that obesity is associated with a significantly higher risk of developing several other disorders, either metabolic (type 2 diabetes mellitus), or 
cardiovascular, sleep apnea, arthrosis, more rapid degradation of musculoskeletal organs and even a higher risk of developing cancer. ${ }^{41-45}$

\section{Current standard surgical procedures and new minimal invasive surgical techniques to treat obesity}

Current bariatric surgical techniques have proven to be more effective in establishing weight loss and decreasing overweight-associated comorbidities than non-surgical treatments. ${ }^{46}$ In addition, surgery also appears to be cost-effective compared to nonsurgical treatments. ${ }^{47}$

Nowadays the most commonly applied surgical techniques are the Roux and $Y$ Gastric Bypass (RYGB) and the sleeve gastrostomy (SG). The SG is a restrictive procedure while RYGB combines a restrictive with a malabsorptive procedure. These two surgical procedures are effective in reducing body weight and reducing comorbidity not only on the short term but also on long-term follow-up. ${ }^{46,48-53}$ Unfortunately these procedures are accompanied by peri- and postoperative complications. The most common complications after LRYGB include infections (1.0\%), bleeding (1.4\%), internal herniation (1.1\%), anastomotic leakage (1.0\%) and anastomotic stenosis $(1.4 \%) .{ }^{54,55}$ In addition, problems with the absorption of iron, calcium and vitamin B12 are frequently encountered, should be anticipated by standardized postoperative supplementation. $^{56}$ In LSG staple line leakage develops in approximately $1 \%$ of patients. ${ }^{57}$ Mortality rates after these procedures is $<1 \%{ }^{53,58}$ According to current guidelines on bariatric surgery, only patients with a $\mathrm{BMI} \geq 35 \mathrm{~kg} / \mathrm{m}^{2}$ with comorbidities or patients with a $B M I \geq 40 \mathrm{~kg} / \mathrm{m}^{2}$ are considered eligible for surgery. ${ }^{59,60}$

To even further minimize surgical complications and to broaden the therapeutic range of bariatric surgery, less invasive new bariatric surgical techniques have been developed with the intention to provide a solution for the growing overweight and obese population. Over the past years several new laparoscopic and endoluminal techniques have been designed to temporarily (intra-gastric balloons, duodenaljejunal bypass liner (DJBL), Gastric Electrical Stimulating Systems) or structurally (such as: Primary Obesity Surgery Endoluminal Procedure, Transoral Gastric Volume Reduction, Transoral Gastroplasty, Articulating Circular Endoscopic Stapler Device, Gastric Electrical Sitimulating Systems) change the gastrointestinal anatomy and/or its function, thereby trying to mimic the results of the standard bariatric surgical procedures. These techniques have not shown uniform positive results concerning weight loss and effects on obesity related comorbidities. ${ }^{61-69}$ Their role in the treatment of obesity remains to be established. Further investigations and long-term follow up studies with adequate designs are urgently needed. 


\section{Aim and outline of this thesis}

In this thesis, we have aimed to investigate 1) the effect of vagus nerve integrity on the outcome of ARS and 2) the safety and effectiveness of new minimal invasive techniques in the treatment of obesity.

The first part of this thesis focuses on the role of vagus nerve integrity on the outcome of reflux symptoms, reflux control, and quality of life after anti-reflux surgery.

Chapter 2 provides an overview of the current literature and evaluates the effect of intended and accidental vagus nerve injury on the outcome of antireflux surgery.

Chapter 3 describes the short and long term effects of vagus nerve integrity, objectively measured by the response of plasma pancreatic polypeptide to insulininduced hypoglycemia, $\mathrm{pH}$-monitoring, manometry and gastric motility testing, on the outcome of antireflux surgery in patients with long term follow up.

The second aim of this thesis was to investigate the safety and effectiveness of new minimal invasive surgical techniques and their potential role in the treatment of obesity.

Chapter 4 provides an extensive literature review describing the safety and effectiveness of structural endoluminal bariatric procedures in the treatment of obesity.

Chapter 5 evaluates the first human experience with the Exilis ${ }^{\mathrm{TM}}$ GES system and its effect on safety of chronic stimulation, gastric motility, food intake and establishing weight loss.

Chapter 6 describes the effect and safety of 6 and 12 months of implantation with the duodenal jejunal bypass liner (DJBL) after a controlled diet period. To examine the effect of the DJBL on obesity and type 2 diabetes mellitus patients underwent a standard physical examination, blood sampling, assessment of adverse events, nutritional and diabetes counseling and a standardized meal tolerance test.

Chapter 7 presents a first report on the long-term outcome of a randomized clinical trail assessing the effect of DJBL treatment on obesity. Four years after removal of the DJBL patients eligible for follow-up underwent a standardized physical examination and blood sampling as previously performed during the initial study. 
Finally, in Chapter 8, we combine and discuss the findings of the various chapters. The data are interpreted taking into account the current knowledge form on literature data. We describe what our findings add with respect to published data on surgical or endoscopic or minimally invasive procedures for GERD and morbid obesity. 


\section{References}

1. El-Serag HB, Sweet S, Winchester CC, Dent J. Update on the epidemiology of gastro-oesophageal reflux disease: a systematic review. Gut. 2014;63(6):871-80.

2. Peery AF, Dellon ES, Lund J, Crockett SD, McGowan CE, Bulsiewicz WJ, et al. Burden of gastrointestinal disease in the United States: 2012 update. Gastroenterology. 2012;143(5):1179-87 e1-3.

3. Shaheen NJ, Hansen RA, Morgan DR, Gangarosa LM, Ringel Y, Thiny MT, et al. The burden of gastrointestinal and liver diseases, 2006. Am J Gastroenterol. 2006;101(9): 2128-38.

4. Gawron AJ, French DD, Pandolfino JE, Howden CW. Economic evaluations of gastroesophageal reflux disease medical management. PharmacoEconomics. 2014;32(8):745-58.

5. Grant AM, Boachie C, Cotton SC, Faria R, Bojke L, Epstein DM, et al. Clinical and economic evaluation of laparoscopic surgery compared with medical management for gastro-oesophageal reflux disease: 5-year follow-up of multicentre randomised trial (the REFLUX trial). Health Technol Assess. 2013;17(22):1-167.

6. Fuchs $\mathrm{KH}$, Babic B, Breithaupt $\mathrm{W}$, Dallemagne B, Fingerhut A, Furnee $E$, et al. EAES recommendations for the management of gastroesophageal reflux disease. Surgical endoscopy. 2014;28(6):1753-73.

7. Schoenfeld AJ, Grady D. Adverse Effects Associated With Proton Pump Inhibitors. JAMA Intern Med. 2016;176(2):172-4.

8. Gomm W, von Holt K, Thome F, Broich K, Maier W, Fink A, et al. Association of Proton Pump Inhibitors With Risk of Dementia: A Pharmacoepidemiological Claims Data Analysis. JAMA Neurol. 2016;73(4): 410-6.

9. Lam JR, Schneider JL, Zhao W, Corley DA. Proton pump inhibitor and histamine 2 receptor antagonist use and vitamin B12 deficiency. JAMA. 2013;310(22):2435-42.

10. Corley DA, Kubo A, Zhao W, Quesenberry C. Proton pump inhibitors and histamine-2 receptor antagonists are associated with hip fractures among at-risk patients. Gastroenterology. 2010;139(1):93-101.

11. Lam JR, Schneider JL, Quesenberry CP, Corley DA. Proton Pump Inhibitor and Histamine-2 Receptor Antagonist Use and Iron Deficiency. Gastroenterology. 2017;152(4):821-9 e1.

12. Jackson MA, Goodrich JK, Maxan ME, Freedberg DE, Abrams JA, Poole AC, et al. Proton pump inhibitors alter the composition of the gut microbiota. Gut. 2016;65(5):749-56.

13. Nissen R. [A simple operation for control of reflux esophagitis]. Schweiz Med Wochenschr. 1956;86(Suppl 20):590-2.

14. Toupet A. [Technic of esophago-gastroplasty with phrenogastropexy used in radical treatment of hiatal hernias as a supplement to Heller's operation in cardiospasms]. Mem Acad Chir (Paris). 1963;89:384-9.

15. Shaw JM, Bornman PC, Callanan MD, Beckingham IJ, Metz DC. Long-term outcome of laparoscopic Nissen and laparoscopic Toupet fundoplication for gastroesophageal reflux disease: a prospective, randomized trial. Surg Endosc. 2010;24(4):924-32.

16. Simorov A, Ranade A, Jones R, Tadaki C, Shostrom V, Boilesen E, et al. Long-term patient outcomes after laparoscopic anti-reflux procedures. J Gastrointest Surg. 2014;18(1):157-62; discussion 62-3.

17. Mardani J, Lundell L, Engstrom C. Total or posterior partial fundoplication in the treatment of GERD: results of a randomized trial after 2 decades of follow-up. Ann Surg. 2011;253(5):875-8.

18. Kamolz T, Granderath FA, Bammer T, Wykypiel H, Jr., Pointner R. "Floppy" Nissen vs. Toupet laparoscopic fundoplication: quality of life assessment in a 5-year follow-up (part 2). Endoscopy. 2002;34(11):917-22.

19. Hagedorn C, Lonroth H, Rydberg L, Ruth M, Lundell L. Long-term efficacy of total (Nissen-Rossetti) and posterior partial (Toupet) fundoplication: results of a randomized clinical trial. J Gastrointest Surg. 2002;6(4):540-5.

20. Engstrom C, Cai W, Irvine T, Devitt PG, Thompson SK, Game PA, et al. Twenty years of experience with laparoscopic antireflux surgery. Br J Surg. 2012;99(10):1415-21.

21. Fein M, Bueter M, Thalheimer A, Pachmayr V, Heimbucher J, Freys SM, et al. Ten-year outcome of laparoscopic antireflux surgery. J Gastrointest Surg. 2008;12(11):1893-9. 
22. Blazejczyk K, Hoene A, Glitsch A, Busemann A, Heidecke CD, Patrzyk M. Evaluation of short-term and long-term results after laparoscopic antireflux surgery: esophageal manometry and 24- $\mathrm{h} \mathrm{pH}$ monitoring versus quality of life index. Langenbeck's archives of surgery / Deutsche Gesellschaft fur Chirurgie. 2013;398(8):1107-14.

23. Dallemagne B, Perretta S. Twenty years of laparoscopic fundoplication for GERD. World J Surg. 2011;35(7):1428-35.

24. Watson DI, de Beaux AC. Complications of laparoscopic antireflux surgery. Surg Endosc. 2001;15(4):344-52.

25. Richter JE. Gastroesophageal reflux disease treatment: side effects and complications of fundoplication. Clin Gastroenterol Hepatol. 2013;11(5):465-71; quiz e39.

26. Koo J, Lam SK, Chan P, Lee NW, Lam P, Wong J, et al. Proximal gastric vagotomy, truncal vagotomy with drainage, and truncal vagotomy with antrectomy for chronic duodenal ulcer. A prospective, randomized controlled trial. Ann Surg. 1983;197(3):265-71.

27. Hoffmann J, Jensen HE, Christiansen J, Olesen A, Loud FB, Hauch O. Prospective controlled vagotomy trial for duodenal ulcer. Results after 11-15 years. Ann Surg. 1989;209(1):40-5.

28. Engel JJ, Spellberg MA. Complications of vagotomy. Am J Gastroenterol. 1978;70(1):55-60.

29. Schwartz TW. Pancreatic polypeptide: a hormone under vagal control. Gastroenterology. 1983;85(6): 1411-25.

30. Schwartz TW, Holst JJ, Fahrenkrug J, Jensen SL, Nielsen OV, Rehfeld JF, et al. Vagal, cholinergic regulation of pancreatic polypeptide secretion. J Clin Invest. 1978;61(3):781-9.

31. DeVault KR, Swain JM, Wentling GK, Floch NR, Achem SR, Hinder RA. Evaluation of vagus nerve function before and after antireflux surgery. J Gastrointest Surg. 2004;8(7):883-8; discussion 8-9.

32. Lindeboom MY, Ringers J, van Rijn PJ, Neijenhuis P, Stokkel MP, Masclee AA. Gastric emptying and vagus nerve function after laparoscopic partial fundoplication. Ann Surg. 2004;240(5):785-90.

33. Nadaleto BF, Herbella FA, Patti MG. Gastroesophageal reflux disease in the obese: Pathophysiology and treatment. Surgery. 2016;159(2):475-86.

34. Ayazi S, Hagen JA, Chan LS, DeMeester SR, Lin MW, Ayazi A, et al. Obesity and gastroesophageal reflux: quantifying the association between body mass index, esophageal acid exposure, and lower esophageal sphincter status in a large series of patients with reflux symptoms. J Gastrointest Surg. 2009;13(8):1440-7.

35. Hajar N, Castell DO, Ghomrawi H, Rackett R, Hila A. Impedance pH confirms the relationship between GERD and BMI. Dig Dis Sci. 2012;57(7):1875-9.

36. Park SK, Lee T, Yang HJ, Park JH, Sohn Cl, Ryu S, et al. Weight loss and waist reduction is associated with improvement in gastroesophageal disease reflux symptoms: A longitudinal study of 15295 subjects undergoing health checkups. Neurogastroenterol Motil. 2017;29(5).

37. Herbella FA, Sweet MP, Tedesco P, Nipomnick I, Patti MG. Gastroesophageal reflux disease and obesity. Pathophysiology and implications for treatment. J Gastrointest Surg. 2007;11(3):286-90.

38. Singh S, Sharma AN, Murad MH, Buttar NS, El-Serag HB, Katzka DA, et al. Central adiposity is associated with increased risk of esophageal inflammation, metaplasia, and adenocarcinoma: a systematic review and meta-analysis. Clin Gastroenterol Hepatol. 2013;11(11):1399-412 e7.

39. World Health Organization, 2006 Contract No.: Fact sheet number 311, updated January 2015.

40. Cawley J, Meyerhoefer C. The medical care costs of obesity: an instrumental variables approach. J Health Econ. 2012;31(1):219-30.

41. Arnold M, Pandeya N, Byrnes G, Renehan AG, Stevens GA, Ezzati M, et al. Global burden of cancer attributable to high body-mass index in 2012: a population-based study. Lancet Oncol. 2015;16(1): 36-46.

42. Martin-Rodriguez E, Guillen-Grima F, Marti A, Brugos-Larumbe A. Comorbidity associated with obesity in a large population: The APNA study. Obes Res Clin Pract. 2015;9(5):435-47.

43. Global Burden of Metabolic Risk Factors for Chronic Diseases C. Cardiovascular disease, chronic kidney disease, and diabetes mortality burden of cardiometabolic risk factors from 1980 to 2010: a comparative risk assessment. Lancet Diabetes Endocrinol. 2014;2(8):634-47.

44. Guh DP, Zhang W, Bansback N, Amarsi Z, Birmingham CL, Anis AH. The incidence of co-morbidities related to obesity and overweight: a systematic review and meta-analysis. BMC Public Health. 2009;9:88. 
45. Mahajan R, Lau DH, Sanders P. Impact of obesity on cardiac metabolism, fibrosis, and function. Trends Cardiovasc Med. 2015;25(2):119-26.

46. Colquitt JL, Pickett K, Loveman E, Frampton GK. Surgery for weight loss in adults. The Cochrane database of systematic reviews. 2014 (8):CD003641.

47. Picot J, Jones J, Colquitt JL, Gospodarevskaya E, Loveman E, Baxter L, et al. The clinical effectiveness and cost-effectiveness of bariatric (weight loss) surgery for obesity: a systematic review and economic evaluation. Health Technol Assess. 2009;13(41):1-190, 215-357, iii-iv.

48. Mehaffey JH, LaPar DJ, Clement KC, Turrentine FE, Miller MS, Hallowell PT, et al. 10-Year Outcomes After Roux-en-Y Gastric Bypass. Ann Surg. 2016;264(1):121-6.

49. Obeid NR, Malick W, Concors SJ, Fielding GA, Kurian MS, Ren-Fielding CJ. Long-term outcomes after Roux-en-Y gastric bypass: 10- to 13-year data. Surg Obes Relat Dis. 2016;12(1):11-20.

50. Gadiot RP, Biter LU, van Mil S, Zengerink HF, Apers J, Mannaerts GH. Long-term results of laparoscopic sleeve gastrectomy for morbid obesity: 5 to 8-year results. Obesity Surg. 2017;27(1): 59-63

51. Arman GA, Himpens J, Dhaenens J, Ballet T, Vilallonga R, Leman G. Long-term (11+years) outcomes in weight, patient satisfaction, comorbidities, and gastroesophageal reflux treatment after laparoscopic sleeve gastrectomy. Surg Obes Relat Dis. 2016 Dec;12(10):1778-86.

52. Dicker D, Yahalom R, Comaneshter DS, Vinker S. Long-term outcomes of three types of bariatric surgery on obesity and type 2 diabetes control and remission. Obes Surg. 2016;26(8):1814-20.

53. Chang SH, Stoll CR, Song J, Varela JE, Eagon CJ, Colditz GA. The effectiveness and risks of bariatric surgery: an updated systematic review and meta-analysis, 2003-2012. JAMA Surg. 2014;149(3): 275-87.

54. Smith MD, Adeniji A, Wahed AS, Patterson E, Chapman W, Courcoulas AP, et al. Technical factors associated with anastomotic leak after Roux-en-Y gastric bypass. Surg Obes Relat Dis. 2015;11(2): 313-20.

55. Rausa E, Bonavina L, Asti E, Gaeta M, Ricci C. Rate of death and complications in laparoscopic and open roux-en-y gastric bypass. A meta-analysis and meta-regression analysis on 69,494 patients. Obes Surg. 2016;26(8):1956-63.

56. Alvarez-Leite Jl. Nutrient deficiencies secondary to bariatric surgery. Curr Opin Clin Nutr Metab Care. 2004;7(5):569-75.

57. Rosenthal RJ, International Sleeve Gastrectomy Expert P, Diaz AA, Arvidsson D, Baker RS, Basso N, et al. International Sleeve Gastrectomy Expert Panel Consensus Statement: best practice guidelines based on experience of $>12,000$ cases. Surg Obes Relat Dis. 2012;8(1):8-19.

58. Longitudinal Assessment of Bariatric Surgery C, Flum DR, Belle SH, King WC, Wahed AS, Berk P, et al. Perioperative safety in the longitudinal assessment of bariatric surgery. N Engl J Med. 2009; 361(5):445-54.

59. Sauerland S, Angrisani L, Belachew M, Chevallier JM, Favretti F, Finer N, et al. Obesity surgery: evidence-based guidelines of the European Association for Endoscopic Surgery (EAES). Surgical endoscopy. 2005;19(2):200-21.

60. Verdam FJ, de Jonge C, Greve JW. Practice guideline for the treatment of morbid obesity. Ned Tijdschr Geneeskd. 2012;156(23):A4630.

61. Koehestanie P, de Jonge C, Berends FJ, Janssen IM, Bouvy ND, Greve JW. The effect of the endoscopic duodenal-jejunal bypass liner on obesity and type 2 diabetes mellitus, a multicenter randomized controlled trial. Ann Surg. 2014;260(6):984-92.

62. Schouten R, Rijs CS, Bouvy ND, Hameeteman W, Koek GH, Janssen IM, et al. A multicenter, randomized efficacy study of the EndoBarrier Gastrointestinal Liner for presurgical weight loss prior to bariatric surgery. Ann Surg. 2010;251(2):236-43.

63. Kim SH, Chun HJ, Choi HS, Kim ES, Keum B, Jeen YT. Current status of intragastric balloon for obesity treatment. World J Gastroenterol. 2016;22(24):5495-504.

64. Brethauer SA, Chand B, Schauer PR, Thompson CC. Transoral gastric volume reduction as intervention for weight management: 12-month follow-up of TRIM trial. Surg Obes Relat Dis. 2012;8(3):296-303.

65. Familiari P, Costamagna G, Blero D, Le Moine O, Perri V, Boskoski I, et al. Transoral gastroplasty for morbid obesity: a multicenter trial with a 1-year outcome. Gastrointest Endosc. 2011;74(6):1248-58.

66. Leccesi L, Panunzi S, De Gaetano A, Familiari P, laconelli A, Guidone C, et al. Effects of transoral gastroplasty on glucose homeostasis in obese subjects. J Clin Endocrinol Metab. 2013;98(5):1901-10. 
67. Espinos JC, Turro R, Mata A, Cruz M, da Costa M, Villa V, et al. Early experience with the Incisionless Operating Platform (IOP) for the treatment of obesity : the Primary Obesity Surgery Endolumenal (POSE) procedure. Obesity Surg. 2013;23(9):1375-83.

68. Verlaan T, Paulus GF, Mathus-Vliegen EM, Veldhuyzen EA, Conchillo JM, Bouvy ND, et al. Endoscopic gastric volume reduction with a novel articulating plication device is safe and effective in the treatment of obesity (with video). Gastrointest Endosc. 2015;81(2):312-20.

69. Cha R, Marescaux J, Diana M. Updates on gastric electrical stimulation to treat obesity: Systematic review and future perspectives. World J Gastrointest Endosc. 2014;6(9):419-31. 



\section{Part}

Surgical complications of antireflux surgery with emphasis on vagus nerve injury 



\section{Chapter 2}

Effect of vagus nerve injury on the outcome of antireflux surgery: an extensive literature review

S. van Rijn, Y.G.M. Roebroek, J.M. Conchillo, N.D. Bouvy, A.A.M. Masclee Dig Surg. 2016;33(3):230-9 


\section{Abstract}

\section{Background}

Vagus nerve injury is a feared complication of antireflux surgery (ARS). The impact of vagus nerve injury on the functional outcomes of antireflux surgery (ARS) has not yet been evaluated systematically. Aim of this review was to evaluate the impact of vagus nerve injury on functional and clinical outcome of ARS.

\section{Methods}

A systematic search was performed until March 2015, using the following online databases: MEDLINE, EMbase and the Cochrane Register of Controlled Clinical Trials. Eight studies remained available for assessment. Articles were divided into two groups: a) one with unintended, accidental vagus nerve injury and b) one group comparing ARS with and without intended vagotomy.

\section{Results}

The prevalence of unintended, accidental vagus nerve injury ranged from $10-42 \%$ after ARS. No clear differences were seen in outcome for reflux control between the vagus nerve injury and vagus nerve intact group. A higher prevalence of diarrhea, nausea and vomiting was present in the vagus nerve injury group.

\section{Conclusion}

Vagus nerve injury is a feared but neglected complication of ARS. Larger prospective studies that objectively assess vagus nerve integrity before and after ARS are needed. 


\section{Introduction}

In Western societies the prevalence of gastroesophageal reflux disease (GERD) is known to be up to $10-20 \% .{ }^{1,2}$ Changes in lifestyle and medical therapy, preferably with proton pump inhibitors (PPI), are the first steps in the treatment of GERD. ${ }^{3}$ Antireflux surgery (ARS) is considered as an alternative treatment modality for patients who need increasing doses of PPI, for patients who require life-long medical treatment, or are refractory to medical treatment with PPIs. The most commonly employed techniques in ARS are Nissen fundoplication (NF) and Toupet fundoplication (TF). ${ }^{4,5}$ With these procedures excellent results have been obtained regarding symptomatic outcome and safety on both short and long term follow-up. ${ }^{6-11}$ Despite these encouraging results, ARS is still accompanied by specific surgery related peri- and postoperative complications and by unwanted postoperative symptoms. ${ }^{9,12-14}$

Vagus nerve injury is a feared complication of ARS. The functional changes and consequences of this type of injury have not been investigated or evaluated systematically and the clinical consequences remain unclear for that reason. Earlier studies reporting on the effect of intended vagotomy for gastric ulcer disease show that vagotomy is accompanied by gastric stasis (nausea 15\%, vomiting $4 \%$ ), diarrhea $(20-30 \%)$ and dumping syndrome (10\%). ${ }^{15-19}$ latrogenic or accidental vagus nerve injury during antireflux surgery may have effects similar to those after intended vagotomy and therefore may contribute to newly developed postoperative symptoms and to impaired reflux control after ARS.

Accidental vagus nerve injury is difficult to diagnose. In the clinical setting no methods are available to directly evaluate vagus nerve (dys)function. The prevalence of vagus nerve injury after ARS has been estimated in the past based on onset of newly developed postoperative symptoms associated with vagus nerve injury such as diarrhea, nausea and vomiting that have been associated with vagus nerve injury. ${ }^{12,17,18,20}$ An objective but indirect method to measure abdominal vagus nerve function is based on the response of plasma pancreatic polypeptide (PP) secretion to insulin-induced hypoglycemia, the IH-PP test or on the response of plasma PP to modified sham feeding, a vagal-cholinergic stimulus. ${ }^{21,22} \mathrm{Up}$ to now, the incidence and prevalence of vagus nerve injury after ARS and its effect on the outcome of ARS has not been evaluated systematically.

The aim of this review is to systematically evaluate the impact of vagus nerve injury on the clinical outcome of ARS. We hypothesize that vagus nerve injury will have a negative impact on reflux control and GERD related symptoms, on gastric emptying and on quality of life after both short and long term follow-up. 


\section{Methods}

The guidelines described in the Preferred Reporting Items for Systematic Reviews and Meta-Analyses (PRISMA) statement on identification and selection of individual studies were followed throughout the search of this extensive literature review. ${ }^{23}$

A comprehensive systematic search was performed until March 2015, using the following online databases: MEDLINE, EMbase and the Cochrane Register of Controlled Clinical Trials. The search terms and Boolean operators that were used are: ("Fundoplication"[Mesh] OR Fundoplication OR Nissen OR Toupet OR (Hernia AND repair) OR (Wrap AND (Stomach OR Fundic OR esophageal OR esophagus)) OR (("General Surgery"[Mesh] OR "Surgical Procedures, Operative"[Mesh] OR "Surgery"[Mesh] OR operation OR procedure) AND ("Gastroesophageal Reflux"[Mesh] OR (Gastroesophageal reflux) OR GERD OR GORD OR Reflux OR anti-reflux OR antireflux))) AND ("Vagotomy"[Mesh] OR "Vagotomy, Truncal"[Mesh] OR "Vagotomy, Proximal Gastric"[Mesh] OR (Vagus nerve) OR (Vagal nerve) OR vagotomy OR (vagal damage) OR (vagal injury)) AND (English[lang]). All abstracts were screened for eligibility by two independent reviewers (YR and SvR).

\section{Study selection}

Only studies that had been conducted in human subjects undergoing surgical treatment for gastroesophageal reflux were included. Articles comparing ARS solely to ARS combined with vagotomy were included, as well as articles diagnosing unintended vagus nerve injury after ARS and reporting on associated outcomes. ARS was defined as any procedure primarily developed for gastroesophageal reflux disease (e.g., Nissen fundoplication, Toupet fundoplication, anterior fundoplication, Hill gastropexy, hiatal hernia repair). Articles were only included when reporting on the type of vagotomy accompanying the ARS, since only truncal and selective vagotomy can be assumed to mimic the type of unintended vagus nerve injury during ARS. In the case of iatrogenic vagus nerve injury, the injury needs to be diagnosed by PP-testing both before surgery (intact) and after surgery (impaired). Furthermore, studies assessing the effect of vagus nerve injury after re-operations were only included when vagus nerve injury was objectively measured prior to the re-operation since vagus nerve injury could already be present after the primary antireflux procedure.

Surgical procedures for acid reflux that remove part(s) of the stomach, esophagus or duodenum were not included in this review. In addition, the following exclusion criteria were used: only reporting on ARS without vagotomy (no intervention group); only reporting on ARS with vagotomy (no control group); vagotomy without ARS; surgical procedures because of malignancy; ARS in patients with malignancy; pediatric study; article reporting only on patients with recurrent symptoms after surgery (no 
systematic follow-up); animal study; review; meta-analysis; case report; (conference) abstract; comment.

In addition to the online search, the references of the selected articles were screened for eligibility following the same selection process. After exclusion of the abstracts not meeting our criteria, full articles were assessed for eligibility using the exclusion criteria mentioned earlier (Figure 2.1). Discrepancies in the selection of studies were solved by discussion with the senior authors (NB and AM).

\section{Results}

\section{Search strategy and study selection}

During the initial systematic search 1328 potentially useful articles were identified. After exclusion of 78 duplicates, 1250 potentially eligible articles remained. Two authors (SR and YR) screened all abstracts separately, thereby excluding 1191 articles. A total of 59 articles were read in detail for further eligibility assessment. The full text of these remaining articles was read and assessed for applicability. In this phase, another 51 articles were excluded and 8 studies were incorporated for final analysis in this systematic review (Flowchart Figure 2.1).

\section{General study characteristics}

In the eight studies selected for this review, data were reported on a total of 893 patients. ${ }^{24-31}$ In all studies two groups were compared: one in which vagus nerve integrity was maintained and one with vagus nerve injury. In total, the vagus nerve intact group consisted of 559 patients and the vagus nerve injury group of 331 patients. Six studies reported on the outcome between both groups comparing antireflux surgery (ARS) alone with ARS combined with an intended vagotomy. ${ }^{26-31}$ In three of these six studies vagotomy was added to the antireflux procedure because of acid hypersecretion, severe esophagitis or peptic ulcer disease (PUD). The two remaining studies reported on unintended, accidental vagus nerve injury objectively measured by the response of pancreas polypeptide to insulin-induced hypoglycemia (PP-IH) or to sham feeding PP-SF). ${ }^{21,22,24,25}$ Different operative techniques were used in the eight selected studies: laparoscopic Toupet fundoplication (LTF), Toupet fundoplication (TF), laparoscopic Nissen fundoplication (LNF), Nissen fundoplication (NF), Anterior fundoplication (AF), Hill posterior gastropexy (HPG), Hiatal hernia repair (HHR) and Lortat Jacobs fundopexia (LJF). In addition, the vagotomy procedure was not uniform: different techniques have been employed from truncal vagotomy combined with pyloroplasty or pyloromyotomy to proximal gastric vagotomy alone. Overall follow-up of patients ranged from 6 months to 12 years post-surgery. A detailed overview of all study characteristics is given in Tables 2.1-2.4. 

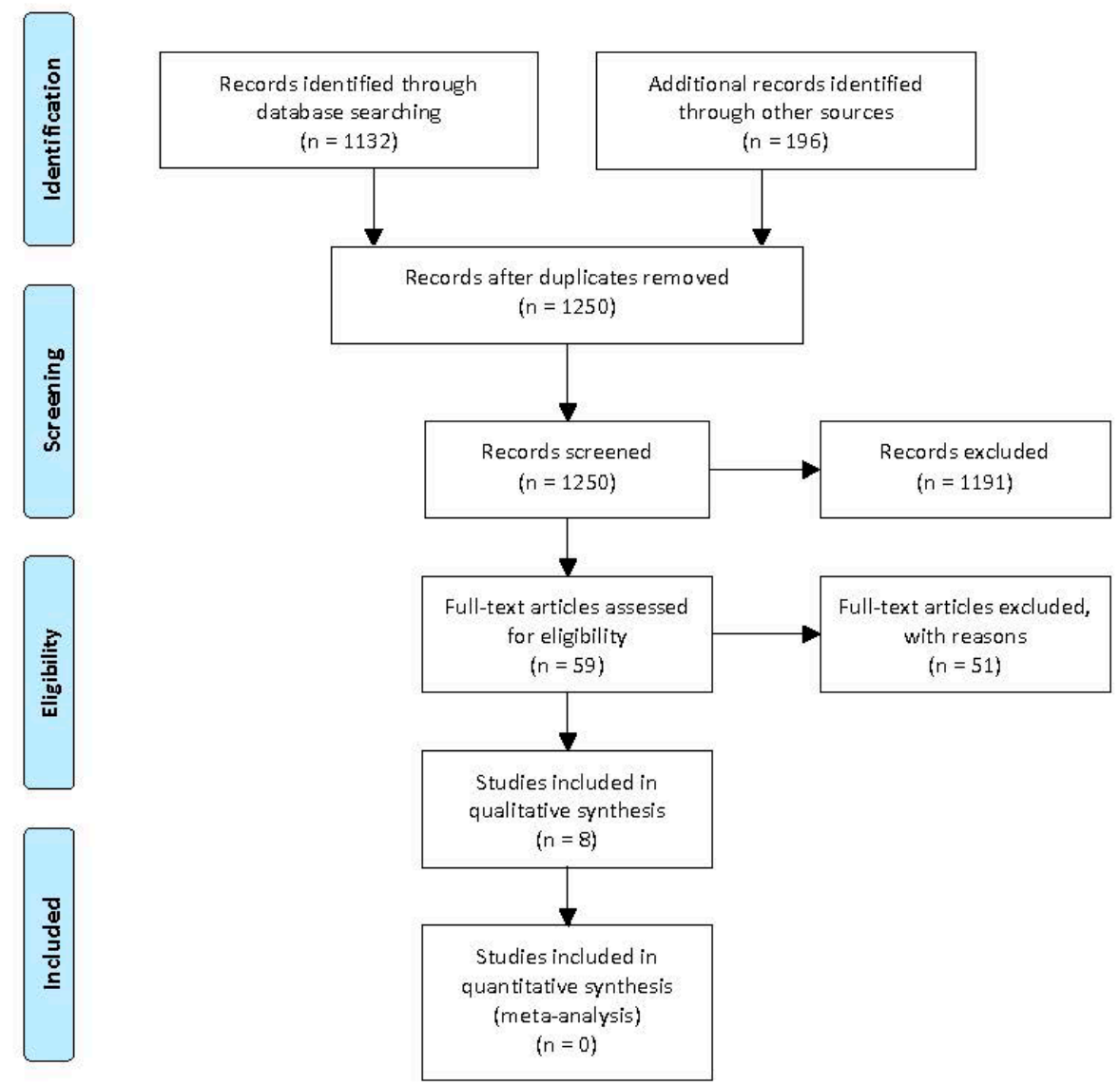

Figure 2.1 Prisma 2009 flow diagram

\section{Intended vagus nerve injury}

The majority of selected studies investigated the influence of intended vagus nerve injury on the outcome of ARS. ${ }^{26-31}$ See Table 2.1 and 2.2. 
Table 2.1 Characteristics of studies reporting on intended vagotomy

\begin{tabular}{lccrrr}
\hline Author & Year & ARS & Type of vagotomy & \multicolumn{2}{c}{ Patients [n] } \\
\cline { 5 - 6 } & & & & With vagotomy & Without vagotomy \\
\hline Woodward & 1971 & CR; NF & VP & 98 & 133 \\
Wilson & 1974 & SR; NF & VP & 25 & 56 \\
Mokka & 1976 & NF; HHR; APF; LF & VP & 17 & 69 \\
Vansant & 1976 & HP & VP & 118 & 152 \\
O'Rourke & 1985 & (N)F; HP & VP & 19 & 37 \\
Jamieson & 1991 & NF & PGV & 34 & 20 \\
\hline
\end{tabular}

ARS: Anti-reflux surgery. CR: Crural repair. NF: Nissen fundoplication. SR: simple repair. HHR: hiatal hernia repair. APF: anterior partial fundoplication. LF: Lortat Jacobs Fundopexia. HP: Hill procedure. VP: vagotomy and pyloroplasty. PGV: proximal gastric vagotomy

\section{Symptomatic outcome: Overall}

Overall symptomatic outcome between ARS alone and ARS + vagotomy was assessed in five of the six articles. ${ }^{26-29,31}$ Since each study used different methods of assessment on specific clinical outcomes, and each study investigated a different subset of clinical outcomes, a large heterogeneity exists among the overall symptomatic outcomes.

Already in the early seventies of the pas century, Wilson et al. compared symptomatic outcome between "simple repair $(n=23)$ and "simple repair + vagotomy and pyloroplasty" $(n=21) .^{29}$ The simple repair technique consisted of closure of the hiatus hernia, followed by suturing of the fundus to esophagus in order to recreate a steep angle of His. Recurrence of reflux symptoms was scored and categorized in four groups: 1) no symptoms, 2) minimal symptoms 3) improved but still with symptoms and 4) no improvement in symptoms. Grades 1 and 2 were defined as 'good overall outcome' and grades 3 and 4 as 'poor overall outcome'. Sixteen percent of the patients that underwent simple repair + vagotomy and pylorplasty (VP) scored poor overall outcome, compared to $0 \%$ of the patients with simple repair only.

Mokka et al. compared outcomes after various ARS techniques (NF, HHR, LF, AF) without vagotomy to one ARS technique NF combined with VP. ${ }^{27}$ These authors categorized overall symptomatic outcome into three grades: excellent, good and poor. These grades were assigned according to severity of complaints including heartburn, regurgitation, fullness, dysphagia and inability to vomit. ${ }^{27}$ Poor outcome was seen in $17 \%$ (12/69) of the patients after ARS alone, compared to 53\% (9/17) after $\mathrm{NF}+\mathrm{VP}$. 


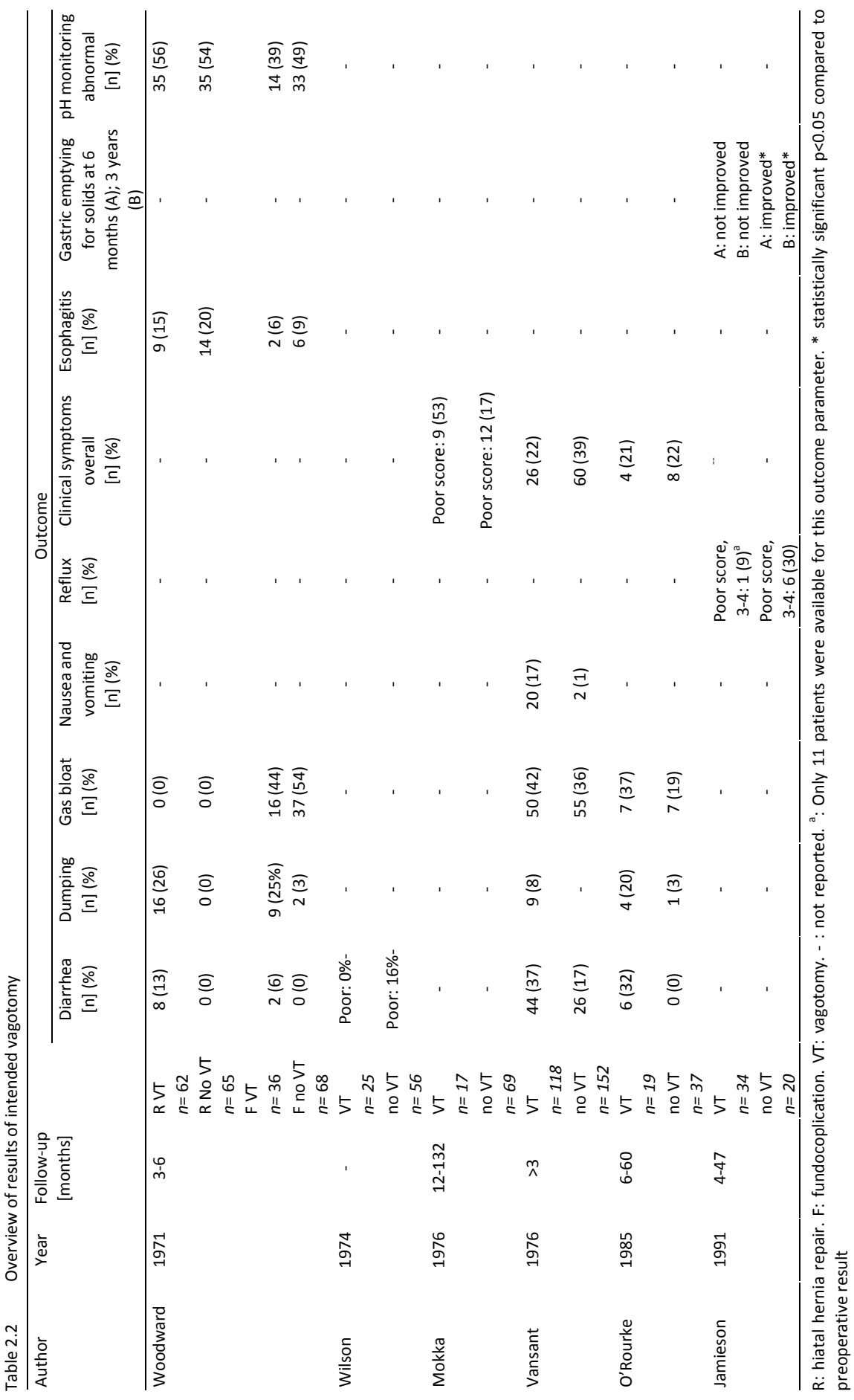


In the study conducted by Vansant et al., overall symptomatic outcome was assessed between Hill gastropexia (HPG) only ( $n=152)$ versus HPG + VP $(n=118) .{ }^{28}$ Symptomatic outcome was evaluated according to duration of symptoms: $<3$ months or $>3$ months. Diarrhea, bloating, nausea, vomiting and dumping were taken into account in this overall outcome. Within the first three months, symptoms were reported by $39.5 \%$ (60/152) of the 'HPG only' group, compared to $22 \%$ (26/118) in the 'HPG + VP' group. After three months, only $1.3 \%(2 / 152)$ of the 'HPG only' group reported symptoms compared to $33 \%(33 / 118)$ in the 'HPG + VP' group.

O'Rourke et al. assessed a total of 56 patients who underwent a standard fundoplication similar to Nissen fundoplication (Nissen like fundoplication, NLF). ${ }^{31}$ Thirty-seven patients underwent fundoplication only, 19 patients underwent NLF with additional VP. Severity of heartburn, regurgitation and dysphagia were scored on a 0-3 point scale with 0 indicating no symptoms and 3 indicating daily presence with a maximum total score for the questionnaire of 9 points. A decrease in mean score from 5.39 to 0.41 was seen after ARS for the whole group. Postoperative comparison between the various operations showed no difference regarding postoperative symptoms.

Jamieson et al., categorized patients in four grades assessing reflux specific symptoms: 1) no or minor symptoms, 2) moderate symptoms, 3) marked symptoms 4) symptoms as bad as or worse than preoperatively. ${ }^{26}$ Thirty-one patients were analyzed at 3 years follow-up; 20 patients with NF and 11 with NF + proximal gastric vagotomy (PGV). Considering grade 3 and 4 as unfavorable, 30\% of patients with fundoplication only had unfavorable results compared to $9 \%$ of patients with fundoplication + PGV group.

\section{Symptomatic outcomes: specific symptoms}

Specific symptomatic outcomes with respect to diarrhea, nausea and vomiting, dumping syndrome, dysphagia and gas bloat syndrome have only been described in three articles of Woodward et al., Vansant et al. and O' Rourke et al.. ${ }^{28,30,31}$ See Table 2.2. None of the selected articles has specifically described the criteria they used to define the presence of each symptom.

\section{Diarrhea}

Woodward et al., compared four groups: 1) HHR only ( $n=65), 2)$ HHR + VP ( $n=62)$, 3) NF only ( $n=68)$ and 4) NF + VP $(n=36) .{ }^{30}$ The authors reported diarrhea solely in the groups where VP had been added to the ARS with percentages of $13 \%$ and $6 \%$ respectively in group 2 and $4 .^{30}$

In the study by O' Rourke et al., diarrhea was seen in six out of the 19 patients (31.6\%) that underwent NLF + VP, whereas none of the patients of the NLF only group 
reported diarrhea $(\mathrm{P}<0.005) .{ }^{31}$ Vansant et al. reported a prevalence of diarrhea of $17 \%$ (26/152) in the HPG group compared to $37 \%(44 / 118)$ in the HPG + VP group. ${ }^{28}$

\section{Dumping syndrome}

O' Rourke reported a prevalence of $2.7 \%(1 / 37)$ in the NLF only group vs $20 \%(4 / 19)$ in the NLF + VP group (difference: ns). ${ }^{31}$ Woodward and Vansant et al. only report dumping syndrome in the groups with added VP, with prevalence's of $25.5 \%$ (25/98) and $8 \%(9 / 118)$ respectively. In addition, Vansant et al. also differentiated between the severity of mild $6 \%(7 / 118)$ and severe $2 \%(2 / 118)$ dumping.

\section{Gas bloat syndrome}

Within the study of Woodward et al., no gas bloat syndrome was reported after HHR. On the contrary, after NF the patients reported gas bloating in 54\% (37/68). In the group were VP was added to the NF, 44\% (16/36) reported gas bloating. O' Rourke and colleagues reported gas bloat syndrome in $18.9 \%(7 / 37)$ after NLF, versus $36.8 \%(7 / 19)$ when VP was added. In the study of Vansant et al., 55 patients (36.2\%) suffered from gas bloat syndrome after HPG only, whereas 50 patients $(42,4 \%)$ reported these complaints after HPG + VP.

\section{Nausea and vomiting}

Nausea and vomiting has only been described by Vansant et al. A prevalence of $1.3 \%$ (2/152) was seen in the HPG only group vs $17 \%$ (20/118) in the group with additional vagotomy + pyloromyotomy.

\section{Dysphagia}

Woodward et al. also reported on the prevalence of dysphagia between the four groups. Dysphagia occurred in almost a quarter of the patients after NF (16/68), compared to only $9 \%(6 / 65)$ after HHR. In the groups were VP was added, $16 \%(10 / 62)$ of the HHR-VP patients suffered from dysphagia, compared to $14 \%(5 / 36)$ of the NFVP patients.

\section{Esophagitis}

Additionally in the report by Woodward et al. endoscopic esophagitis was present in $20 \%$ after HHR and $9 \%$ after NF and was less frequent when these procedures had been combined with VP: $15 \%$ and $6 \%$ respectively.

\section{Satisfaction rate}

O' Rourke et al. also evaluated outcome with respect to patient satisfaction between the various groups. A significantly worse outcome was noted in the group where VP was added to NLF $(P<0.01)$. 


\section{Gastric emptying}

Jamieson et al. have assessed gastric emptying both for solids and liquids using a dual isotope radionuclide technique. Patients were evaluated at 6 months and 3 years after NF alone $(n=20)$ and after NF with added proximal gastric vagotomy (PGV) $(n=34)$. In patients with NF alone a significant acceleration $(\mathrm{P}<0.05)$ of gastric emptying for solids was seen at 6 months and 3 years after surgery compared to preoperatively. In contrast, gastric emptying for solids did not change after the operation in patients with NF + PGV. Both groups showed a significant acceleration of liquid gastric emptying six months after the operation $(P<0.05)$. At 3 years follow-up a significant acceleration for liquids was seen only in the NF group $(P<0.05)$. The authors evaluated the relation between symptomatic outcome and gastric emptying: no correlation was found. Of the ten patients with troublesome complaints of postprandial epigastric fullness only three patients had delayed gastric emptying of solids.

\section{Unintended, accidental vagus nerve injury}

Only two studies assessed unintended vagus nerve injury objectively by the response of pancreas polypeptide to either sham feeding (PP-SF) or to insulin induced hypoglycemia (PP-IH). ${ }^{24,25}$ For details see Table 2.3 .

Table 2.3 Characteristics of studies reporting on accidental vagus nerve injury

\begin{tabular}{lllccc}
\hline Author & Year & \multicolumn{4}{c}{ Procedure } \\
\cline { 3 - 5 } & & ARS & diagnostics for VNI & Patients [n] & VNI [n] \\
\hline DeVault & 2004 & LNF & Sham-feeding & 12 & 5 \\
Lindeboom & 2004 & LTF & PP-IH test & 41 & 4 \\
\hline
\end{tabular}

ARS: Anti-reflux surgery. LNF: laparoscopic Nissen fundoplication. LTF: laparoscopic Toupet fundoplication. VNI: vagus nerve injury. PP-IH: plasma pancreatic polypeptide secretion to insulin-induced hypoglycemia

As described by Schwartz and colleagues, the secretion of pancreas polypeptide by the pancreas is mediated through efferent vagal activity. Stimulation of PP secretion through vagus nerve activity can either be evoked by sham feeding or by insulin induced hypoglycemia. An absent or minimal response in PP secretion to one of both stimuli is considered to be compatible with vagus nerve dysfunction. ${ }^{21,22}$

\section{PP-IH test}

Within the study by Lindeboom et al. the PP-IH test was performed on fasted patients at the outpatient department where at $\mathrm{t}=0 \mathrm{~min} 0.1 \mathrm{U} / \mathrm{Kg}$ of insulin bolus was administered intravenous. ${ }^{24}$ During a period of 90 minutes at 10 minutes intervals blood was drawn for measurement of PP and glucose. The nadir blood glucose response was $<2.5 \mathrm{mmol} / \mathrm{L}$ in all patients (adequate stimulus). A peak increment response in plasma $\mathrm{PP}<47 \mathrm{pmol} / \mathrm{L}$ was considered to be compatible with truncal 
vagotomy, based on data obtained in a large group of patients with previous intended truncal vagotomy.

\section{PP-SF test}

DeVault et al. assessed vagus nerve injury using the PP-SF test. After an overnight fast, two baseline blood samples were obtained from the patients. ${ }^{25}$ Next, patients were given a meal with the instruction to chew the food but not to swallow it. Blood samples were taken during a period of 30 minutes with 5 minutes time intervals. A peak increment of $<25 \mathrm{pg} / \mathrm{ml}$ was considered compatible with vagus nerve injury.

\section{Prevalence}

The prevalence of vagus nerve injury after ARS can only be assessed by objectively measuring vagus nerve integrity both pre- and postoperatively. Lindeboom et al. reported a vagus nerve injury (VNI) prevalence of $10 \%$ (4/41) six months after LTF in a prospective cohort. ${ }^{24}$ In the study by DeVault et al. 20 patients were assessed prior to and 1 week after LNF. ${ }^{25}$ Among the patients with a normal PP response in the preoperative state $(n=12)$, an abnormal postoperative test result was seen in five patients (42\%). (Table 2.4).

Table 2.4 Overview of results of accidental vagus nerve injury

\begin{tabular}{|c|c|c|c|c|c|c|c|c|c|}
\hline \multirow[t]{3}{*}{ Author } & \multirow[t]{3}{*}{ Year } & \multirow{3}{*}{$\begin{array}{l}\text { Follow- } \\
\text { up } \\
\text { [months] }\end{array}$} & & \multicolumn{6}{|c|}{ Outcome } \\
\hline & & & & \multicolumn{2}{|c|}{$\begin{array}{c}\text { Clinical } \\
\text { symptoms overall } \\
{[\mathrm{n}]}\end{array}$} & \multicolumn{2}{|c|}{$\begin{array}{l}\text { Gastric emptying rate, } \\
50 \% \text { emptying time } \\
\text { [min] (SEM) }\end{array}$} & \multicolumn{2}{|c|}{$\begin{array}{c}24 \mathrm{~h} \mathrm{pH} \text { monitoring } \\
\text { [mean \% pH <4] (range) }\end{array}$} \\
\hline & & & & worse & $\begin{array}{c}\text { same or } \\
\text { better }\end{array}$ & preop & postop & preop & postop \\
\hline \multirow[t]{2}{*}{ DeVault } & 2004 & 12 & $\begin{array}{l}\mathrm{VNI} \\
n=5\end{array}$ & 2 & 3 & - & - & - & - \\
\hline & & & $\begin{array}{l}\text { no VNI } \\
n=7\end{array}$ & 3 & 4 & - & - & - & - \\
\hline \multirow[t]{2}{*}{ Lindeboom } & 2004 & $3-6$ & $\begin{array}{l}\mathrm{VNI} \\
n=4\end{array}$ & - & - & $\begin{array}{l}141 \\
(63)\end{array}$ & $\begin{array}{c}92 \\
(23)\end{array}$ & $\begin{array}{c}9.2 \\
(4.2-12.7)\end{array}$ & $\begin{array}{c}3.2 \\
(1.8-7.4)\end{array}$ \\
\hline & & & $\begin{array}{l}\text { no VNI } \\
n=37\end{array}$ & - & - & $\begin{array}{l}114 \\
(8)\end{array}$ & $\begin{array}{c}79 \\
(4)^{*}\end{array}$ & $\begin{array}{c}8.7 \\
(2.5-20.2)\end{array}$ & $\begin{array}{c}1.1^{*} \\
(0-14.4)\end{array}$ \\
\hline
\end{tabular}

Clinical symptoms overall: Bowel habit questionnaire. Min: minutes. Preop: preoperative. Postop: postoperative. VNI: vagus nerve injury. - : not reported. * statistically significant $p<0.05$ compared to preoperative result

\section{Symptoms}

Heartburn, fullness and nausea were assessed prior to and six months after LTF by Lindeboom et al. A grading system was used to combine severity and frequency per symptom, resulting in a minimum score of 0 and a maximum score of 3 for each symptom. Both the LTF group and the LTF+VNI group showed a significant decrease 
for heartburn and nausea. The LTF+VNI group did not show a reduction of fullness compared to preoperative scores, where as the LTF group decreased significantly in fullness postoperatively.

DeVault et al. assessed symptoms only at 12 months after operation. Symptoms of diarrhea, constipation, abdominal pain, bloating or distention and frequency of bowel movements were assessed before and after LNF. Six out of 15 patients developed new symptoms or had worse symptoms consisting of flatus $(n=2)$ and diarrhea $(n=4)$ postoperatively. Three of these six patients were considered to have vagus nerve injury, however the distribution of new symptoms or worsening of symptoms among groups was not reported. No correlation was found between symptoms and PP test results.

\section{Gastric Emptying and 24-hour pH monitoring}

Additionally Lindeboom et al. also reported on the outcome of gastric emptying and 24-hour $\mathrm{pH}$ monitoring between patients after LTF. Patients with vagus nerve injury did not differ in gastric emptying or 24-hour $\mathrm{pH}$ monitoring results compared to the vagus nerve intact group (Table 2.4 ).

\section{Discussion}

Antireflux surgery can be accompanied by vagus nerve injury, a complication that may negatively affect overall outcome of the procedure., ${ }^{9-12}$ Because little is known on the prevalence of vagus nerve injury after ARS, an extensive review of the existing literature was performed. The effects of both intended and unintended, accidental vagus nerve injury on outcome of ARS were assessed. A total of eight published articles were evaluated after careful systematic selection. ${ }^{24-31}$

Only two of the eight studies objectively assessed vagus nerve integrity: one study measured the response of PP to insulin-induced hypoglycemia before and after LTF, the other measured PP response to sham feeding before and after LNF. ${ }^{24,25}$ The prevalence of VNI (defined as an absent or reduced PP response to IH or SF) after LTF appeared to be $10 \%$, whereas LNF resulted in $42 \%$ absent or reduced PP response to $\mathrm{SF}$, indicative for vagus nerve injury. It is well known that about $10 \%$ of healthy controls in the population will have an absent or reduced PP response to sham feeding without any evidence for vagus nerve injury or dysfunction. ${ }^{21,22}$ This should be taken into consideration when interpreting the high percentage of patients with an abnormal SF-PP test result. Symptomatic outcomes after ARS did not differ between groups with and without VNI according to both studies. Lindeboom et al reported no significant differences in postoperative gastric emptying or 24-hour $\mathrm{pH}$ monitoring between the groups with and without VNI. 
In summary, unintended vagus nerve injury was observed in at least $10 \%$ of patients undergoing ARS, a percentage that is higher than previously has been assumed. On short-term follow up, the outcome of ARS with respect to reflux control, overall symptoms, gastric emptying and 24-hour $\mathrm{pH}$ monitoring appeared not to be negatively affected by unintended, accidental vagus nerve injury. Results on longer term follow up after ARS related to vagus nerve injury have not been published up to now.

Six of the eight studies compared ARS procedures with and without intended vagotomy. ${ }^{26-31}$ Overall symptomatic outcome has been assessed in five studies, three of these studies used a composite score. Outcome was poor (with symptoms still present) in $16-53 \%$ of the patients after ARS with added VP, versus $0-17 \%$ of the patients after ARS alone. It should be noted that the composite score after ARS with VP was negatively affected by newly developed postoperative symptoms such as diarrhea and dumping.

With respect to reflux control, the symptomatic outcome was slightly in favor of ARS with added vagotomy or VP. O'Rourke and colleagues found a significant improvement of reflux control in the patients after ARS, independent of VP. In contrast, Jamieson et al found that $9 \%$ of patients scored worse (or did not improve) in reflux control after ARS + PGV, compared to $30 \%$ in the ARS only group. In addition, Woodward et al report fewer cases of esophagitis after ARS with added VP.

Three studies reported specifically on diarrhea, dumping syndrome, nausea, vomiting and gas bloat after ARS. All three studies combined vagotomy with pyloromyotomy or pyloroplasty. Also the degree of vagotomy differed between studies. Diarrhea, nausea and vomiting occurred more often in the ARS + VP group compared to ARS alone. However, the symptoms of gas bloat and dysphagia were equally prevalent in both groups and dumping syndrome was only present when VP was added to ARS.

Certain limitations of the present review have to be taken into account. The methodological quality of the studies on which we based our review is relatively poor. Five of the articles were prospective in design and three were retrospective cohort studies. Randomized clinical trials were not available. The surgical details have poorly been described, that is also true for the statistical analyses. Five out of the eight articles did not specifically describe at what time point data had been assessed. The majority of studies did not use standardized questionnaires or specified criteria to assess the prevalence of symptoms. In addition to the vagotomy, pyloromyotomy or pyloroplasty may have a significant impact on diarrhea and dumping syndrome. ${ }^{32-35}$ Therefore, no straightforward conclusions on the impact of vagus nerve injury on dumping syndrome and diarrhea can be drawn since in the majority of studies either pyloromytomy or pyloroplasty has been added to vagotomy. 
With respect to the outcome of ARS after unintended, accidental vagus nerve injury, it should be acknowledged that patient groups were small and that only one study reported extensively with respect to symptomatic outcome. Therefore, definite conclusions about the prevalence and impact of accidental vagus nerve injury on the outcome of ARS have to be drawn with caution.

How should we deal with these findings in daily clinical practice? Vagus nerve injury should be considered in patients after antireflux surgery who either have a poor outcome with respect to reflux control or in patients who postoperatively develop new symptoms such as diarrhea, dumping, nausea and/or vomiting. Confirmation of vagus nerve injury by nerve function testing through the PP secretory response to insulin induced hypoglycemia or to sham feeding should be undertaken, when test facilities available. Therapy should be directed at controlling the major symptoms. Redo antireflux surgery is not advised in case of (suspected) vagus nerve injury because of significantly lower success rates. In case of documented delayed gastric emptying treatment with prokinetics, pyloric botulin toxin injections or pyloromyotomy should be considered. ${ }^{36}$ Dumping syndrome usually does respond to dietary measures, with or without motility reducing drugs. In severe and invalidating cases, somatostatin analog therapy should be considered. ${ }^{37}$

In summary, the prevalence of accidental vagus nerve injury after antireflux surgery, measured by indirect tests, is much higher than previously assumed. With respect to intended vagotomy added to the antireflux procedure the symptomatic outcome of diarrhea, dumping and nausea is worse while reflux control is equal or slightly better. However, the level of evidence of the studies we have evaluated is low and larger prospective studies are necessary.

In conclusion vagus nerve injury is a feared but generally neglected complication of antireflux surgery. Recognition of the clinical impact of unintended vagus nerve injury and strategies to prevent vagus nerve damage should be encouraged. Larger, prospective studies are needed to assess the prevalence and impact of objectively determined vagus nerve injury on the outcome of ARS. 


\section{References}

1 El-Serag HB, Sweet S, Winchester CC, Dent J. Update on the epidemiology of gastro-oesophageal reflux disease: A systematic review. Gut. 2014;63:871-80.

2 Dent J, El-Serag HB, Wallander MA, Johansson S. Epidemiology of gastro-oesophageal reflux disease: A systematic review. Gut 2005;54:710-7.

3 Fuchs KH, Babic B, Breithaupt W, Dallemagne B, Fingerhut A, Furnee E, Granderath F, Horvath P, Kardos P, Pointner R, Savarino E, Van Herwaarden-Lindeboom M, Zaninotto G, European Association of Endoscopic S. Eaes recommendations for the management of gastroesophageal reflux disease. Surg Endosc. 2014;28:1753-73.

4 Nissen R. A simple operation for control of reflux esophagitis. Schweiz Med Wochenschr. 1956;86: 590-2.

5 Toupet A. Technic of esophago-gastroplasty with phrenogastropexy used in radical treatment of hiatal hernias as a supplement to heller's operation in cardiospasms. Mem Acad Chir (Paris). 1963;89:384-9.

6 Engstrom C, Cai W, Irvine T, Devitt PG, Thompson SK, Game PA, Bessell JR, Jamieson GG, Watson DI. Twenty years of experience with laparoscopic antireflux surgery. Br J Surg. 2012;99:1415-21.

7 Fein M, Bueter M, Thalheimer A, Pachmayr V, Heimbucher J, Freys SM, Fuchs KH. Ten-year outcome of laparoscopic antireflux surgery. J Gastrointest Surg. 2008;12:1893-9.

8 Dallemagne B, Perretta S. Twenty years of laparoscopic fundoplication for gerd. World J Surg. 2011;35:1428-35.

9 Broeders JA, Mauritz FA, Ahmed Ali U, Draaisma WA, Ruurda JP, Gooszen HG, Smout AJ, Broeders IA, Hazebroek EJ. Systematic review and meta-analysis of laparoscopic nissen (posterior total) versus toupet (posterior partial) fundoplication for gastro-oesophageal reflux disease. $\mathrm{Br} J$ Surg. 2010;97:1318-30.

10 Robinson B, Dunst CM, Cassera MA, Reavis KM, Sharata A, Swanstrom LL. 20 years later: Laparoscopic fundoplication durability. Surg Endosc. 2015;29(9):2520-4.

11 Simorov A, Ranade A, Jones R, Tadaki C, Shostrom V, Boilesen E, Oleynikov D. Long-term patient outcomes after laparoscopic anti-reflux procedures. J Gastrointest Surg. 2014;18:157-62; discussion 162-3.

12 Papasavas P. Functional problems following esophageal surgery. Surg Clin North Am. 2005;85:525-38.

13 Broeders JA, Sportel IG, Jamieson GG, Nijjar RS, Granchi N, Myers JC, Thompson SK. Impact of ineffective oesophageal motility and wrap type on dysphagia after laparoscopic fundoplication. $\mathrm{Br} J$ Surg. 2011;98:1414-21.

14 Kessing BF, Broeders JA, Vinke N, Schijven MP, Hazebroek EJ, Broeders IA, Bredenoord AJ, Smout AJ. Gas-related symptoms after antireflux surgery. Surg Endosc. 2013;27:3739-47.

15 Engel JJ, Spellberg MA. Complications of vagotomy. Am J Gastroenterol. 1978;70:55-60.

16 Lagoo J, Pappas TN, Perez A. A relic or still relevant: The narrowing role for vagotomy in the treatment of peptic ulcer disease. Am J Surg. 2014;207:120-6.

17 Goligher JC, Pulvertaft CN, Irvin TT, Johnston D, Walder B, Hall RA, Willson-Pepper J, Matheson TS. Five- to eight-year results of truncal vagotomy and pyloroplasty for duodenal ulcer. $\mathrm{Br} \mathrm{Med} J$. 1972;1:7-13.

18 Hoffmann J, Jensen HE, Christiansen J, Olesen A, Loud FB, Hauch O. Prospective controlled vagotomy trial for duodenal ulcer. Results after 11-15 years. Ann Surg. 1989;209:40-5.

19 Koo J, Lam SK, Chan P, Lee NW, Lam P, Wong J, Ong GB. Proximal gastric vagotomy, truncal vagotomy with drainage, and truncal vagotomy with antrectomy for chronic duodenal ulcer. A prospective, randomized controlled trial. Ann Surg. 1983;197:265-71.

20 Kozarek RA, Low DE, Raltz SL. Complications associated with laparoscopic anti-reflux surgery: One multispecialty clinic's experience. Gastrointest Endosc. 1997;46:527-31.

21 Schwartz TW. Pancreatic polypeptide: A hormone under vagal control. Gastroenterology. 1983;85:1411-25.

22 Schwartz TW, Holst JJ, Fahrenkrug J, Jensen SL, Nielsen OV, Rehfeld JF, de Muckadell OB, Stadil F. Vagal, cholinergic regulation of pancreatic polypeptide secretion. J Clin Invest. 1978;61:781-9. 
23 Moher D, Liberati A, Tetzlaff J, Altman DG, Group P. Preferred reporting items for systematic reviews and meta-analyses: The prisma statement. PLoS Med. 2009;6:e1000097.

24 Lindeboom MY, Ringers J, van Rijn PJ, Neijenhuis P, Stokkel MP, Masclee AA. Gastric emptying and vagus nerve function after laparoscopic partial fundoplication. Ann Surg. 2004;240:785-90.

25 DeVault KR, Swain JM, Wentling GK, Floch NR, Achem SR, Hinder RA. Evaluation of vagus nerve function before and after antireflux surgery. J Gastrointest Surg. 2004;8:883-8; discussion 888-9.

26 Jamieson GG, Maddern GJ, Myers JC. Gastric emptying after fundoplication with and without proximal gastric vagotomy. Arch Surg. 1991;126:1414-7.

27 Mokka RE, Laitinen S, Punto L, Kairaluoma MI, Pokela R, Karkola P, Huttunen R, Larmi TK. Hiatal hernia repair. Ann Chir Gynaecol. 1976;65:369-75.

28 Vansant JH, Baker JW Jr. Complications of vagotomy in the treatment of hiatal hernia. Ann Surg. 1976;183:629-35.

29 Wilson MG, Bailey IS, Penry AB. The surgical treatment of reflux oesophagitis: Results of surgical repair over a 12-year period. Br J Surg. 1974;61:193-200.

30 Woodward ER, Thomas HF, McAlhany JC. Comparison of crural repair and nissen fundoplication in the treatment of esophageal hiatus hernia with peptic esophagitis. Ann Surg. 1971;173:782-92.

31 O'Rourke IC. Fundoplication for gastro-oesophageal reflux. Aust N Z J Surg. 1985;55:347-54.

32 Cheadle WG, Baker PR, Cuschieri A. Pyloric reconstruction for severe vasomotor dumping after vagotomy and pyloroplasty. Ann Surg. 1985;202:568-72.

33 Frederiksen HJ, Johansen TS, Christiansen PM. Postvagotomy diarrhoea and dumping treated with reconstruction of the pylorus. Scand J Gastroenterol. 1980;15:245-8.

34 Humphrey CS, Johnston D, Walker BE, Pulvertaft CN, Goligher JC. Incidence of dumping after truncal and selective vagotomy with pyloroplasty and highly selective vagotomy without drainage procedure. Br Med J. 1972;3:785-8.

35 Wastell C, Colin J, Wilson T, Walker E, Gleeson J, Zeegen R. Prospectively randomised trial of proximal gastric vagotomy either with or without pyloroplasty in treatment of uncomplicated duodenal ulcer. Br Med J. 1977;2:851-3.

36 Camilleri M, Parkman HP, Shafi MA, Abell TL, Gerson L, American College of G. Clinical guideline: Management of gastroparesis. Am J Gastroenterol. 2013;108:18-37; quiz 38.

37 Tack J, Arts J, Caenepeel P, De Wulf D, Bisschops R. Pathophysiology, diagnosis and management of postoperative dumping syndrome. Nat Rev Gastroenterol Hepatol. 2009;6:583-90. 



\section{Chapter 3}

\section{Effect of vagus nerve integrity on short and long term efficacy of antireflux surgery}

S. van Rijn, N.F. Rinsma, M.Y.A. van Herwaarden-Lindeboom, J. Ringers, H.G. Gooszen, P.J.J. van Rijn, R.A. Veenendaal, J.M. Conchillo, N.D. Bouvy, A.A.M Masclee Am J Gastroenterol. 2016;111(4):508-15 


\section{Abstract}

\section{Background}

Vagus nerve injury is a feared complication of antireflux surgery (ARS) that may negatively affect reflux control. The aim of the present prospective study was to evaluate short term and long term impact of vagus nerve injury, evaluated by pancreatic polypeptide response to insulin-induced hypoglycemia (PP-IH), on the outcome of ARS.

\section{Methods}

In the period from 1990 until 2000, 125 patients with gastroesophageal reflux disease (GERD) underwent antireflux surgery at a single center. Prior to and 6 months after surgery vagus nerve integrity testing (PP-IH), 24 hour $\mathrm{pH}$-monitoring, gastric emptying and reflux-associated symptoms were evaluated. In 2014, 14-25 years after surgery, 110 patients were contacted again for evaluation of long term symptomatic outcome using two validated questionnaires (GRSR and GERD-HRQL).

\section{Results}

Short term follow up: vagus nerve injury (PP peak $\leq 47 \mathrm{pmol} / \mathrm{L}$ ) was observed in 23 patients (18\%) 6 months after fundoplication. In both groups a comparable decrease of reflux parameters and symptoms was observed at 6 months follow-up. Postoperative gastric emptying was significantly delayed in the vagus nerve injury group compared to vagus nerve intact group.

Long term follow up: Patients with vagus nerve injury showed significantly less effective reflux control and a higher re-operation rate.

\section{Conclusions}

Vagus nerve injury occurs in up to $20 \%$ of patients after ARS. Reflux control 6 months after surgery was not affected by vagus nerve injury. However, long term follow up showed a negative effect on reflux symptom control and re-operation rate in patients with vagus nerve injury. 


\section{Introduction}

Gastroesophageal reflux disease (GERD) is a common health problem that affects $10-20 \%$ of individuals in Western society. ${ }^{1}$ Antirefux surgery (ARS) is indicated for patients with documented GERD and chronic symptoms refractory to proton pump inhibitors (PPI) or not willing to take lifelong PPI's. The aim of ARS is optimal long-term control of reflux symptoms and reflux signs, without or with minimal side effects.

Despite improvements in surgical techniques such as laparoscopic antireflux surgery, ${ }^{2,3}$ postoperative complications still occur. ${ }^{4-9}$ Vagus nerve injury is a wellknown complication of ARS. Abdominal vagus function cannot be measured or evaluated directly. Data on prevalence of vagus nerve dysfunction after antireflux surgery are therefore based on presence of symptoms such as diarrhea, nausea and vomiting. ${ }^{6,10,11}$ In the past, an indirect method has been developed to measure vagus (dys)function by measuring the response of plasma pancreatic polypeptide (PP) secretion to insulin-induced hypoglycemia, the IH-PP test. ${ }^{12,13}$

In a previous study by our group, vagus nerve injury measured by IH-PP test was observed in $10 \%$ of GERD patients after laparoscopic hemi-fundoplication. ${ }^{14}$ In that study, no significant differences were observed in short term postoperative outcome, that is symptom control, reflux recurrence and delayed gastric emptying between patients with or without vagus nerve injury. It should however be noted that the number of patients in that study ${ }^{14}$ as in other studies assessing vagus nerve injury after antireflux surgery was small and follow-up of patients was only short. ${ }^{14-16}$

Data on the impact of vagotomy on outcome of antireflux surgery have been obtained by Oelschlager et al. These investigators reported on the effect of intended vagus nerve injury on outcome of antireflux surgery. During a mean follow up period of 18 months vagus nerve damage did not negatively influence the outcome of antireflux surgery, nor that of gastric emptying. ${ }^{17}$

It should be beyond any doubt that vagus nerve dysfunction measured by PP response to insulin hypoglycemia (IH-PP) truly results from injury during ARS and not from other causes. Therefore, the test should be performed both before and after surgery. Up to now vagus nerve function in ARS has not been systematically and prospectively evaluated in a large cohort.

Aim of our study was to evaluate both short and long term impact of vagus nerve injury as evaluated by IH-PP test on reflux symptoms, reflux control and quality of life after ARS. We hypothesize that ARS related vagus nerve injury will have a negative outcome on symptoms, reflux control, gastric emptying and quality of life both after short and long term follow-up. In the nineties of the past century, as part of clinical work-up, we prospectively evaluated vagus nerve function by PP response to insulin hypoglycemia in patients undergoing ARS at the Leiden University Medical Center. 
Only data from patients with vagus nerve testing both before and after ARS have been evaluated. At six months after surgery objective and subjective reflux parameters were measured. In 2014 a follow-up of this prospective cohort for long term efficacy has been performed with questionnaires on reflux symptoms and quality of life.

\section{Materials and methods}

In the period from 1990 until 2000, out of a larger group, 125 patients with GERD underwent ARS at the Leiden University Medical Centre (LUMC) with detailed evaluation on the effect of ARS on several parameters. Patients underwent esophageal manometry, 24-h pH-monitoring, gastric emptying and vagus nerve integrity tests both prior and 6 months after surgery as clinical evaluation. Symptoms were evaluated using questionnaires. In 2014, up to 25 years after surgery patients were contacted again and two validated questionnaires evaluating typical and atypical GERD symptoms were sent. Of the initial 125 patients 110 were eligible for follow-up (Figure 3.1).

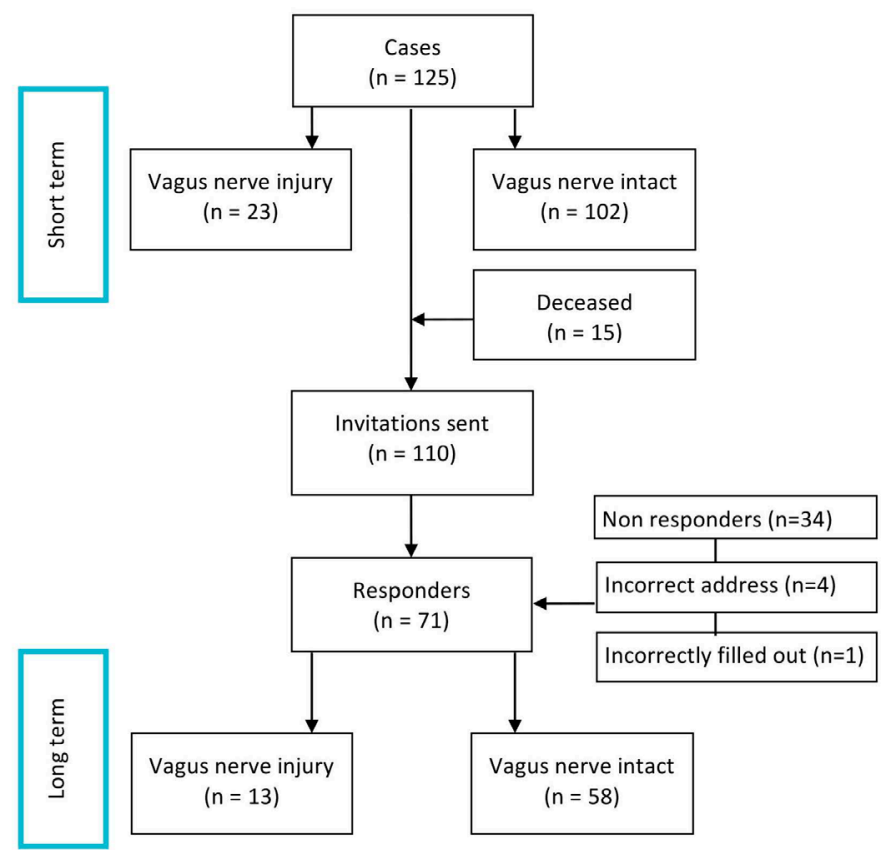

Figure 3.1 Cohort Flow Diagram 


\section{Operation}

Several surgical procedures were performed as procedure of choice from 1990 until 2000. The selection of the procedure was based upon time dependent surgeon's preference, not on patient characteristics. Initially, in the early nineties, the open Belsey Mark IV procedure was standard. ${ }^{18}$ After laparoscopic surgery became available at the LUMC in the year 1994 the laparoscopic Nissen, ${ }^{19}$ and later on the Toupet fundoplication ${ }^{20}$ became procedure of choice based on literature data. In all patients surgery was indicated based on documented GERD and symptoms refractory to medical therapy including PPI's.

\section{Short term follow-up}

\section{4 hour pH-monitoring}

We performed 24-h ambulatory intraesophageal $\mathrm{pH}$-monitoring as previously described. ${ }^{4}$ Reflux parameters used in this study were the percentage of time with $\mathrm{pH}$ level $<4$ for total recording time, for time in the upright and the supine position. Abnormal acid exposure time was defined as the percentage of time with $\mathrm{pH}<4$ for total time $\geq 4.0 \%$, upright time $\geq 4.4 \%$ and supine time $\geq 1.2 \%$. ${ }^{21}$

\section{Esophageal manometry}

Esophageal body and lower LES pressure recordings were obtained by a polyvinyl assembly with a $5 \mathrm{~mm}$ outer diameter incorporating a $6 \mathrm{~cm}$ long sleeve sensor and seven side holes as described previously. ${ }^{9}$ The outcome variable used in this study was the LES mean pressure measured in $\mathrm{mm} \mathrm{Hg}$.

\section{Gastric emptying}

Gastric emptying was measured using a radionuclide scintigraphy with a dual-isotope method as previously described. ${ }^{14}$ Patients underwent gastric emptying testing preand postoperatively. Data of gastric emptying for solids was analyzed by determining lag phase, gastric emptying and gastric half emptying time. The retention for liquids was calculated at 15, 30, 60 and 90 minutes. Gastric emptying for solids was considered normal if values for lag phase ranged from 13 to 31 minutes and for emptying rate from $36 \%$ to $79 \%$ per hour. Gastric emptying for solids was considered delayed if the emptying rate was $<35 \%$ per hour.

\section{Vagus nerve integrity}

As previously described, vagus nerve integrity was measured indirectly by the response of PP to insulin-induced hypoglycemia. ${ }^{14}$ After an overnight fast, patients were administered a bolus of $0.1 \mathrm{U} / \mathrm{kg}$ of insulin (Actrapid, Novo Nordisk Farma BV, Bagsvaerd, Denmark) intravenously. After administration of insulin, blood samples 
were drawn at regular intervals during $150 \mathrm{~min}$ to measure PP and glucose levels. During the first 90 min blood was drawn with 10-min time intervals. At 90 min a standard test meal was given to the patients and blood was withdrawn with 15-min intervals up to $150 \mathrm{~min}$. PP levels were measured by a specific radioimmunoassay, as described previously. ${ }^{22}$ Nadir blood glucose levels in response to administration of insulin were $<2.5 \mathrm{mmol} / \mathrm{L}$ in all patients. A peak increment in plasma PP $\leq 47 \mathrm{pmol} / \mathrm{L}$ was considered to be compatible with truncal vagotomy. Cut-off values calculated for this IH-PP-test were based upon data obtained from patients who underwent intentional vagotomy in comparison to a healthy control group. ${ }^{14}$ All participants in this study underwent vagus nerve integrity testing prior to and six months after surgery.

\section{Symptoms}

GERD symptoms were scored by a standardized symptom questionnaire before and 6 months after operation. Symptoms included heartburn, dysphagia, diarrhea, sensation of fullness, abdominal distention, vomiting, nausea and belching. Severity and frequency of symptoms were combined according to a scoring system as shown in Table 3.1.

Table 3.1 Grading system to combine severity and frequency of reflux symptoms such as heartburn, fullness, and nausea

\begin{tabular}{lcccc}
\hline & Sever & Moderate & Mild & Absent \\
\hline Daily & Grade 3 & Grade 2 & Grade 1 & Grade 1 \\
Weekly & Grade 2 & Grade 1 & Grade 1 & Grade 1 \\
Monthly & Grade 1 & Grade 1 & Grade 1 & Grade 0 \\
Infrequent & Grade 0 & Grade 0 & Grade 0 & Grade 0 \\
\hline
\end{tabular}

\section{Long term follow-up}

In May 2014 two validated GERD-symptom questionnaires, the GERD-HRQL and GSRS symptom questionnaire, were sent out to the initial cohort.

We used these quantitative methods to evaluate symptom severity in GERD. Subjects were asked for severity and frequency of gastrointestinal symptoms (burning, bloating, belching, sensation of abdominal fullness, nausea and pain) 14-25 years after surgery. The questionnaires assess typical and atypical GERD symptoms and patients' quality of life. In the GERD-HRQL questionnaire patients were asked to indicate on a scale from 0-5 which number reflects best the severity of the symptom asked for in the question. The questionnaire has a minimum score of 0 and a maximum score of 45 . $^{23}$ The GSRS questionnaire has a scale from 0-3 for symptom severity and a scale from 0-4 for symptom frequency for every question with a minimum of 0 and maximum of 12 points per question. ${ }^{24}$ All these questions are anchored at the high 
end with the most negative or lowest intensity feelings (e.g., extremely unpleasant, not at all), and with opposing terms at the low end (e.g., extremely pleasant, very high, extreme). The survey also contained questions regarding the use of antireflux medication postoperatively and on reoperation.

\section{Statistical analysis}

All data are presented as mean and standard error of mean (SEM) for normally distributed data and as median and interquartiles (IQR) for abnormally distributed data. Comparisons were performed using the Wilcoxon signed-ranked test, Mann Whitney $\mathrm{U}$ test, Chi-square test and dependent or independent T-test as appropriate. $\mathrm{P}<0.05$ was regarded as significant. All statistical analyses were performed using commercially available computer software (IBM Corp. Released 2012. IBM SPSS Statistics for Windows, Version 21.0. Armonk, NY: IBM Corp.)

\section{Results}

\section{Baseline characteristics}

The vagus nerve injury group contained 23 patients (11 males, mean age 51 (range: 21-77) years, mean follow-up 19 (range: 14-25) years). The vagus nerve intact group consisted of 102 patients (49 males, mean age 48 (range: 19-73) years, mean followup 19 (range: 14-24) years). There were no statistical significant differences between these groups with respect to age, gender and duration of follow-up. Prior to surgery patients underwent gastric emptying testing, esophageal manometry, 24-hour $\mathrm{pH}$ monitoring and vagus nerve integrity testing. Preoperative characteristics with respect to symptoms, acid exposure time, LES pressure, vagus nerve integrity testing or gastric emptying were not significantly different between the vagus nerve injury and the vagus nerve intact group. The results of the preoperative work-up are listed in Table 3.2. 


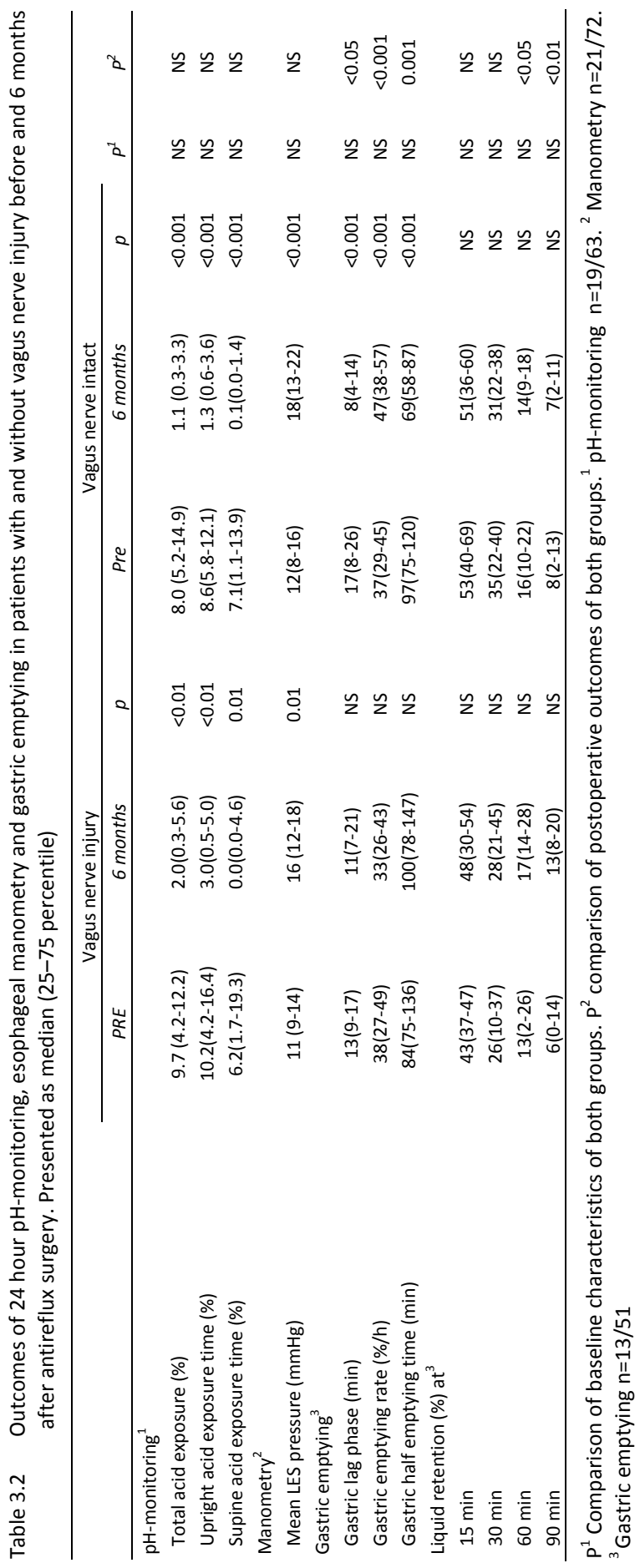




\section{Short term outcome}

\section{Vagus nerve integrity}

Prior to surgery, none of the 125 patients had evidence of vagus nerve dysfunction. The plasma PP peak increase in response to insulin-induced hypoglycemia had a median value of 143 (100-193) pmol/L. After surgery the median value in the vagus nerve injury group was 17 (5-31) pmol/L compared to 113 (83-170) pmol/L in the vagus nerve intact group (Figure 3.2). Postoperative plasma PP response was compatible with truncal vagotomy (PP peak increase $\leq 47 \mathrm{pmol} / \mathrm{L}$ ) in 23 patients. With respect to the surgical procedure: 47 patients underwent Nissen fundoplication (13\% vagus nerve injury) 47 patients underwent Toupet hemifundoplication (17\% vagus nerve injury) and 31 underwent BM IV fundoplication (29\% vagus nerve injury) No significant difference in distribution of vagus nerve injury was seen among type of operations. We divided the patient population in two groups: one group with and one group without vagus nerve injury.

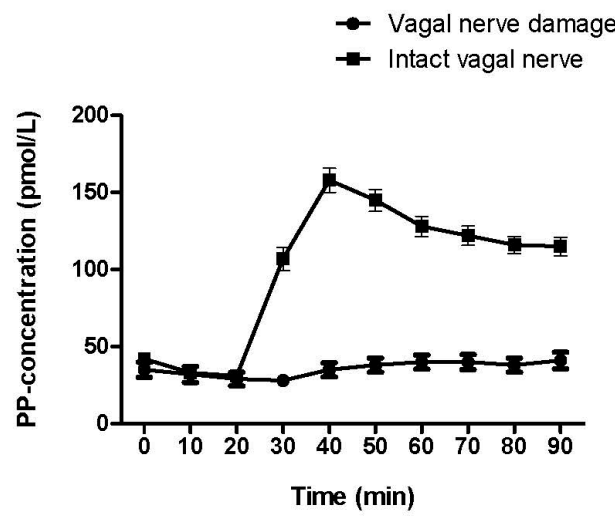

Figure 3.2 Difference between vagus nerve injury and vagus nerve intact group 6 months after surgery for hypoglycemia induced pancreas polypeptide test. At time $0 \mathrm{~min}$ insulin $(0.1 \mathrm{U} / \mathrm{kg})$ was administered

\section{Gastric Emptying}

\section{Solids}

Gastric emptying of solids increased significantly after ARS for patients in the vagus nerve intact group. In the vagus nerve injury group gastric emptying of solids did not change significantly after ARS compared to preoperatively. The groups were not 
significantly different with respect to emptying parameters in the preoperative state; however, after ARS lag phase, emptying rate and half emptying time were significantly delayed in the patients with vagus nerve injury when compared to the vagus nerve intact group (Figure 3.3).

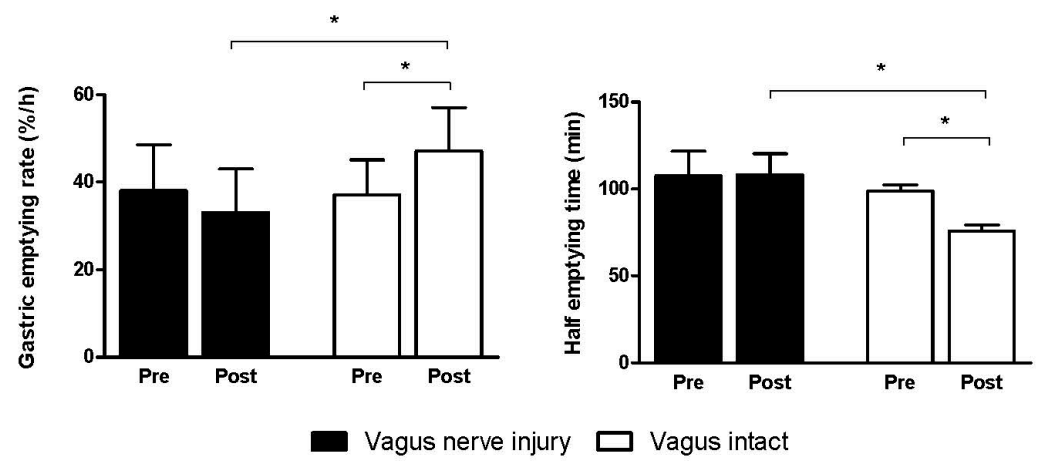

Figure 3.3 Comparison between vagus nerve injury and vagus nerve intact group for the difference in gastric emptying rate $(\% / \mathrm{h})$ (left panel) and gastric half emptying time (min) (right panel) 6 months post-surgery. ${ }^{*} \mathrm{P}<0.001$

Liquids

No differences in gastric emptying of liquids were observed apart from a minor but statistically significant difference in retention of liquids at 60 and 90 min postoperative between vagus nerve injury versus vagus nerve intact patients (Table 3.2).

\section{4 hour pH-monitoring and esophageal manometry}

ARS significantly reduced acid exposure time and increased the mean LES pressure 6 months after the procedure (Table 3.2). No statistical significant differences were found between both groups.

\section{Reflux Symptoms}

Prior and 6 months after ARS patients filled in a standard symptom questionnaire. The prevalence of symptoms after ARS was higher in the vagus nerve injury group. However, this did not reach statistical significance (Figure 3.4). 


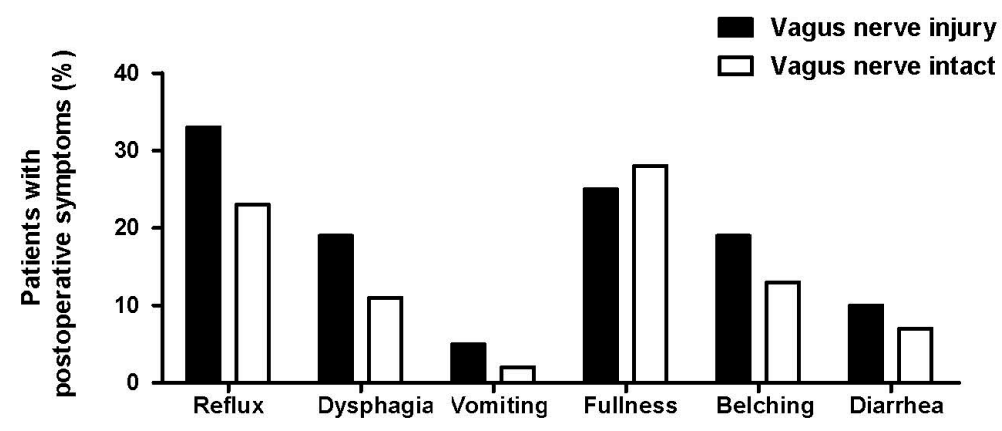

Figure 3.4 Difference in symptomatic outcome 6 months after surgery between the vagus nerve injury and vagus nerve intact group

\section{Long term outcome}

\section{Responders}

Of the 110 patients who received questionnaires via a letter, completed questionnaires were received from 71 patients (65\%). Thirty-four patients did not respond, four cases were excluded from the study because of an incorrect address and 1 patient did not fill out the questionnaires correctly (Figure 3.1). Of these 71 patients, $13(18 \%)$ had vagus nerve injury and $58(82 \%)$ had an intact vagus nerve.

\section{Heartburn - GERD-HRQL}

For the assessment of reflux symptoms $>10$ years after surgery, the GERD-HRQL questionnaire was used. Comparison between groups showed higher scores in the vagus nerve injury group (Table 3.3 ).

Table 3.3 Long term outcome of antireflux surgery in patients with and without vagus nerve injury

\begin{tabular}{lccc}
\hline & $\begin{array}{c}\text { Vagus nerve injury } \\
(\mathrm{n}=13)\end{array}$ & $\begin{array}{c}\text { Vagus nerve intact } \\
(\mathrm{n}=58)\end{array}$ & $\mathrm{P}$ \\
\hline $\begin{array}{l}\text { GERD-HRQL questionnaire } \\
\text { Total score }\end{array}$ & $13(5-25)$ & $3(0-9)$ & $<0.001$ \\
Satisfaction rate (\%) & 33 & 68 & $<0.05$ \\
PPI use (\%) & 54 & 41 & $\mathrm{NS}$ \\
Reoperation rate (\%) & 54 & 16 & 0.007 \\
GSRS questionnaire & & & \\
$\quad$ Heartburn & $2(0-6)$ & $1(0-3)$ & NS \\
Regurgitation & $1(0-8)$ & $0(0-2)$ & NS \\
Abdominal distention & $3(1-6)$ & $1(0-6)$ & NS \\
Dysphagia & $2(0-5)$ & $1(0-6)$ & NS \\
Coughing & $2(0-6)$ & $2(0-6)$ & NS \\
\hline
\end{tabular}




\section{Dysphagia, Regurgitation, Gas-bloating and Cough}

Severity and frequency of postoperative dysphagia, regurgitation, gas-bloating and cough were assessed for both groups using the GSRS questionnaire. Similar results for all symptoms were shown in both groups (Table 3.3).

\section{Satisfaction}

For the assessment of general satisfaction the GERD-HRQL was used. Three categories for satisfaction, "satisfied", "neutral" and "unsatisfied", were described at the end of the questionnaire. Of the total group of 71 patients that responded 14-25 years after their antireflux surgery $62 \%$ was satisfied, $23 \%$ was neutral and $15 \%$ was unsatisfied. In the vagus nerve injury group $33,3 \%$ of patients were satisfied, $33,3 \%$ neutral and $33,3 \%$ unsatisfied. In the group vagus nerve intact group $68 \%$ were satisfied, $21 \%$ neutral and $11 \%$ unsatisfied. A statistical significant difference was found between the two groups for satisfaction rate (Table 3.3).

\section{Proton-pump inhibitor usage}

Of the 71 patients, $42 \% \quad(n=30)$ were using a proton pump inhibitor after fundoplication. The other $58 \%(n=41)$ had not used PPI's since surgery. In the vagus nerve injury group 7 patients (54\%) restarted PPI use, in the vagus nerve intact group 24 patients (41\%) had recommenced taking PPI (Table 3.3).

\section{Re-operation rate}

Re-operation rate in the vagus nerve injury group was significantly higher: 7 of 13 patients (54\%) underwent re-operation. Three patients were operated because of reflux recurrence, 3 patients due to dysphagia and 1 patient had severe gastroparesis for which a Bll resection of the stomach was performed. In patients without vagus nerve injury 9 out of 58 (16\%) patients underwent re-operation. Six patients were operated because of reflux recurrence, 1 patient due to dysphagia, 1 due to a slipped fundoplication and 1 due to a rotated fundoplication. This difference in re-operation rate between the two groups was statistically significant (Table 3.3). In addition, no significant difference in distribution of re-operation rate was seen among the different type of surgical procedures (Belsey Mark IV, laparoscopic Nissen, laparoscopic Toupet). 


\section{Discussion}

In this short and long term follow-up of a prospective cohort we evaluated the impact of vagus nerve injury on reflux control after antireflux surgery. The prevalence of vagus nerve injury tested by IH-PP was $20 \%$ in patients who underwent ARS. Our short term data (6 months) indicate that symptom control and reflux control was not different among patients with and without vagus nerve injury. Postoperative gastric emptying was significantly delayed in the vagus nerve injury vs vagus intact group. Concerning the data at 20 years follow-up, a significantly worse outcome with respect to heartburn symptoms, satisfaction rate and re-operation rate was seen in patients with vagus nerve injury. Our results indicate that vagus nerve injury during antireflux surgery negatively affects long term reflux control.

Using the IH-PP test, we observed a high prevalence of vagus nerve injury after ARS. In a previous study we reported on vagus nerve injury after partial fundoplication. In that study the prevalence of vagus nerve injury after ARS was $10 \%{ }^{14}$ It should be taken into account that the number of patients in that study was much smaller and that we evaluated only one single surgical technique and therefore that study may not give an accurate estimate of the prevalence of vagus nerve injury after ARS in general, that is after all types of ARS. In the present study three different surgical techniques (BM IV, Toupet and Nissen) have been employed and a large group of patients was included. In twenty-three patients the results were compatible with vagus nerve injury: $13 \%$ (6/47) in the Nissen group, $18 \%(8 / 47)$ in the Toupet group and $29 \%(9 / 31)$ in the BM IV fundoplication group. We did not observe significant differences between surgical procedures with respect to the prevalence of vagus nerve injury.

Risk factors for vagus nerve injury after ARS have not been studied systematically. One may assume that the risk of vagus nerve injury is both procedure and surgeon related since operating and manipulating near the branches of the vagus nerve may easily lead to direct or indirect injury. An intrathoracic approach (BM IV) is technically more challenging and therefore more prone to vagus nerve injury. As mentioned earlier, we did not observe significant differences in vagus nerve dysfunction between the surgical procedures that have been employed in this study although the percentage of patients with vagus nerve injury after BM IV was higher than after the two other procedures.

Other factors that potentially may increase a risk of vagus nerve injury during ARS include presence of a large para-esophageal or axial hiatal hernia, previous abdominal surgery, severe esophagitis causing adhesions, poor visibility of the anatomy in the gastroesophageal region, anatomical variations of the vagus nerve and limited experience with the procedure of the surgeon. Patients included in this study underwent antireflux surgery as a primary procedure and no paraesophageal hiatal 
hernia's were present. Furthermore, all patients were operated in a high volume center by surgeons experienced with the types of operations employed in this study. The mechanisms by which vagus nerve injury negatively affects the outcome after ARS are not fully understood. The vagus nerve is known to play an important role in the motor and sensory regulatory functions of the esophagus and stomach. Vagus nerve injury may impair these functions and thereby lead to upper gastrointestinal symptoms.

Previous studies have established an association between vagus nerve injury after ARS and impaired gastric motility, resulting in delayed gastric emptying or even gastroparesis. ${ }^{25-27}$ In more detail, impairment of the gastric accommodation of the proximal stomach, hypomotility of the antrum (with loss of trituration and retention of solids), and loss of pyloric relaxation (with stasis) have been associated with vagotomy and conditions after gastric surgery. ${ }^{28-34}$

Longer retention of food in the stomach leads to higher intragastric pressures and thereby may promote reflux even in the presence of a restored esophago-gastric barrier. Recently, Gourcerol et al. showed that in GERD patients with delayed gastric emptying the number of postprandial reflux events measured with $\mathrm{pH}$-impedance monitoring was increased, with a longer bolus clearance time and more proximal esophageal extension of the refluxate. This was also true for reflux symptoms in patients with delayed gastric emptying compared to patients with normal gastric emptying. ${ }^{35}$ Rebecchi et al. evaluated the association between gastric emptying with long term reflux control in GERD patients after ARS. These authors showed that delayed gastric emptying was strongly associated with poor reflux control. ${ }^{36}$ Taken together, these findings indicate that delayed gastric emptying contributes to GERD and that it may negatively influence the effect of ARS.

We observed that gastric emptying improved for solids but not for liquids after ARS in the vagus nerve intact group, while it remained unchanged both for liquids and solids in the vagus nerve injury group at six months after surgery.

Delayed gastric emptying is seen in up to $40 \%$ of patients with GERD. ${ }^{37}$ Fundoplication is known to accelerate gastric emptying. ${ }^{14,38}$ In ARS, part of the fundus is utilized for creating the fundoplication thereby reducing postprandial gastric volume and gastric capacity. This results in a higher proximal gastric tone and reduces duration of postprandial relaxation of the proximal stomach, leading to propulsion of food into the antrum with acceleration in gastric emptying. ${ }^{38-40}$ Acceleration of gastric emptying after fundoplication may positively influence the antireflux effect of the procedure. The delay in liquid emptying at 60 and 90 min seen after ARS in the vagus nerve injury group vs vagus nerve intact group is not in line with literature data. It has been indicated that vagotomy leads to a reduction in fundus accommodation and body of the stomach and thereby an acceleration of liquid emptying. ${ }^{26,41-43}$ In our study testing of solid and liquid gastric emptying was done simultaneously, with potential interference of the solid and liquid components. 
We confirmed findings from previous studies and extended there upon: vagus nerve injury did not negatively affect outcomes 6 months after ARS despite the persistence of delayed gastric emptying. ${ }^{14,15,17}$ However, during long term follow-up a worse outcome of reflux control was found in the vagus nerve injury group. A possible explanation for the difference in control of reflux symptoms during short and longterm follow-up is not readily available. One option is that the newly created gastroesophageal valve may gradually lose efficacy with respect to its reflux barrier over time. ${ }^{44}$ Increasing age with loss of compliance and elasticity of tissue, may lead to reduced efficacy of the gastroesophageal valve.

The re-operation rate differed significantly between both groups. Over $50 \%$ of patients in the vagus nerve injury group have been re-operated. Most patients underwent re-operation because of recurrence of reflux. In one patient from the vagus nerve injury group severe gastroparesis had developed. This was so debilitating that a partial resection of the stomach had to be performed. Despite high reoperation rates, symptoms associated with GERD persisted in this patient group. The findings of our study suggest that patients who have recurrent reflux symptoms following ARS might benefit from vagal integrity testing before deciding on additional treatment since a normal outcome of gastric emptying testing does not appear to exclude vagal nerve injury. Therefore, we believe careful and objective evaluation of symptoms and measurement of gastric emptying and PP-IH testing after ARS is warranted before considering re-operation in these patients.

Some limitations to this study should be addressed. The long-term symptomatic outcome cannot be directly compared with the 6 months data because other types of questionnaires were used. Furthermore, not all patients underwent all tests such as gastric emptying test, esophageal manometry, and 24-h $\mathrm{pH}$-monitoring pre and 6 months after surgery.

The strength of our study is the evaluation of vagus nerve integrity by IH-PP measurements both before and after fundoplication in all 125 patients so that we are certain that the outcome of the test when pointing to vagus nerve dysfunction was related to the surgical procedure. To our best knowledge, our study is the largest to date reporting on vagus nerve dysfunction after ARS with long term results.

In conclusion: Vagus nerve injury occurs in up to $20 \%$ of patients who undergo antireflux surgery. Vagus nerve injury does not negatively affect short-term reflux control six months after antireflux surgery. However long term follow-up showed a negative effect on symptom control and a significantly higher re-operation rate in patients with vagus nerve injury. Preserving the main trunks of the vagus nerve is therefore of utmost importance in order to maintain vagus nerve integrity and contribute to reflux control after ARS. 


\section{References}

1. Dent J, El-Serag HB, Wallander MA, et al. Epidemiology of gastro-oesophageal reflux disease: a systematic review. Gut. 2005;54:710-7.

2. Dallemagne B, Weerts JM, Jehaes C, et al. Laparoscopic Nissen fundoplication: preliminary report. Surg Laparosc Endosc. 1991;1:138-43.

3. Dallemagne B, Perretta S. Twenty years of laparoscopic fundoplication for GERD. World J Surg. 2011;35:1428-35.

4. Wang YR, Dempsey DT, Richter JE. Trends and perioperative outcomes of inpatient antireflux surgery in the United States, 1993-2006. Dis Esophagus. 2011;24:215-23.

5. Broeders JA, Mauritz FA, Ahmed Ali U, et al. Systematic review and meta-analysis of laparoscopic Nissen (posterior total) versus Toupet (posterior partial) fundoplication for gastro-oesophageal reflux disease. Br J Surg. 2010;97:1318-30.

6. Papasavas P. Functional problems following esophageal surgery. Surg Clin North Am. 2005;85:525-38.

7. Broeders JA, Sportel IG, Jamieson GG, et al. Impact of ineffective oesophageal motility and wrap type on dysphagia after laparoscopic fundoplication. Br J Surg. 2011;98:1414-21.

8. Kessing BF, Broeders JA, Vinke N, et al. Gas-related symptoms after antireflux surgery. Surg Endosc. 2013;27:3739-47.

9. Lindeboom MY, Ringers J, Straathof JW, et al. The effect of laparoscopic partial fundoplication on dysphagia, esophageal and lower esophageal sphincter motility. Dis Esophagus. 2007;20:63-8.

10. Kozarek RA, Low DE, Raltz SL. Complications associated with laparoscopic anti-reflux surgery: one multispecialty clinic's experience. Gastrointest Endosc. 1997;46:527-31.

11. Trus TL, Bax T, Richardson WS, et al. Complications of laparoscopic paraesophageal hernia repair. J Gastrointest Surg. 1997;1:221-7; discussion 228.

12. Schwartz TW. Pancreatic polypeptide: a hormone under vagal control. Gastroenterology. 1983;85:1411-25.

13. Schwartz TW, Holst JJ, Fahrenkrug J, et al. Vagal, cholinergic regulation of pancreatic polypeptide secretion. J Clin Invest. 1978;61:781-9.

14. Lindeboom MY, Ringers J, van Rijn PJ, et al. Gastric emptying and vagus nerve function after laparoscopic partial fundoplication. Ann Surg. 2004;240:785-90.

15. DeVault KR, Swain JM, Wentling GK, et al. Evaluation of vagus nerve function before and after antireflux surgery. J Gastrointest Surg. 2004;8:883-8; discussion 888-9.

16. Straathof JW, Ringers J, Masclee AA. Prospective study of the effect of laparoscopic Nissen fundoplication on reflux mechanisms. Br J Surg. 2001;88:1519-24.

17. Oelschlager BK, Yamamoto K, Woltman T, et al. Vagotomy during hiatal hernia repair: a benign esophageal lengthening procedure. J Gastrointest Surg. 2008;12:1155-62.

18. Skinner DB, Belsey RH. Surgical management of esophageal reflux and hiatus hernia. Long-term results with 1,030 patients. J Thorac Cardiovasc Surg. 1967;53:33-54.

19. Nissen R. [A simple operation for control of reflux esophagitis]. Schweiz Med Wochenschr. 1956;86:590-2.

20. Toupet A. [Technic of esophago-gastroplasty with phrenogastropexy used in radical treatment of hiatal hernias as a supplement to Heller's operation in cardiospasms]. Mem Acad Chir (Paris). 1963; 89:384-9.

21. Masclee AA, de Best AC, de Graaf R, et al. Ambulatory 24-hour pH-metry in the diagnosis of gastroesophageal reflux disease. Determination of criteria and relation to endoscopy. Scand J Gastroenterol. 1990;25:225-30.

22. Lamers CB, Diemel CM, van Leer $E$, et al. Mechanism of elevated serum pancreatic polypeptide concentrations in chronic renal failure. J Clin Endocrinol Metab. 1982;55:922-6.

23. Velanovich V. The development of the GERD-HRQL symptom severity instrument. Dis Esophagus. 2007;20:130-4.

24. Allen CJ, Parameswaran K, Belda J, et al. Reproducibility, validity, and responsiveness of a diseasespecific symptom questionnaire for gastroesophageal reflux disease. Dis Esophagus. 2000;13:265-70.

25. Camilleri M, Parkman HP, Shafi MA, et al. Clinical guideline: management of gastroparesis. Am J Gastroenterol. 2013;108:18-37; quiz 38. 
26. Jamieson GG, Maddern GJ, Myers JC. Gastric emptying after fundoplication with and without proximal gastric vagotomy. Arch Surg. 1991;126:1414-7.

27. Olinde AJ, Maher JW, McGuigan JE, et al. The effect of fundoplication with or without proximal gastric vagotomy on gastric emptying and serum gastrin. Am Surg. 1985;51:690-2.

28. Shafi MA, Pasricha PJ. Post-surgical and obstructive gastroparesis. Curr Gastroenterol Rep. 2007;9:280-5.

29. Behrns KE, Sarr MG. Diagnosis and management of gastric emptying disorders. Adv Surg. 1994;27:233-55.

30. Miyano Y, Sakata I, Kuroda K, et al. The role of the vagus nerve in the migrating motor complex and ghrelin- and motilin-induced gastric contraction in suncus. PLoS One. 2013;8:e64777.

31. Fich $A$, Neri $M$, Camilleri $M$, et al. Stasis syndromes following gastric surgery: clinical and motility features of 60 symptomatic patients. J Clin Gastroenterol. 1990;12:505-12.

32. Azpiroz F, Malagelada JR. Gastric tone measured by an electronic barostat in health and postsurgical gastroparesis. Gastroenterology. 1987;92:934-43.

33. Bredenoord AJ, Chial HJ, Camilleri M, et al. Gastric accommodation and emptying in evaluation of patients with upper gastrointestinal symptoms. Clin Gastroenterol Hepatol. 2003;1:264-72.

34. Lagoo J, Pappas TN, Perez A. A relic or still relevant: the narrowing role for vagotomy in the treatment of peptic ulcer disease. Am J Surg. 2014;207:120-6.

35. Gourcerol G, Benanni Y, Boueyre E, et al. Influence of gastric emptying on gastro-esophageal reflux: a combined pH-impedance study. Neurogastroenterol Motil. 2013;25:800-e634.

36. Rebecchi F, Allaix ME, Giaccone C, et al. Gastric emptying as a prognostic factor for long-term results of total laparoscopic fundoplication for weakly acidic or mixed reflux. Ann Surg. 2013;258:831-6; discussion 836-7.

37. Gonlachanvit S, Maurer AH, Fisher RS, et al. Regional gastric emptying abnormalities in functional dyspepsia and gastro-oesophageal reflux disease. Neurogastroenterol Motil. 2006;18:894-904.

38. Vu MK, Straathof JW, v d Schaar PJ, et al. Motor and sensory function of the proximal stomach in reflux disease and after laparoscopic Nissen fundoplication. Am J Gastroenterol. 1999;94:1481-9.

39. Vu MK, Ringers J, Arndt JW, et al. Prospective study of the effect of laparoscopic hemifundoplication on motor and sensory function of the proximal stomach. Br J Surg. 2000;87:338-43.

40. Lindeboom MY, Vu MK, Ringers J, et al. Function of the proximal stomach after partial versus complete laparoscopic fundoplication. Am J Gastroenterol. 2003;98:284-90.

41. Van Hee R, Mistiaen W, Block P. Gastric emptying of liquids after highly selective vagotomy for duodenal ulcer. Hepatogastroenterology. 1989;36:92-6.

42. Stadaas JO. Effect of vagotomy on gastric motility. Scand J Gastroenterol Suppl. 1976;42:85-8.

43. Gleysteen JJ, Burdeshaw JA, Hallenbeck GA. Gastric emptying of liquids after different vagotomies and pyloroplasty. Surg Gynecol Obstet. 1976;142:41-8.

44. Robinson B, Dunst CM, Cassera MA, et al. 20 years later: laparoscopic fundoplication durability. Surg Endosc. 2015;29:2520-4. 



\section{Part II}

Safety and efficacy of new minimal invasive endoscopic and surgical techniques in the treatment of obesity 



\section{Chapter 4}

Structural endoscopic techniques to treat obesity:

a review

S. van Rijn*, Y.G.M. Roebroek*, A.A.M. Masclee, E.L.W.E. van Heurn, N.D. Bouvy ${ }^{*}$ Both authors contributed equally Surg Technol Int. 2015;26:84-91 


\section{Abstract}

The prevalence of overweight and obesity increased significantly during the past decades, affecting now roughly $30 \%$ of the people worldwide. Bariatric surgery has proven to be the most effective treatment modality for obesity in the long term. However, current surgical procedures are accompanied by a substantial risk of complications. Several endoluminal techniques have been developed to achieve weight loss in obese patients, and claim to be as effective as surgery but safer. The aim of this review is to evaluate the efficacy and safety of endoscopic bariatric procedures that provide structural changes in anatomy and physiology of the gastrointestinal tract. A comprehensive search was conducted, using online databases and the references of the selected articles. All studies included in this review show excess weight loss in the short to medium-term, which ranges from $24-58 \%$. Seven serious adverse events were reported. Therefore we conclude that endoscopic bariatric procedures providing structural changes show relatively low complication rates and promising short-term weight loss and effect on obesity related comorbidities. Long-term results in large study populations are necessary before these techniques can be incorporated in the standard treatment of obesity. 


\section{Introduction}

Obesity has become epidemic worldwide and its prevalence has more than doubled during the last three decades. ${ }^{1}$ In Europe, $15 \%$ to $30 \%$ of the people suffer from obesity, while the percentage of affected people in the United States has risen to more than $30 \%$ of the total population. ${ }^{2-4}$ A body mass index (BMI) of $\geq 25 \mathrm{~kg} / \mathrm{m}^{2}$ is defined as overweight, $\geq 30 \mathrm{~kg} / \mathrm{m}^{2}$ is defined as obesity and a $\mathrm{BMI} \geq 40$ is described as morbid obesity. ${ }^{1}$ Both obesity and morbid obesity have been proven to be associated with an increased risk of comorbidities and even death. ${ }^{5,6}$ Risk factors associated with obesity include hypertension, diabetes mellitus type II (DMII), coronary heart disease, osteoarthritis, and cancer. ${ }^{1,7}$

Current treatment options for obesity consist of lifestyle interventions, drug therapy, and bariatric surgery. Bariatric surgery has proven to be more effective in the long term than lifestyle interventions or drug therapy. ${ }^{8-10}$ Commonly performed techniques in bariatric surgery include Roux-en- $Y$ gastric bypass (RYGB), sleeve gastrectomy (SG) and laparoscopic adjustable gastric banding (LAGB). Although these surgical procedures have been proven to be very effective, the incidence of complications is considerable. $^{11-19}$

To provide a less-invasive and therefore safer alternative for bariatric surgery, several endoluminal techniques have been developed. In the past decades different devices have been designed to accomplish temporary or structural changes to gastroduodenal anatomy and function. Several temporary techniques for weight loss (e.g., intragastric balloons, endoscopic jejunal bypass liners) show promising results in the short term. ${ }^{20-23}$ However, once these devices have been removed, the earlier effect may not last. $^{21,23}$ The aim of this review is to evaluate the efficacy and safety of endoscopic bariatric procedures that provide permanent restrictive changes in anatomy of the gastrointestinal tract.

\section{Methods}

The Preferred Reporting Items for Systematic Reviews and Meta-Analyses (PRISMA) guidelines on identification and selection of individual studies were applied throughout the conduction of this search. ${ }^{24} \mathrm{~A}$ systematic bibliographic search was performed until January 2015, using the following online databases: MEDLINE, EMbase and the Cochrane Register of Controlled Clinical Trials. The following search terms in combination with Boolean operators were used: (obesity [MeSH Terms] OR obesity) AND (endoscopy [MeSH Terms] OR gastrointestinal endoscopy OR endoluminal OR transoral) AND (gastrointestinal [MeSH Terms] OR gastric OR stomach OR stomach restriction $O R$ stomach reduction $O R$ gastric restriction $O R$ gastric 
reduction) AND (prospective studies [MeSH Terms] OR prospective OR feasibility OR pilot). All abstracts were screened for eligibility by two independent reviewers (Dr. Roebroek and Dr. van Rijn) using the following exclusion criteria: surgical procedure; endoscopic procedure assisted by surgery; endoscopy for reasons other than bariatric therapy; temporary measure; non-restrictive measure; lack of outcomes of interest (excess weight loss (EWL), change in BMI, morbidity, mortality, safety of procedure); animal studies; reviews; meta-analyses; language other than English; (conference) abstract only available; comments. Because literature was scarce on this topic and many devices remain still in their initial stages, it was decided to include not only randomized controlled trials (RCTs) but also feasibility and pilot studies.

In addition to the online search, the references of the selected articles were screened for eligibility following the same selection process. After exclusion of the abstracts not meeting our criteria, full articles were assessed for eligibility using the exclusion criteria mentioned earlier (Figure 4.1). Discrepancies in the selection of studies were solved by discussion with the senior author (Dr. Bouvy).

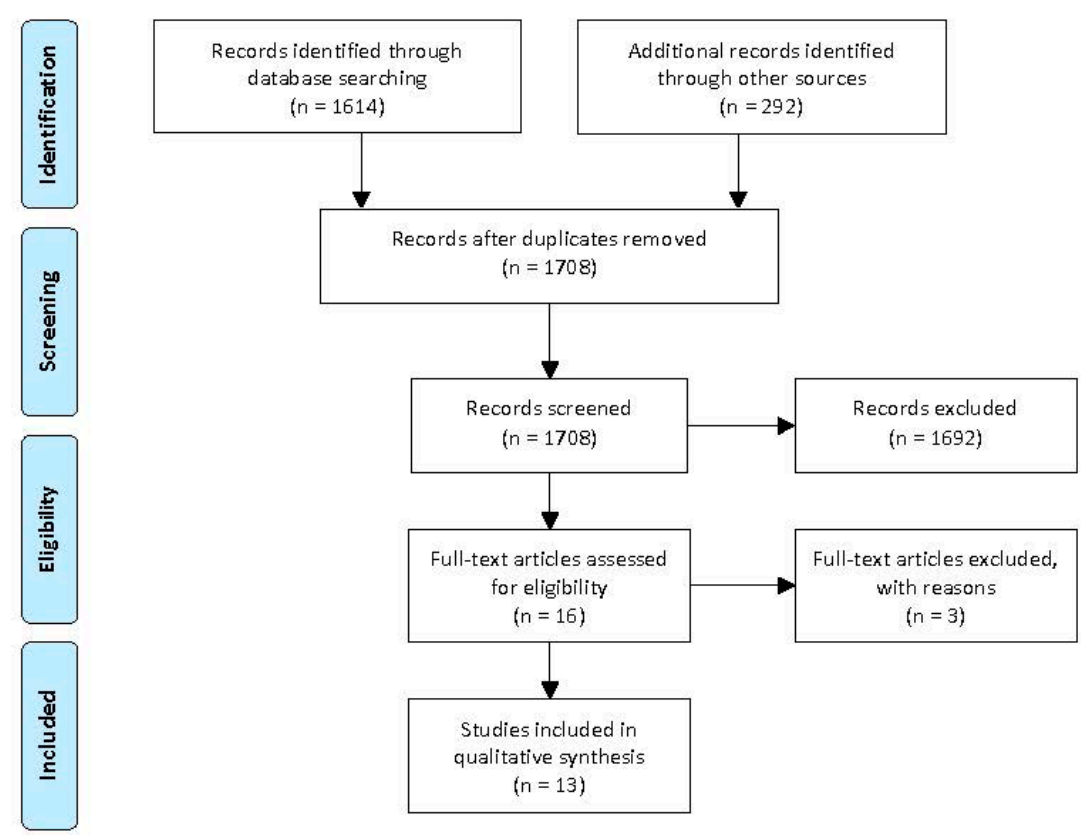

Figure 4.1 Preferred reporting items for systematic reviews and meta-analyses (PRISMA) diagram of the search 


\section{Results}

\section{Restriction of stomach}

Several endoluminal devices have been developed to exclude or disable (most of) the greater curvature of the stomach. Most procedures use suturing systems, whereas others use an endoluminal stapler device.

\section{Endoluminal vertical gastroplasty}

Using one continuous suture throughout the entire procedure, the Endocinch suturing system (C.R. Bard Inc, Murray Hill, NJ; product currently discontinued) produces an endoluminal vertical gastroplasty (EVG). Starting at the anterior face of the gastric fundus, five to seven stiches are placed in a distal and subsequently proximal direction, following a specific woven pattern made by one suture that runs through anterior and posterior parts of the gastric wall (Figure 4.2).

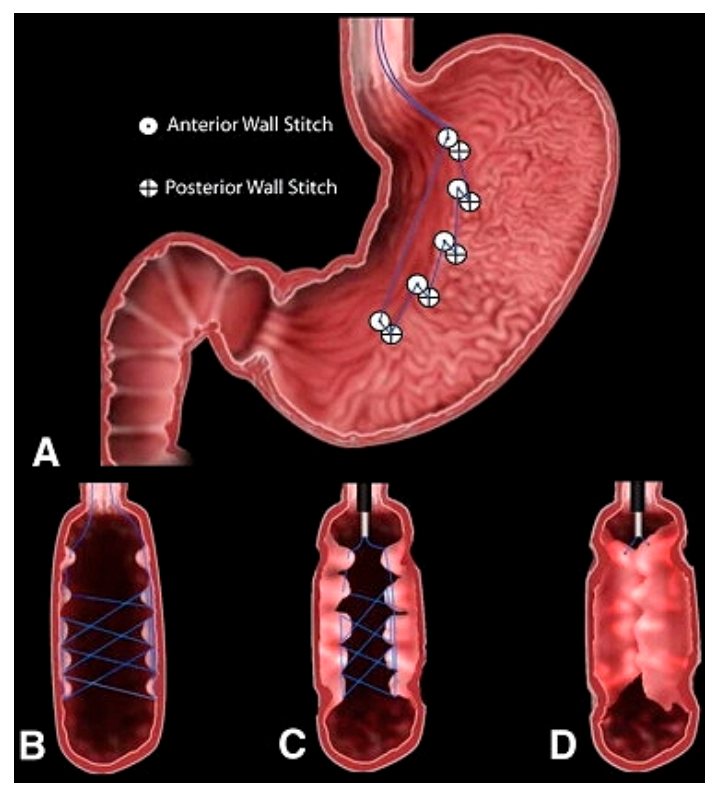

Figure 4.2 Stitching pattern and physical result of the EVG created with the Endocinch device. ${ }^{25}$ Reprinted with permission from Elsevier

Next, the suture is tightened and apposes the anterior and posterior walls of the stomach, creating an EVG from the fundus down to the distal end of the corpus. Fogel et al. presented their results on this technique based on a series of 64 patients of whom 59 completed their follow-up. ${ }^{25}$ After one year of follow-up, a reduction in 
mean BMI ( \pm standard deviation [SD]) from $39.9 \pm 5.1 \mathrm{~kg} / \mathrm{m}^{2}$ to $30.6 \pm 4.7 \mathrm{~kg} / \mathrm{m}^{2}$ was achieved, corresponding with a mean EWL of $58.1 \% \pm 19.9 \%$. No complications or serious adverse events (SAE's) were recorded. In one case vomiting was reported during recovery, other adverse events (AEs) consisted of sore throat and reflux-like symptoms not requiring medical treatment. Follow-up endoscopies were performed if patients reported loss of satiety; 14 endoscopies were performed showing a completely intact EVG in five patients, a loosened (though intact) EVG in six patients and a disrupted EVG in three patients.

\section{Transoral gastric volume reduction}

As a modified version of the Endocinch suturing system, the RESTORe Suturing System (RSS, Bard-Davol, Warwick, RI; product currently discontinued) was developed for transoral gastric volume reduction (TGVR). The RSS mainly differs in suture pattern; it creates interrupted sutures apposing direct opposite tissue, compared with Endocinch's one running stitch in a woven pattern. The RSS forms a plication by applying suction to the gastric wall, retracting the tissue into the device, and deploying a suture through the gastric tissue. Directly after retrieving the suture by reactivating the device, the RSS is ready for the next suture placement. Once opposing sutures are in place, a suture fastening system is positioned over the free suture ends, pulling them together and fastening them under direct endoscopic vision, apposing opposite sites of the stomach (Figure 4.3). Approximately six plications are required for adequate gastric volume reduction. Brethauer et al. published results of this procedure on feasibility as well as weight loss and adverse events after 12 months. ${ }^{26,27}$ Eighteen patients were included and 14 completed follow-up, resulting in a decrease in mean BMI of $4.0 \pm 3.5 \mathrm{~kg} / \mathrm{m}^{2}$ and an EWL of $27.7 \% \pm 21.9 \%$ after one year. Endoscopies performed one month after the procedure showed a partial release of plications in 15 out of 18 patients; after 12 months (with only 14 patients left) a partial or even full release was seen in eight and five patients, respectively. No SAEs were reported during or after procedure. Except for one case of moderate diarrhea, all AEs with at least a possible relationship to the procedure (no numbers available) were of mild intensity including nausea, diarrhea, abdominal distention, and abdominal pain. 


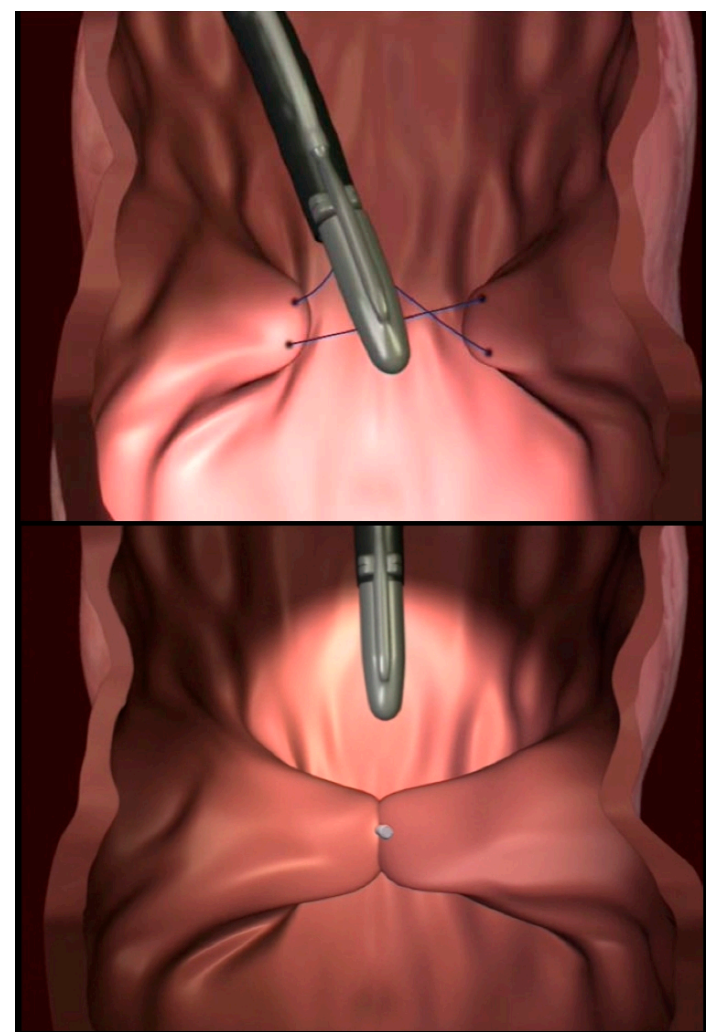

Figure 4.3 Tissue apposition and tightening in TGVR using the RSS system.(26) Reprinted with permission from Elsevier

\section{Endoscopic sleeve gastroplasty}

Mimicking the effects of a sleeve gastrectomy, endoscopic sleeve gastroplasty (ESG) creates a sleeve along the lesser curvature of the stomach. The Overstitch Suturing System (Apollo Endosurgery Inc, Austin, TX) has been designed to appose anterior and posterior walls of the greater curvature with two parallel rows of interrupted sutures, leading from the antrum up to the fundus (Figure 4.4). To create a suture, a tissue screw is placed full thickness through the gastric wall and is then retracted, pulling the gastric tissue into the suturing device. An anchored suture is placed, penetrating both layers of the created plication. At the opposing suture site, the same maneuver is repeated using the free end of the same suture, connecting anterior and posterior walls of the stomach. The suture is then tightened using a cinching device, assuring formation of a full thickness plication. Approximately 25 sutures are needed to accomplish full reduction of the gastric cavity, resulting in a tubular lumen along the 
lesser curvature. Abu Dayyeh et al. first described this technique in $2013 .{ }^{28}$ Their feasibility study included only four patients and reports no results on EWL or change in BMI. One patient was hospitalized because of abdominal pain and nausea (SAE), symptoms improved with conservative treatment within three days. AEs included postoperative abdominal pain and nausea in three patients and acid reflux symptoms in one patient, all managed with a short period of drug therapy.

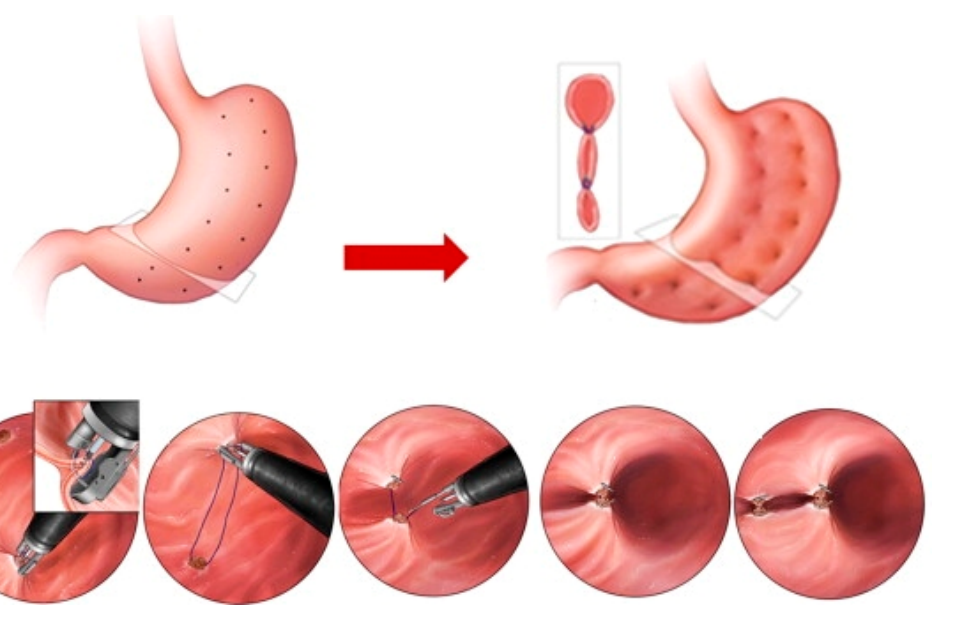

Figure 4.4 Top: orientation of the suture rows and the physical result of ESG. Bottom: the consecutive steps of the procedure.(28) Reprinted with permission from Elsevier

Two research groups slightly modified the procedure: Lopez-Nava et al. by using triangular stitches and Sharaiha et al. by using a running stitch on the lateral suture row $^{29,30}$ Lopez-Nava presented prospective results on 20 patients, showing a decrease in mean BMI from $38.5 \pm 4.8 \mathrm{~kg} / \mathrm{m}^{2}$ to $31.9 \pm 4.9 \mathrm{~kg} / \mathrm{m}^{2}$ in six months, corresponding with a mean EWL of $53.9 \% \pm 26.3 \%$. In two patients intraoperative bleeding occurred, managed by local injection therapy (not further specified). Sharaiha included ten patients and established a decrease in mean BMI from $45.2 \pm 8.9 \mathrm{~kg} / \mathrm{m}^{2}$ to $39.7 \pm 7.1 \mathrm{~kg} / \mathrm{m}^{2}$ and a mean EWL of $30 \%$ (SD not available) after six months. Postoperative abdominal pain and nausea occurred in eight patients and chest pain in two patients. The management of these complaints was not specified.

\section{Transoral gastroplasty}

The Transoral Gastroplasty (TOGA) System (Satiety Inc., Palo Alto, CA; company currently out of business) was designed to produce an endoscopic vertical gastroplasty using staples. In the stomach, the stapler body of the device is positioned along the lesser curvature, pointing its stapler jaws toward the fundus. Anterior and 
posterior stomach tissue directly below the angle of His is then retracted by suction into the vacuum pods of the stapler jaws. To ensure that anterior and posterior plica are stapled together as two distinct folds, a septum with attached wire is kept in between the folds while the stapler is closed and three parallel rows of staples are fired. To extend the created sleeve, the procedure can be repeated once more in a downward direction, resulting in a sleeve of approximately 8 to $9 \mathrm{~cm}$ along the proximal lesser curvature (Figure 4.5). Afterward, a single suction pod stapler can be used to narrow the distal sleeve outlet by creating additional separate plications. Devière et al. investigated feasibility and effects of this technique in 21 patients, achieving a decrease in mean BMI from $43.3 \pm 5.0 \mathrm{~kg} / \mathrm{m}^{2}$ to $38.5 \mathrm{~kg} / \mathrm{m}^{2}$ (SD not available) and mean EWL of $24.4 \%$ after six months (SD not available).(31) No SAEs were reported. Device-related AEs included only temporary complaints: e.g., vomiting $(n=7)$, pain $(n=13)$, nausea $(n=6)$, and dysphagia $(n=6)$. At six months, five patients had fully intact sleeves, while staple line gaps or incomplete distal sleeves were observed in 13 and three patients, respectively.

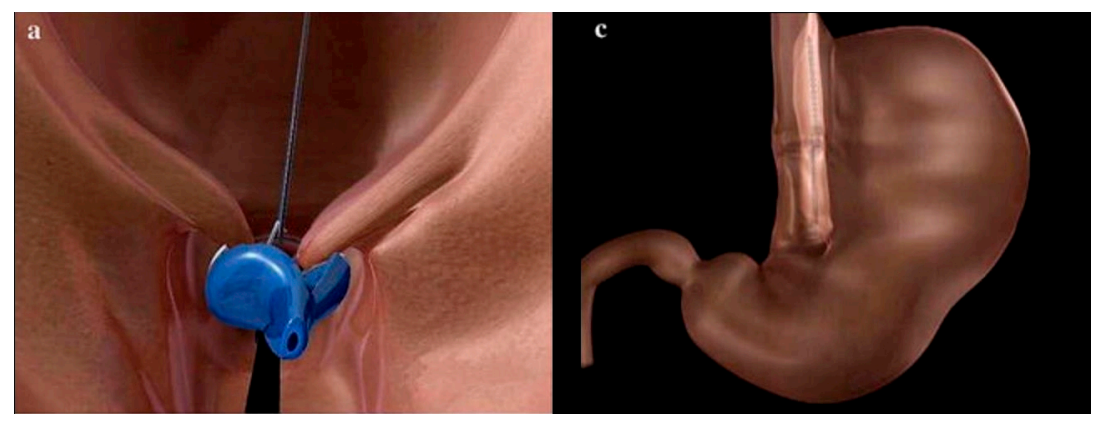

Figure 4.5 Left: tissue approximation in EVG using the TOGA system. Right: physical result after the TOGA procedure.(31) Reprinted with permission from Elsevier

After development of an adjustable septum for the TOGA device (aiming for fewer gaps) and optimizing the perioperative management, the same research group conducted another trial with 11 patients.(32) Mean BMI decreased from $41.6 \pm 4.3$ $\mathrm{kg} / \mathrm{m}^{2}$ to $33.1 \pm 5.8 \mathrm{~kg} / \mathrm{m}^{2}$ after six months, corresponding with a mean EWL of $46.0 \% \pm 20.7 \%$. Again no SAEs were reported and procedure-related AEs (pain, esophagitis, nausea, vomiting, etc.) were mild to moderate and resolved spontaneously or after drug therapy. Ten patients underwent endoscopy at six months, revealing a staple line gap in four of them.

Familiari et al. conducted a trial using the TOGA device in 67 patients; 53 patients completed the 12 months of follow-up with a mean EWL of $38.7 \% \pm 17.1 \%$, corresponding with a mean excess BMI loss of $44.8 \% \pm 20.0 \%{ }^{33}$ Twenty-five of the 
51 patients who underwent endoscopy at 12 months showed a staple line gap. One SAE was reported perioperative in a patient with preexistent COPD, who required extended ventilation because of respiratory insufficiency. Furthermore, two other SAEs were reported: one patient was diagnosed with an asymptomatic pneumoperitoneum, managed with antibiotics and monitoring; one patient developed symptomatic gallstones, treated with a cholecystectomy. Two patients underwent conversion to another bariatric procedure.

Investigating the effect of TOGA on glucose metabolism, Lecessi et al. reported data based on 43 patients. In half of the cases, a decrease in mean BMI of $7.6 \mathrm{~kg} / \mathrm{m}^{2}$ was accompanied by improvement of glucose disposal and regression of diabetes or impaired glucose tolerance. ${ }^{34}$

\section{Selective restriction}

Three endoluminal procedures are based on volume reduction of the fundus, aiming for a decrease in accommodation of the proximal stomach. Depending on the type of procedure, additional plications of the antral body of the stomach are created with the intent to cause dysmotility thereby delaying gastric emptying.

\section{Primary Obesity Surgery Endoluminal procedure}

Utilizing a trans-oral Incisionless Operating Platform (IOP; USGI Medical, San Clemente, CA), the Primary Obesity Surgery Endoluminal (POSE) procedure creates 11 to 13 suture-anchor plications in the fundus ( 8 to 9 pieces) and distal body of the antrum ( 3 to 4 pieces). Tissue of the stomach wall is mobilized by a tissue grasper and pulled into a small-jawed gripper, thereby forming a plication and enabling a Suture Anchor Delivery Catheter to deploy the suture-anchor and fixate the plication (Figure 4.6). Subsequent plications ( 2 to 3 ) can be placed in line with the previous plication to create a continuing tissue ridge.

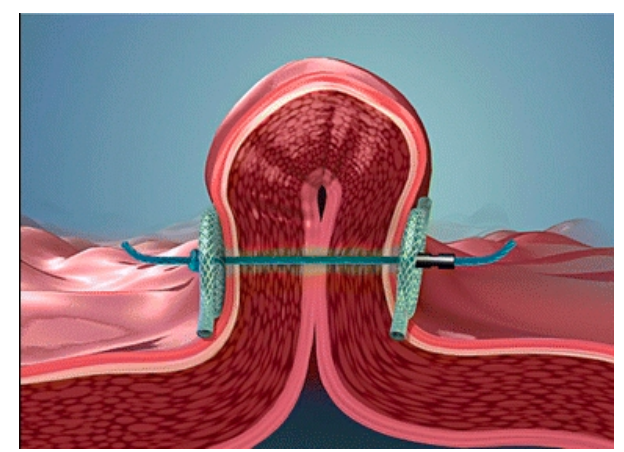

Figure 4.6 A plication created during the POSE procedure. Fixation is secured by anchors on both sides of the suture. ${ }^{35}$ Reprinted with permission from Elsevier 
During the prospective trial of Espinós et al., 45 patients underwent a POSE procedure. $^{35}$ Only 27 patients were compliant with the postoperative protocol (calorie-restricted diet, exercise) and available for 6 months follow-up. Mean BMI decreased from $37.2 \pm 3.9 \mathrm{~kg} / \mathrm{m}^{2}$ to $31.3 \pm 3.3 \mathrm{~kg} / \mathrm{m}^{2}$ and a mean EWL of $49.4 \% \pm 21.5 \%$ was achieved. No complications or SAEs were reported. One patient suffered from low-grade postoperative fever, which resolved after treatment with antibiotics. Other AEs included vomiting, sore throat, stomach pain, nausea, and chest pain.

\section{Articulating Circular Endoscopic ptapling procedure}

The Articulating Circular Endoscopic (ACE) stapler (BaroSense, Redwood City, CA; acquisition by Boston Scientific Corporation, Marlborough, MA) creates full thickness, transmural plications in both the fundus and antrum of the stomach. After introduction of the device via an overtube, the stomach tissue is imbibed inside the cover of the stapler head by applying a vacuum. Stomach tissue is then compressed by hydraulics inside the stapler after which a $10-\mathrm{mm}$ plastic ring with eight staples is fired to create a full thickness, transmural plication. Eight such plications are created in the fundus of the stomach for sufficient volume reduction; two additional plications in the antrum are created for dysmotility (Figure 4.7).

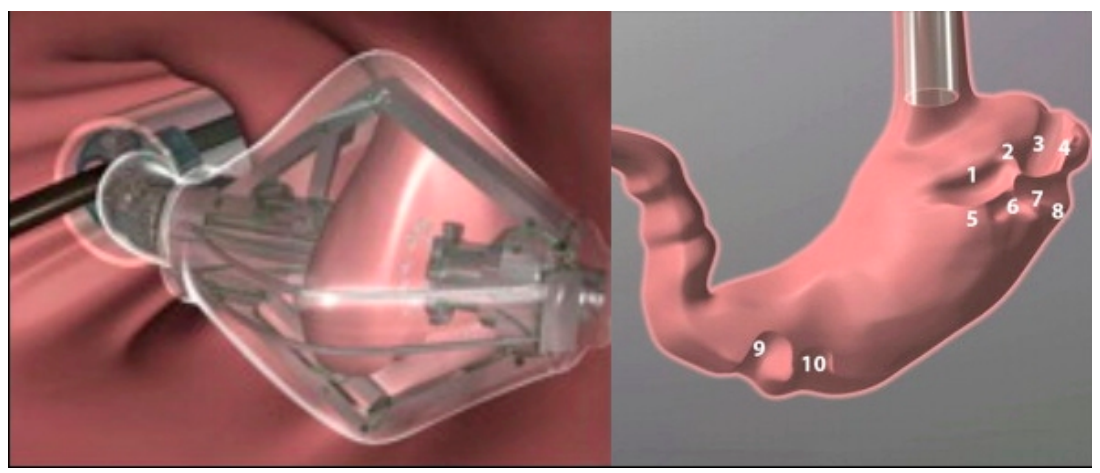

Figure 4.7 Left: The ACE stapling device creating an plication in de fundus of the stomach. Right: locations of the plications created during the ACE procedure. ${ }^{36}$ Reprinted with permission from Elsevier

In a prospective trial conducted by Verlaan et al., 17 patients were included for an ACE procedure, of whom 15 were available for one-year follow-up. ${ }^{36}$ At 12 months, median BMI had improved from $40.2 \mathrm{~kg} / \mathrm{m}^{2}$ (interquartile range 37.6-42.8) to $34.5 \mathrm{~kg} / \mathrm{m}^{2}$ (interquartile range 30.2-37.6), corresponding with a median EWL of $34.9 \%$ (interquartile range $17.8 \%-46.6 \%$ ). No SAEs were reported and AEs consisted of 
gastric pain $(n=7)$, sore throat $(n=4)$, diarrhea $(n=4)$, constipation $(n=4)$, nausea $(n=3)$, and vomiting $(n=3)$. All AEs were treated conservatively.

\section{Transoral Mucosal Excision Sutured Gastroplasty}

Aiming for full thickness durable plications, the Transoral Mucosal Excision Sutured Gastroplasty (TMESG) procedure has been developed as endoscopic treatment for both obesity and gastro-esophageal reflux disease (GERD). The excision device is introduced into the stomach and retracts gastric tissue of the greater curvature by applying a vacuum. A hypertonic saline and adrenaline solution is injected in the retracted tissue for vasoconstriction, after which the (sub)mucosa of the tissue is excised. This process is repeated twice to create a confluent adjacent excision bed. A suturing device is then positioned over the excision bed and two sets of full thickness sutures are placed on the sides of the excision bed. The suture ends are tightened and knotted using a stitchknotter, creating a plication of the treated area that partially closes the gastro-esophageal junction. In addition, a hypertonic saline solution is injected along the proximal lesser curvature to form a restrictive fibrotic ring.

In a feasibility study by Legner et al., four patients underwent TMESG for obesity. ${ }^{37}$ At 24 months, an EWL of $23 \%, 30 \%$, and $68 \%$ was achieved in three patients, respectively. Apart from intermittent dysphagia reported by one of these three patients, no (S)AEs occurred. The fourth patient suffered from repeated vomiting directly after the procedure and again on day nine, the latter requiring rehospitalization. Furthermore, the gastroplasty integrity was lost within six months in this patient, resulting in a BMI comparable to baseline at 24 months follow-up. 


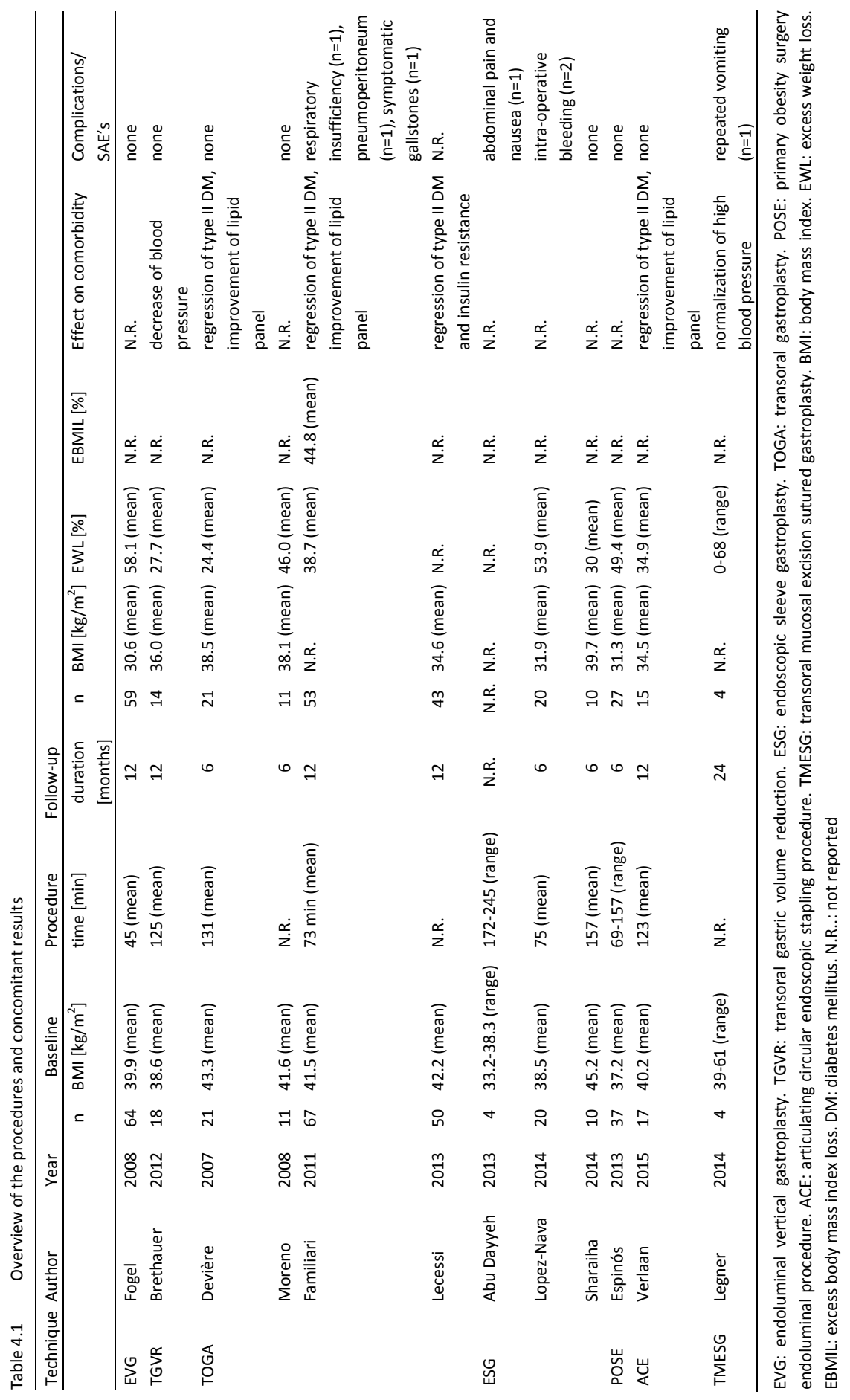




\section{Discussion}

The aim of this review is to evaluate the efficacy and safety of endoscopic bariatric procedures creating structural restriction of the gastrointestinal tract. After a comprehensive search in online databases, 13 publications describing seven procedures were included in this review. Because many structural endoscopic bariatric procedures are still in their initial stages, most of these publications concern feasibility or pilot studies investigating relatively small patient groups in the short term or mid-term. Due to heterogeneity of procedure type, outcome parameters and duration of follow-up, no firm conclusions can be drawn. However, the results of our review show certain trends of weight loss and safety of the procedures (Table 4.1). All studies show EWL in the short- to medium-term, which ranges from $24 \%$ to $58 \%$. In a total of 277 patients completing at least six months of follow-up, seven SAEs were reported of which one required a second surgical procedure. Only a few adverse events required drug therapy, and most events were self-limiting and resolved within two weeks.

Bariatric surgery has evolved tremendously since the first performed procedures in the 1950s. To date, EWL five years after LAGB, laparoscopic SG (LSG) or laparoscopic RYGB (LRYGB) ranges between $35-60 \%, 60-70 \%$, or $65-75 \%$ respectively. ${ }^{12,13,38-40}$ Despite the good clinical results with relatively high EWL, these surgical procedures are associated with considerable risk of complications. Overall postoperative complication rates range from $21 \%$ for LRYGB to $13 \%$ for both LAGB and LSG. ${ }^{12}$ Common complications after LRYGB or LSG include anastomotic leakage (0-5.6\% and $0-10 \%$ respectively) and stenosis or stricture $\left(1.2 \%-4.4 \%\right.$ and $0-5 \%$ respectively). ${ }^{17-19}$ LAGB is notorious for its erosion into the gastric lumen $(0.5 \%-2.9 \%)$ and proximal pouch dilatation or slippage $(1.7 \%-11.1 \%) .{ }^{11,13-16}$

In clinical practice, a BMI $\geq 35 \mathrm{~kg} / \mathrm{m}^{2}$ is generally accepted as a cut-off point for bariatric surgery, stating that the health benefits do not outweigh the risks of the procedures in patients with a $\mathrm{BMI}<35 \mathrm{~kg} / \mathrm{m}^{2}{ }^{41}$ Comparing the trends in results of this review with previously mentioned results of bariatric surgery, it seems that the current endoscopic techniques are not (yet) capable of achieving the same EWL. On the contrary, complication rates appear to be lower with endoscopic techniques, and the vast majority of the adverse events reported were mild and self-limiting. In addition, the results of Familiari et al. show that the overweight and the obese (i.e. $\mathrm{BMI}<35 \mathrm{~kg} / \mathrm{m}^{2}$ ) seem to benefit more from endoscopic techniques than the morbid obese (BMI $\geq 35 \mathrm{~kg} / \mathrm{m}^{2}$ ) in terms of weight loss. ${ }^{33}$ The innovative endoscopic techniques described may therefore be a good alternative for this specific patient group. 
The seven different procedures included in this review were classified into two groups: one group consisted of devices developed to exclude or disable the greater curvature of the stomach and the other group consisted of devices designed for selective restriction of specific stomach parts (fundus, antrum). Although both groups show promising results in terms of weight loss, the techniques of the first group seem to be endured more by device-related failure. After 12 months, nine out of 14 EVGs and 13 out of 14 TGVRs were (partially) disrupted. In addition, the multicenter trial of the TOGA stapling procedure reported on gaps in the staple lines in approximately half $(25 / 51)$ of the patients at 1-year follow-up. A possible explanation for failures in EVG and TGVR might be sought in the relatively superficial sutures that are placed by the specific devices, not reaching full thickness and therefore not assuring a lasting effect. Another explanation can be found in the lack of compliance of the sleeves created in EVG, TGVR, or TOGA procedures, resulting in high pressures building up in the sleeve that seek for a less-resistant way and thereby disperse the staple or suture lines.

\section{Conclusion}

Structural endoscopic bariatric procedures show relatively low complication rates (especially the procedures for selective restriction) and promising short- to mediumterm results with regard to weight loss. Randomized controlled trials in larger populations are necessary to assess the long-term results of these new techniques and to find out if they may be used as standard treatment of obesity in the future. 


\section{References}

1. Obesity and overweight. World Health Organization, 2006 Contract No.: Fact sheet number 311, updated January 2015.

2. Flegal KM, Carroll MD, Kit BK, Ogden CL. Prevalence of obesity and trends in the distribution of body mass index among US adults, 1999-2010. JAMA. 2012;307:491-7.

3. von Ruesten A, Steffen A, Floegel A, van der AD, Masala G, Tjonneland A, et al. Trend in obesity prevalence in European adult cohort populations during follow-up since 1996 and their predictions to 2015. PloS One. 2011;6:e27455.

4. Ng M, Fleming T, Robinson M, Thomson B, Graetz N, Margono C, et al. Global, regional, and national prevalence of overweight and obesity in children and adults during 1980-2013: a systematic analysis for the Global Burden of Disease Study 2013. Lancet. 2014;384:766-81.

5. Adams KF, Schatzkin A, Harris TB, Kipnis V, Mouw T, Ballard-Barbash R, et al. Overweight, obesity, and mortality in a large prospective cohort of persons 50 to 71 years old. N Engl J Med. 2006;355:763-78.

6. Bender R, Trautner C, Spraul M, Berger M. Assessment of excess mortality in obesity. Am J Epidemiol. 1998;147:42-8.

7. Friedman N, Fanning EL. Overweight and obesity: an overview of prevalence, clinical impact, and economic impact. Disease management : DM. 2004;7 Suppl 1:S1-6.

8. Sjostrom L. Review of the key results from the Swedish Obese Subjects (SOS) trial - a prospective controlled intervention study of bariatric surgery. J Intern Med. 2013;273:219-34.

9. Picot J, Jones J, Colquitt JL, Gospodarevskaya E, Loveman E, Baxter L, et al. The clinical effectiveness and cost-effectiveness of bariatric (weight loss) surgery for obesity: a systematic review and economic evaluation. Health Technol Assess. 2009;13:1-190, 215-357, iii-iv.

10. Colquitt JL, Pickett K, Loveman E, Frampton GK. Surgery for weight loss in adults. The Cochrane database of systematic reviews. 2014;8:CD003641.

11. Brown WA, Egberts KJ, Franke-Richard D, Thodiyil P, Anderson ML, O'Brien PE. Erosions after laparoscopic adjustable gastric banding: diagnosis and management. Ann Surg. 2013;257:1047-52.

12. Chang SH, Stoll CR, Song J, Varela JE, Eagon CJ, Colditz GA. The effectiveness and risks of bariatric surgery: an updated systematic review and meta-analysis, 2003-2012. JAMA Surg. 2014;149:275-87.

13. Cobourn C, Chapman MA, Ali A, Amrhein J. Five-year weight loss experience of outpatients receiving laparoscopic adjustable gastric band surgery. Obesity Surg. 2013;23:903-10.

14. Cobourn C, Degboe A, Super PA, Torre M, Robinson J, Jin J, et al. Safety and effectiveness of LAPBAND AP System: results of Helping Evaluate Reduction in Obesity (HERO) prospective registry study at 1 year. J Am Coll Surg. 2013;217:907-18.

15. Egberts K, Brown WA, O'Brien PE. Systematic review of erosion after laparoscopic adjustable gastric banding. Obesity Surg. 2011;21:1272-9.

16. Lee WK, Kim SM. Three-year experience of pouch dilatation and slippage management after laparoscopic adjustable gastric banding. Yonsei Med J. 2014;55:149-56.

17. Qureshi A, Podolsky D, Cumella L, Abbas M, Choi J, Vemulapalli P, et al. Comparison of stricture rates using three different gastrojejunostomy anastomotic techniques in laparoscopic Roux-en-Y gastric bypass. Surg Endosc. 2015;29:1737-40.

18. Trastulli S, Desiderio J, Guarino S, Cirocchi R, Scalercio V, Noya G, et al. Laparoscopic sleeve gastrectomy compared with other bariatric surgical procedures: a systematic review of randomized trials. Surg Obes Relat Dis. 2013;9:816-29.

19. Zellmer JD, Mathiason MA, Kallies KJ, Kothari SN. Is laparoscopic sleeve gastrectomy a lower risk bariatric procedure compared with laparoscopic Roux-en-Y gastric bypass? A meta-analysis. Am J Surg. 2014;208:903-10; discussion 9-10.

20. Koehestanie P, de Jonge C, Berends FJ, Janssen IM, Bouvy ND, Greve JW. The effect of the endoscopic duodenal-jejunal bypass liner on obesity and type 2 diabetes mellitus, a multicenter randomized controlled trial. Ann Surg. 2014;260:984-92.

21. Mathus-Vliegen EM. Endoscopic treatment: the past, the present and the future. Best Pract Res Clin Gastroenterol. 2014;28:685-702. 
22. Schouten R, Rijs CS, Bouvy ND, Hameeteman W, Koek GH, Janssen IM, et al. A multicenter, randomized efficacy study of the EndoBarrier Gastrointestinal Liner for presurgical weight loss prior to bariatric surgery. Ann Surg. 2010;251:236-43.

23. Tsesmeli N, Coumaros D. Review of endoscopic devices for weight reduction: old and new balloons and implantable prostheses. Endoscopy. 2009;41:1082-9.

24. Moher D, Liberati A, Tetzlaff J, Altman DG, Group P. Preferred reporting items for systematic reviews and meta-analyses: the PRISMA statement. PLoS Med. 2009;6:e1000097.

25. Fogel R, De Fogel J, Bonilla Y, De La Fuente R. Clinical experience of transoral suturing for an endoluminal vertical gastroplasty: 1-year follow-up in 64 patients. Gastrointest Endosc. 2008;68:51-8.

26. Brethauer SA, Chand B, Schauer PR, Thompson CC. Transoral gastric volume reduction for weight management: technique and feasibility in 18 patients. Surg Obes Relat Dis. 2010;6:689-94.

27. Brethauer SA, Chand B, Schauer PR, Thompson CC. Transoral gastric volume reduction as intervention for weight management: 12-month follow-up of TRIM trial. Surg Obes Relat Dis. 2012;8:296-303.

28. Abu Dayyeh BK, Rajan E, Gostout CJ. Endoscopic sleeve gastroplasty: a potential endoscopic alternative to surgical sleeve gastrectomy for treatment of obesity. Gastrointest Endosc. 2013;78: 530-5.

29. Lopez-Nava G, Galvao MP, da Bautista-Castano I, Jimenez A, De Grado T, Fernandez-Corbelle JP. Endoscopic sleeve gastroplasty for the treatment of obesity. Endoscopy. 2014;47:449-52.

30. Sharaiha RZ, Kedia P, Kumta N, DeFilippis EM, Gaidhane M, Shukla A, et al. Initial experience with endoscopic sleeve gastroplasty: technical success and reproducibility in the bariatric population. Endoscopy. 2015;47:164-6.

31. Deviere J, Ojeda Valdes G, Cuevas Herrera L, Closset J, Le Moine O, Eisendrath P, et al. Safety, feasibility and weight loss after transoral gastroplasty: First human multicenter study. Surg Endosc. 2008;22:589-98.

32. Moreno C, Closset J, Dugardeyn S, Barea M, Mehdi A, Collignon L, et al. Transoral gastroplasty is safe, feasible, and induces significant weight loss in morbidly obese patients: results of the second human pilot study. Endoscopy. 2008;40:406-13.

33. Familiari P, Costamagna G, Blero D, Le Moine O, Perri V, Boskoski I, et al. Transoral gastroplasty for morbid obesity: a multicenter trial with a 1-year outcome. Gastrointest Endosc. 2011;74:1248-58.

34. Leccesi L, Panunzi S, De Gaetano A, Familiari P, laconelli A, Guidone C, et al. Effects of transoral gastroplasty on glucose homeostasis in obese subjects. J Clin Endocrinol Metab. 2013;98:1901-10.

35. Espinos JC, Turro R, Mata A, Cruz M, da Costa M, Villa V, et al. Early experience with the Incisionless Operating Platform (IOP) for the treatment of obesity : the Primary Obesity Surgery Endolumenal (POSE) procedure. Obesity Surg. 2013;23:1375-83.

36. Verlaan T, Paulus GF, Mathus-Vliegen EM, Veldhuyzen EA, Conchillo JM, Bouvy ND, et al. Endoscopic gastric volume reduction with a novel articulating plication device is safe and effective in the treatment of obesity (with video). Gastrointest Endosc. 2015;81:312-20.

37. Legner A, Altorjay A, Juhasz A, Stadlhuber R, Reich V, Hunt B, et al. Transoral mucosal excision sutured gastroplasty: a pilot study for GERD and obesity with two-year follow-up. Surg Innov. 2014;21:456-63.

38. Dogan K, Gadiot RP, Aarts EO, Betzel B, van Laarhoven CJ, Biter LU, et al. Effectiveness and safety of sleeve gastrectomy, gastric bypass, and adjustable gastric banding in morbidly obese patients: a multicenter, retrospective, matched cohort study. Obesity Surg. 2015;25:1110-8.

39. Obeid A, Long J, Kakade M, Clements RH, Stahl R, Grams J. Laparoscopic Roux-en-Y gastric bypass: long term clinical outcomes. Surgical Endosc. 2012;26:3515-20.

40. van Rutte PW, Smulders JF, de Zoete JP, Nienhuijs SW. Outcome of sleeve gastrectomy as a primary bariatric procedure. Br J Surg. 2014;101:661-8.

41. Jones DB. Perioperative management of morbid obesity. In: Fischer JE, editor. Mastery of Surgery. 1. 6th ed. Philadelphia: Wolters Kluwer Health - Lippincott Williams \& Wilkins; 2011:1097-103. 



\section{Chapter 5}

Multicenter, phase 1, open prospective trial in gastric electrical stimulation for the treatment of obesity: first in human results with the Exilis system

G.F. Paulus*, M. van Avesaat*, S. van Rijn, A.M.E Alleleyn, J.M. Swain, T.L Abell, B. Williams, N.D. Bouvy, A.A.M. Masclee ${ }^{*}$ Both authors contributed equally 


\section{Abstract}

\section{Background and aims}

Assess safety of the Exilis gastric electrical stimulation (GES) system and to investigate whether the settings can be adjusted for comfortable chronic use in subjects with morbid obesity. Gastric emptying, motility and meal intake were evaluated.

\section{Method}

In a multicenter, phase 1 , open prospective cohort study, 20 morbidly obese subjects (17 female, mean BMI of $40.8 \pm 0.7 \mathrm{~kg} / \mathrm{m}^{2}$ ) were implanted with the Exilis system. Amplitude of the Exilis system was individually set during titration visits. Subjects underwent two baseline test days (GES ON vs. OFF), after which long-term monthly follow-up started up to 52 weeks.

\section{Results}

The procedure was safe and electrical stimulation was accepted and comfortable in all subjects. No significant differences in gastric emptying half time ( $203 \pm 16$ vs. $212 \pm 14$ min, $p>0.05$ ), food intake ( $713 \pm 68$ vs. $799 \pm 69 \mathrm{kcal}, \mathrm{p}>0.05)$, insulin AUC (2448 \pm 347 vs. $2186 \pm 204, p>0.05)$ and glucose AUC (41 \pm 2 vs.41 $\pm 2, p>0.05)$ were found between GES ON and OFF. At week 4,13 and 26 a significant $(p<0.01)$ reduction in weight loss was observed, but not at week 52. At this time point the mean excess weight loss (EWL) was $14.2 \pm 4.5 \%$.

\section{Conclusion}

Gastric electrical stimulation with the Exilis system can be considered as safe. No significant effect on food intake, gastric emptying or gastric motility was observed. The reduction in weight loss with Exiles GES was significant but short lasting. Further electrophysiological research is needed to gain more insight in optimal stimulation parameters and lead localization. 


\section{Introduction}

Currently bariatric surgery is the only long-term effective treatment for morbid obesity. However, only a small percentage of potentially eligible subjects will ever undergo a bariatric procedure. ${ }^{1}$ Bariatric surgical procedures such as laparoscopic adjustable gastric banding (LAGB), laparoscopic sleeve gastrectomy (LSG) and Rouxen-Y gastric bypass (RYGB) ${ }^{2,3}$ modify gastrointestinal anatomy and physiology, require life long medical observation and are associated with a considerable amount of complications and long term adverse effects such as GERD, chronic vomiting, dumping syndrome and nutritional deficiencies. Taking the abovementioned considerations into account, there is room for other, less invasive therapies for morbid obesity. In this respect gastric electrical stimulation (GES) has been studied for over a decade as a minimal invasive, anatomy-preserving alternative for traditional bariatric procedures for the management of morbid obesity. ${ }^{4,5}$ The technique aims to impair gastric motor function and to modulate afferent signaling from the stomach, leading to delayed gastric empting with prolonged gastric distension, leading to enhanced satiety, thus resulting in decreased food intake and weight loss. ${ }^{6}$

Initial results with the Transcend implantable gastric stimulator (IGS) were promising, but consecutive double-blind randomized controlled trials initiated between 2000 and 2005 , have failed to show a clear beneficial effect on body weight relative to shamstimulated controls. ${ }^{7-9}$

Up to now, in the reported clinical trials only a narrow range of stimulation parameters and electrode configurations has been evaluated. Most clinical data on GES for obesity have been obtained using a single pulse frequency and duty cycle setting $(40 \mathrm{~Hz}, 2 \mathrm{~s}$ On-3s Off). Unfortunately the efficacy and functional implications of these settings have not been systematically explored in animals nor in humans. Nearly all subjects in these prior GES clinical trials were implanted with a single model of bipolar intramuscular lead, embedded in the stomach wall near the middle of the lesser curvature.

In a five-year period of extensive animal studies in rodents, both canine and swine, each major component of GES was systematically reexamined. It was shown that a pulse width of $>2.0 \mathrm{~ms},{ }^{10}$ a $40 \mathrm{~Hz}$ pulse frequency, continuous stimulation (16h On-8h Off) and pre-pyloric pulse delivery led to an optimal delay in gastric emptying, gastric distension and reduction in food intake. ${ }^{10}$ Moreover, chronic daily delivery of the GES treatment resulted in weight loss. The encouraging results of these animal studies have been used to define the required capabilities of the current Exilis ${ }^{\mathrm{TM}}$ system.

The aim of this early feasibility study was to gain first-in-human experience, to assess safety of the GES system and to investigate whether the settings can be adjusted for comfortable chronic use. Furthermore, we aimed to discover whether acute gastrointestinal (GI) and feeding effects as observed in animals can be reproduced in humans. In addition we aimed to enhance understanding of the mechanisms of action by which GES might induce weight loss. 
We hypothesized that GES for obesity is safe, decreases food intake and induces weight loss, possibly through a delay in gastric emptying.

\section{Methods}

\section{Study design}

We initiated a multicenter, phase 1 , open prospective cohort study conducted in the Netherlands and the United States. The study was approved by the medical ethics committee of all participating hospitals and was conducted in full accordance with the Declaration of Helsinki (latest amendment by the World Medical Association in 2013). Participants gave written informed consent prior to participation. This study was registered in the US National Library of Medicine (http://www.clinicaltrials.gov, NCT01823705).

\section{Subjects}

Patients were enrolled via the outpatient clinics of the participating hospitals. Patients were considered eligible to enroll in this study if they were weight stable, between 21-64 years of age and had a body mass index (BMI) of $40-45 \mathrm{~kg} / \mathrm{m}^{2}$ or $35-39.9 \mathrm{~kg} / \mathrm{m}^{2}$ with at least one weight-related comorbidity (e.g. nonalcoholic steatohepatitis, hypertension, dyslipidemia, obstructive sleep apnea, arthrosis). In case a subject was diagnosed with diabetes mellitus, the diagnosis had to be made within the last 7 years, had currently to be treated with oral agents and should have an $\mathrm{HbA1c} \leq 8 \%$. Exclusion criteria were prior major GI surgery (including bariatric surgery), pregnancy or the intention to become pregnant, functional and/or motility disorder and medical, surgical or psychiatric conditions that would limit study participation. Possible candidates underwent evaluation by a psychologist and dietician before they were included in the trial. They were excluded from participation if behavioral issues (personality disorder, depression and/or binge eating) were observed.

\section{Procedure}

Enrolled subjects underwent placement of the gastric electrical stimulator and charging coil under general anesthesia. The implanted components (Figure 5.1) consisted of an implantable pulse generator (IPG, Model VNT0016 Version 3, Medtronic, Minneapolis, USA) with implantable charge coil (ICC, Version 1, Medtronic, Minneapolis, USA) and two $35 \mathrm{~cm}$ insulated unipolar leads (Model 4351M, Medtronic, Minneapolis, USA). The leads were laparoscopically implanted into the muscle wall of the gastric antrum and were placed 3 to $5 \mathrm{~cm}$ proximal to the pylorus and parallel to the lesser curvature. A fixation disk was used to suture the leads to the serosal surface of the stomach. During placement of the leads, upper endoscopy was performed to 
prevent intraluminal placement of the electrodes, if indicated the leads were reinserted. When correct placement of the leads was confirmed, the distal ends were pulled through the skin incision of the caudal trocar and connected to the IPG. The IPG was implanted in a subcutaneous pocket ( 1.5 to $4.5 \mathrm{~cm}$ deep) off midline between the patient's iliac crest and ribs, and sutured in place. A similar pocket for the ICC was created above the ribs in the subcostal region of the $9^{\text {th }}$ rib along the anterior axillary line. The ICC receives electromagnetic energy through magnetic coupling with the external charge coil to recharge the IPG (Figure 5.1). ICC and leads were connected to the IPG, checked for integrity and switched off at the end of the procedure with the programming interface (Figure 5.1). Final position of the entire Exilis system was recorded with a post-operative abdominal X-ray. The implant surgery was followed by a two-week recovery period prior to continuation of the study protocol.
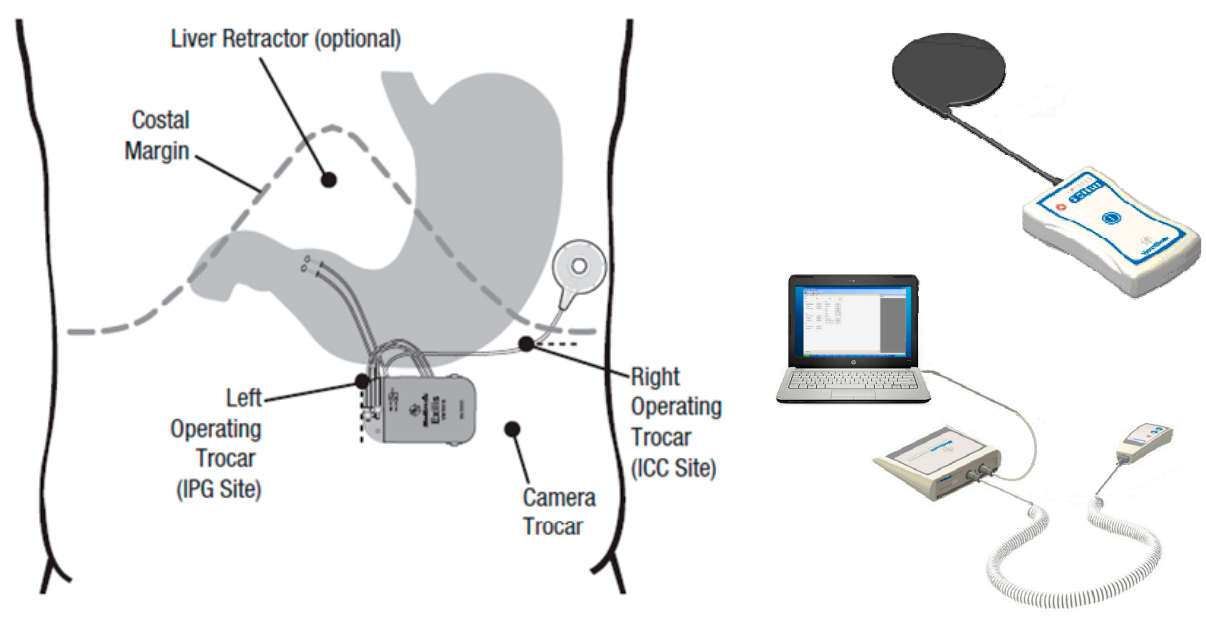

Figure 5.1 Implanted components (left), patient charging system (upper right) and external programming interface (lower right)

\section{Study protocol}

The study protocol continued with four amplitude titration visits (visit $A, B, C$ and D) occurring at weekly intervals. During the first of these visits the IPG was switched on and subjects underwent sensory threshold tests in which they were exposed to stimulation at progressively higher amplitudes. Visit A was used to identify the lowest amplitude that caused any visceral sensation, while at the fourth and final titration visit, subjects were programmed to the highest comfortable pulse amplitude. Fixed parameters of the IPG were a pulse width of $5.0 \mathrm{~ms}$, frequency of $40 \mathrm{~Hz}$ and a continuous duty cycle for 16 hours per day (off during 8 hours at night). The amplitude titration visits were followed by two Gl function test days performed in randomly 
assigned order and repeated twice (once with GES ON and once with GES OFF). Each GI function test day was preceded by a washout period (GES OFF) of seven days, and subjects were blinded to the assigned GES treatment. Testing included simultaneous measurement of gastric emptying (using a stable isotope breath test), gastric motility (SmartPill $)^{\circ}$, plasma concentrations of glucose and insulin and food intake over a fourhour period in the morning following an overnight fast (Figure 5.2). After completion of the GI function test days, each participant was programmed to GES ON (with the amplitude as determined during titration visit D) and long-term follow up was started. Participants had to charge the IPG (by connecting the external charge coil to the ICC) once every 48 hours. Monthly follow-up visits were planned during the first twelve months. Furthermore, GI function tests (with GES ON) were scheduled at weeks 26 and 52 of follow-up.

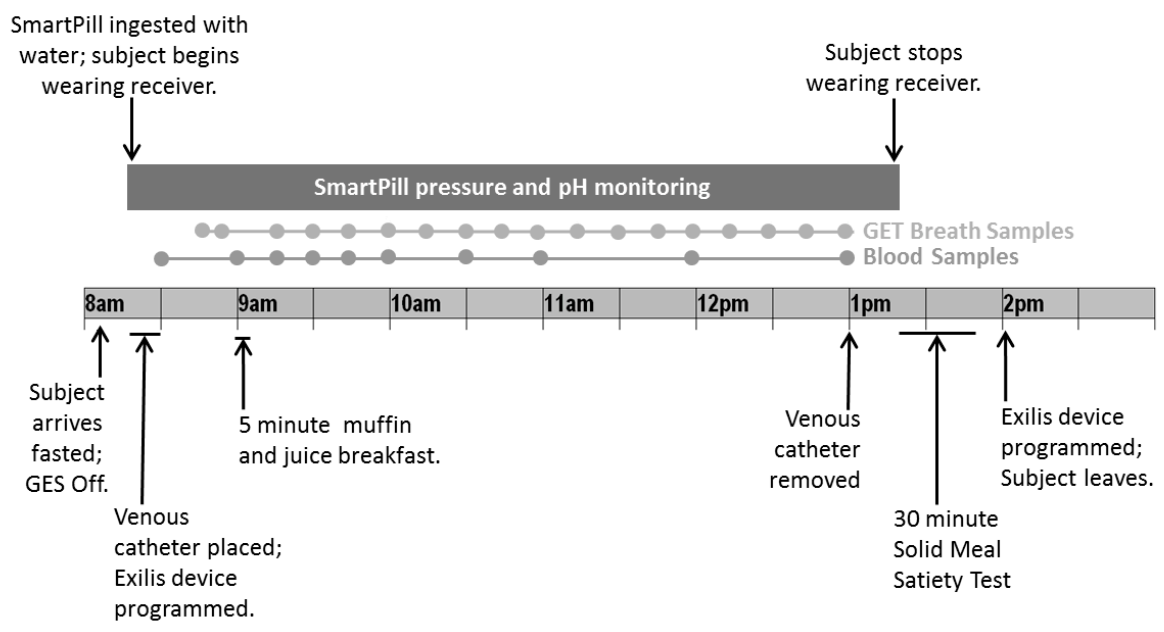

Figure $5.2 \quad$ Gl function testing

\section{Gl function tests}

Participants arrived at the hospital after an overnight fast. After programming of the GES device into ON or OFF mode (randomly assigned), baseline blood and breath samples were collected. Thereafter, participants swallowed a SmartPill (measuring gastrointestinal pressure and profiles, $\mathrm{pH}$ and temperature; SmartPill, Buffalo, NY) immediately followed by the ingestion of a standardized breakfast muffin (with ${ }^{13} \mathrm{C}$ octanoic acid to measure gastric emptying) and $200 \mathrm{~mL}$ of orange juice ( $82 \mathrm{kcal}, 19.2 \mathrm{~g}$ sugar). Blood and breath samples were collected at regular intervals during a fourhour period. Test days ended with the ingestion of an ad libitum pasta meal (Lasagna Bolognese; Plus Supermarkt, the Netherlands; energy density per 100 gram: 160 kcal, 
$11 \mathrm{~g}$ carbohydrates, $7.1 \mathrm{~g}$ protein and $9.4 \mathrm{~g}$ fat), of which participants could eat until comfortably full.

\section{Gastric emptying}

Gastric emptying was determined by using the gastric emptying breath test kit provided by Metabolic Solutions, Inc. (Nashua, NH). $100 \mathrm{mg}$ of ${ }^{13} \mathrm{C}$-octanoic acid is mixed into the standardized breakfast muffin $(350 \mathrm{kcal}, 64 \mathrm{~g}$ carbohydrates, $9 \mathrm{~g}$ protein, $7 \mathrm{~g}$ fat) ingested at $\mathrm{t}=0$. Breath samples of ${ }^{13} \mathrm{CO}_{2}$ were obtained twice at baseline and every 15 minutes in 4 hours following ingestion of the breakfast meal. Samples were analyzed by using a gas isotope ratio mass spectrometer and gastric emptying half time and lag time were calculated using the Ghoos model. ${ }^{11}$

\section{SmartPill}

A wired motility capsule (WMC, SmartPill , Buffalo, USA) was used to obtain pressure data of the stomach and small intestine. The WMC has several sensors that monitor $\mathrm{pH}$, pressure and temperature and transmits these data to a receiver. Our participants ingested the Smart Pill after breakfast (breakfast muffin with orange juice) was consumed at each Gl function test. Subjects wore the data receiver (to enable continued data collection from the capsule) for 72 hours (or stopped when collection with the capsule was lost after a bowel movement). The motility index was calculated as follows: $\operatorname{Ln}($ sum of pressure amplitudes $x$ number of contractions $(C t)+1){ }^{12}$

\section{Blood samples (glucose and insulin)}

Sodium fluoride- and SST II Plus gold tubes (Becton \& Dickinson, New Jersey, USA) were used for determination of glucose and insulin, respectively. Glucose measurements were performed on an Olympus AU 640/2700/5400 (Olympus, Tokyo, Japan). SST II Plus gold tubes were stored at room temperature for 30 minutes before centrifugation at $3000 \mathrm{rpm}, 20^{\circ} \mathrm{C}$ for 15 minutes. Serum insulin was measured using the Linco Human Insulin-specific RIA (HI-14K) on a Gamma counter with an inter-assay precision of $2.9-6.0 \%$.

\section{Statistical analysis}

Statistical analyses were performed using SPSS 23.0 (IBM Corporation, Somers, NY). Data were visually checked for normality and for constant variance of residuals by plots of residuals vs. corresponding predicted values. If data were not normally distributed, log transformation was applied for further analysis of the data. Area under the curve (AUC) was calculated by the trapezoid rule.

All variables were compared with a mixed analysis of variance model that included the fixed factor testday and random factor subject. For insulin and glucose (multiple time 
points per testday), time and the interaction between testday and time were added to the model. If a statistically significant intervention effect occurred, a post hoc Bonferroni test was performed. Data are presented as the mean \pm SEM (unless specified otherwise) and considered significant at $p<0.05$.

\section{Results}

\section{Participants}

After screening 32 subjects, 12 were excluded for failure to meet inclusion criteria. A total of 20 subjects ( 3 male, 17 female with a mean age of $43.6 \pm 1.6$ yrs, a mean weight of $116.4 \pm 4.1 \mathrm{~kg}$ and a mean $\mathrm{BMI}$ of $40.8 \pm 0.7 \mathrm{~kg} / \mathrm{m}^{2}$ ) were included after giving informed consent and were implanted with the Exilis system. Considering comorbidities, one subject had diabetes mellitus, two had dyslipidemia and five hypertension. The procedure was performed without any serious adverse events in all 20 subjects. All patients were discharged after one night and none of the patients had to be readmitted. With the exception of incisional hernias $(\mathrm{N}=2$, which had to be corrected surgically), all other adverse events were mild and could be treated conservatively or with medication therapy (Table 5.1, adverse events). As described earlier, 20 participants were implanted with the Exilis GES. At 26 weeks follow-up 3 subjects had withdrawn from the study due to not reaching the desired effect ( $N=17$ remaining). At 52 weeks follow-up another 4 subjects had withdrawn for similar reasons ( $\mathrm{N}=13$ remaining).

Table $5.1 \quad$ Adverse events

\begin{tabular}{lll}
\hline Adverse event & Action undertaken & $\mathrm{N}(\%)$ \\
\hline Misplacement of leads (inside stomach lumen) & replacement of leads & $2(10 \%)$ \\
Liver laceration & electrocautery & $1(5 \%)$ \\
Seroma at IPG site & none & $3(15 \%)$ \\
Wound infection at IPG site (superficial) & antibiotic therapy & $3(15 \%)$ \\
Incisional hernia & surgically corrected & $2(10 \%)$ \\
\hline
\end{tabular}

\section{Amplitude titration visits}

All 20 subjects were able to undergo the amplitude titration visits at the desired time. At the first titration visit $(A)$, intended to determine the lowest amplitude that caused visceral sensations, $60 \%$ of the patients were set on an amplitude of $\leq 8.5 \mathrm{~mA}$. $80 \%$ of subjects reached the maximum amplitude of $10 \mathrm{~mA}$ after titration visit two (B). Longterm follow-up started with $90 \%$ of subjects set to an amplitude of $10 \mathrm{~mA}$ (Table 5.2, amplitude settings). 
Table 5.2 Amplitude titration visits

\begin{tabular}{|l|c|c|c|c|}
\hline Amplitude & A & B & C & D \\
\hline$\leq 5$ & $2(10 \%)$ & $1(5 \%)$ & & $1(5 \%)$ \\
\hline 6 & $1(5 \%)$ & & & $1(5 \%)$ \\
\hline 7 & $3(15 \%)$ & & & \\
\hline 8 & $2(10 \%)$ & & & \\
\hline 8.5 & $4(20 \%)$ & $2(10 \%)$ & $1(5 \%)$ & $1(5 \%)$ \\
\hline 9 & $1(5 \%)$ & $1(5 \%)$ & & $18(90 \%)$ \\
\hline 9.5 & $1(5 \%)$ & & $18 \%)$ & $18 \%)$ \\
\hline 10 & $6(30 \%)$ & $16(80 \%)$ & $180 \%)$ & \\
\hline
\end{tabular}

$\mathrm{N}=20$. A: titration visit $A, B$ : titration visit $B, C$ : titration visit $C, D$ : titration visit $D$

\section{Gl function tests}

Ingestion of the breakfast muffin meal resulted in increases in plasma glucose and insulin concentrations that were not significantly different between the 4 test days (Figure 5.3). Neither were the areas under the curve (AUC) for glucose or insulin levels different between the 4 test days (Table 5.3, insulin AUC and glucose AUC).

Gastric emptying half time was not significantly different between the test day ON versus OFF: $202.9 \pm 15.7 \mathrm{~min}$, versus $212.2 \pm 13.6 \mathrm{~min}$ respectively. At week 26 gastric emptying half time was $191.6 \pm 14.8 \mathrm{~min}$ and at week $52161.6 \pm 6.6, p=0.07$ ).

Food intake was not significantly different between the day with the device ON versus OFF nor was intake at week 52 significantly different (Table 5.3).

The motility index calculated form the SmartPill ${ }^{\circ}$ recording was not significantly different between GES ON and OFF.

Glucose levels

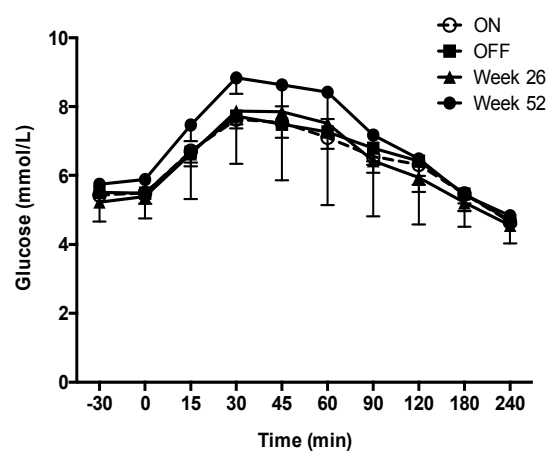

Insulin levels

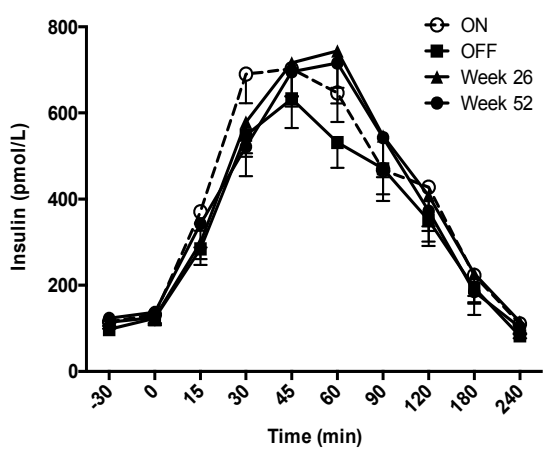

Figure 5.3 Glucose and insulin levels 
Table 5.3 Results of GI function test (with follow-up)

\begin{tabular}{|c|c|c|c|c|c|c|}
\hline & Scr & ON & OFF & Wk 26 & Wk 52 & $P$ \\
\hline Insulin AUC & & $2448 \pm 347$ & $2186 \pm 204$ & $2187 \pm 301$ & $2388 \pm 278$ & 0.47 \\
\hline Glucose AUC & & $41.4 \pm 1.5$ & $41.4 \pm 2.0$ & $41.0 \pm 1.5$ & $43.3 \pm 2.6$ & 0.60 \\
\hline GE T1/2 (min) & $179.2 \pm 8.3$ & $202.9 \pm 15.7$ & $212.2 \pm 13.6$ & $191.6 \pm 14.8$ & $161.6 \pm 6.6$ & 0.07 \\
\hline Food intake (kcal) & & $712.7 \pm 68.4$ & $798.8 \pm 68.9$ & & $800.2 \pm 86.3$ & 0.62 \\
\hline Motility index & & $53.4 \pm 9.4$ & $60.9 \pm 10.5$ & & & 0.60 \\
\hline
\end{tabular}

All data are means \pm SEMs. P values are for testday effects determined by mixed analysis of variance model. Significant differences were determined by using post hoc comparisons with Bonferroni's correction. Scr: screening, ON: GI function test with GES ON, OFF: GI function test with GES OFF, Wk 26: week 26, Wk 52: week $52 .{ }^{1}$ Significantly different from OFF, $p<0.05$

\section{Weight follow up}

Mean body weight at baseline was $116.4 \pm 4.1 \mathrm{~kg}$ and decreased significantly to $109.9 \pm 4.3 \mathrm{~kg}$ at week $26(\mathrm{p}<0.01)$ as shown in Figure 5.4. At week 52 body weight was not significantly different from baseline. The mean percentage of excess weight loss (\%EWL) at $4,13,25$ and 52 weeks was $8.6 \pm 2.1 \%, 11.1 \pm 2.4 \%, 12.8 \pm 3.7 \%$, $14.2 \pm 4.5 \%$, respectively (as shown in Figure 5.4 ).
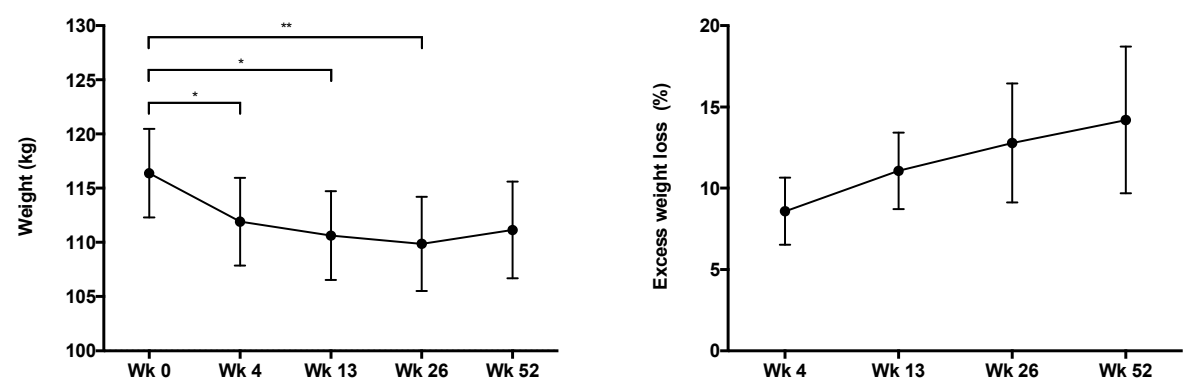

Figure 5.4 Weight $(\mathrm{kg})$ and Excess weight loss (\%). Wk $0(\mathrm{~N}=20)$, Wk $4(\mathrm{~N}=20), \mathrm{Wk} 13(\mathrm{~N}=20)$, Wk 26 $(\mathrm{N}=17), \mathrm{Wk} 52(\mathrm{~N}=13) .{ }^{*} \mathrm{p}<0.005 .^{* *} \mathrm{p}<0.01$

\section{Changes in systemic parameters and quality of life (QOL)}

No significant differences were observed in cholesterol levels, fasting glucose, HbA1c, waist or hip circumference during the 1 year follow up of this study (Table 5.4). Regarding QOL, significant differences were observed in SF-12 PCS and IWQOL-lite total score. Mean SF-12 PCS improved from $41.3 \pm 1.9$ at screening to $46.6 \pm 1.9$ at 1 year follow-up $(p<0.05)$. Mean IWQOL-lite total score improved from $55.4 \pm 3.8$ at screening to $75.0 \pm 3.4$ at 1-year follow-up $(p<0.001)$ 
Table 5.4 Cholesterol, glucose, HbA1c, waist and hip circumference and SF-12 and IWQOL-lite outcome

\begin{tabular}{lcccccc}
\hline & Scr & Wk 0 & Wk 13 & Wk 26 & Wk 52 & $P$ \\
\hline Triglycerides & $1.33 \pm 0.13$ & $1.26 \pm 0.16$ & $1.40 \pm 0.20$ & $1.22 \pm 0.14$ & $1.38 \pm 0.16$ & 0.75 \\
HDL & $1.20 \pm 0.07$ & $1.23 \pm 0.09$ & $1.24 \pm 0.09$ & $1.33 \pm 0.10$ & $1.34 \pm 0.10$ & 0.08 \\
LDL & $3.04 \pm 0.19$ & $3.13 \pm 0.19$ & $3.04 \pm 0.16$ & $3.03 \pm 0.18$ & $3.21 \pm 0.20$ & 0.85 \\
Total cholesterol & $4.84 \pm 0.22$ & $4.88 \pm 0.24$ & $4.88 \pm 0.22$ & $4.88 \pm 0.21$ & $5.10 \pm 0.27$ & 0.75 \\
Fasting glucose & $5.54 \pm 0.19$ & $5.45 \pm 0.16$ & $5.64 \pm 0.18$ & $5.42 \pm 0.19$ & $5.45 \pm 0.20$ & 0.33 \\
HbA1c & $5.60 \pm 0.10$ & $5.43 \pm 0.07$ & $5.48 \pm 0.07$ & $5.45 \pm 0.07$ & $5.50 \pm 0.11$ & 0.35 \\
Waist circumference & $122.4 \pm 3.2$ & $114.1 \pm 5.1$ & $115.9 \pm 3.0$ & $114.6 \pm 3.4$ & $118.7 \pm 3.2$ & 0.08 \\
Hip circumference & $131.3 \pm 1.9$ & $122.9 \pm 4.8$ & $125.5 \pm 1.9$ & $125.8 \pm 2.2$ & $127.8 \pm 1.7$ & 0.1 \\
SF-12 PCS & $41.3 \pm 1.9$ & $44.4 \pm 2.0$ & $46.6 \pm 1.7^{1}$ & $45.5 \pm 1.7$ & $46.6 \pm 1.9^{1}$ & $<0.001$ \\
SF-12 MCS & $53.5 \pm 2.8$ & $56.4 \pm 2.7$ & $55.7 \pm 2.4$ & $58.4 \pm 1.8$ & $56.6 \pm 2.7$ & 0.40 \\
IWQOL-lite total score & $55.4 \pm 3.8$ & $67.8 \pm 3.7^{2}$ & $70.8 \pm 3.4^{2}$ & $74.0 \pm 3.7^{2}$ & $75.0 \pm 3.4^{2}$ & $<0.001$ \\
\hline
\end{tabular}

All data are means \pm SEMs. P values are for testday effects determined by mixed analysis of variance model. Significant differences were determined by using post hoc comparisons with Bonferroni's correction. Scr: screening, Wk 0: week 0, Wk 13: week 13, Wk 26: week 26, Wk 52: week $52 .{ }^{1}$ Significantly different from Scr, $p<0.05 .^{2}$ Significantly different from Scr, $p<0.001$

\section{Discussion}

In this first-in-human study with the Exilis GES system we have shown that the system can be used safely, that GES was induced without causing discomfort in any participant. Despite the absence of discomfort, subjects were able to accurately predict whether the pulse generator was turned on or off. At baseline, food intake and satiety revealed non-significant differences between the GES ON versus the OFF test day. A significant reduction in body weight occurred until week 26 . We observed an excess weight loss of $14 \%$ at 52 weeks. This percentage is comparable with data from studies of subjects on diet and/or exercise alone, but this effect should be considered as disappointing when compared to minimal invasive procedures, such as gastric banding (50\%) or endoscopic gastroplication (35\%). Furthermore, we did not observe changes in plasma glucose and insulin levels, while some other bariatric procedures are known to improve glucose metabolism independent from weight loss.

Up to now various devices with different patterns of electrical stimulation, have been evaluated for the treatment of morbid obesity. The first open and uncontrolled clinical trials investigating the Transcend $^{\circledR}$ Implantable Gastric Stimulator (Medtronic Inc.) reported excess weight loss (EWL) varying in the range of $20-30 \%$ after 29 months of stimulation. ${ }^{13}$ In the present study we found a mean EWL of $14 \%$ at 52 weeks (corresponding with a mean weight loss of $6.5 \mathrm{~kg}$ ). Our results are comparable to those found in the SHAPE trial investigating the Transcend ${ }^{\circledR}$ device and the studies using the Tantalus gastric electrical stimulatory device (DIAMOND ${ }^{\mathrm{TM}}$ ). ${ }^{9,14,15}$ Interestingly, a recent open, uncontrolled study using the closed-loop gastric electrical stimulation system Abiliti ${ }^{\circledR}$ showed a mean EWL of $29 \%$ at 12 months. ${ }^{15}$ Although considerable variability 
in weight loss has been observed in several clinical studies, one could argue whether the abovementioned variations are related to differences in stimulation parameters, to anatomical localization of leads, to differences in stimulation paradigm or other factors. Extensive animal work, preceding the present study, focused on acquiring the most effective lead position and stimulation parameters. Based on these canine data the Exilis system uses continuous (16 hrs per day), current-controlled, monophasic pulses (width of 5.0ms) with alternating polarities and a fixed frequency of $40 \mathrm{~Hz}$. Although an infinite variation in programmer parameters can be obtained, such as pulse width, frequency and amplitude, it is evident that the total amount of energy delivered is of utmost importance.

Yoa at al. expressed the energy delivered by GES in $\mathrm{smA}^{2}$ and found in their study in humans that the stimulation energy for the first visceral sensation varied between 112.5 and $480 \mathrm{smA}^{2}$, while the highest tolerated stimulation energy varied between 480 and $3840 \mathrm{smA}^{2}{ }^{16}$ These authors also found that the subjects that were most sensitive to GES showed the greatest response to stimulation at $112.5 \mathrm{smA}^{2}$, leading to a significantly decreased water intake and gastric emptying rate. The stimulation energy delivered by the Exilis pulse generator at the maximum amplitude of $10 \mathrm{~mA}$ is $1200 \mathrm{smA}^{2}$. Although this energy is well within the viscerally sensible and therapeutic range, no changes in food intake or gastric emptying rate were observed. An explanation for this lack of effect despite adequate stimulation is not readily available. It is possible that the lead position or specific stimulation parameters do not deliver the same amount of energy through the gastric tissue. Although the leads were placed $1 \mathrm{~cm}$ apart in both procedures, we placed them through the serosa of the stomach while Yoa et. al. used a transoral technique and placed them through the mucosa. Furthermore, our subjects may have been less sensitive to GES. This assumption is supported by the finding that a relatively large amount of energy was needed for visceral sensation.

Previous human in vivo experiments have shown a correlation between visceral sensitivity to GES and gastric responses, such as gastric motility and food intake. A higher response was noted in subjects more sensitive to GES. ${ }^{16}$ A total of $30 \%$ of our subjects were titrated up to the maximum of $10.0 \mathrm{~mA}$ already at the first visit, before any visceral sensation had occurred (a higher setting was technically not possible). The amplitude that caused the first sensation varied greatly in the remaining subjects (Table 5.3), but in those who were more sensitive to GES, a greater effect was not observed. Eventually, $90 \%$ of our subjects received chronic GES therapy at the highest technically feasible amplitude of $10 \mathrm{~mA}$. The gradual increase in amplitude setting showed that subjects experience visceral sensations at the fourth titration visit milder when compared to the first visit. This observation points to adaptation to GES after prolonged application and is in line with our findings that GES effects were most pronounced in the short post-operative period after implantation. 
In the current study we applied continuous (16hr a day) electrical stimulation with a standardized pulse width. In such a setting adaptation to this signal may have occurred, eventually even resulting in loss of efficacy. Adaptation of the gastric smooth muscle to chronic GES for the treatment of obesity has been shown previously in a dog model. ${ }^{17}$ Pulses with higher amplitude (i.e. higher stimulation energy), or pulse sequences that are unlikely to induce adaptation might be necessary in order to achieve adequate and long-term gastric responses. This might explain why a GES system, with less frequent, meal initiated stimulation results in a greater and more persistent effect on food intake and weight loss. ${ }^{18}$

In the present study we report several (minor) adverse events. Most adverse events were related to the IPG pocket (seroma, infection, hernia) and are most likely due to the relatively superficial placement of the IPG in the loose subcutaneous tissue. Ideally the IPG would be sutured to the abdominal fascia, which could however cause connectivity problems in patients with a significant amount of subcutaneous fat. Contrary to the popular bariatric procedures, a clear advantage of the current technique is its reversibility: all devices can be explanted without interference with GI anatomy and function.

Our study has several limitations. Due to the aims and deliverables of this study - to assess safety and preliminary effectiveness of the Exilis system - a control group was not included. In all studies and trials on interventions for weight loss a control group is required. Several studies have shown between $12-14 \%$ of excess weight loss in the control groups. The percentage excess weight loss we observed with the GES Exiles is in the range of that observed in control groups. ${ }^{9,19}$ Therefore we conclude that the additional effect of GES with the Exilis system with its current settings is limited. Up to now, substantial work with GES for the treatment of obesity has been performed and results vary considerably. Much more essential basic research has to be performed before we come to clinical applications. Pacing protocols should be optimized to achieve physiologically and clinically useful outcomes. Essential electrophysiological knowledge of the human stomach is still lacking and more basic electrophysiogical research should be done before proceeding to new pacing protocols. ${ }^{20}$ Potentially, high resolution mapping of gastric slow-wave activity and the effects of gastric pacing on these waves may be a method to assess whether pacing protocols will be effective. $^{21}$ When optimal stimulation parameters have been assessed, we recommend that they will be tested in a blinded randomized placebo-controlled trial.

In conclusion, gastric electrical stimulation with the Exilis system can be considered as safe. No significant effect on food intake, gastric emptying or gastric motility was observed. The reduction in weight loss with Exiles GES was significant but short lasting. More basic electrophysiological research is needed to develop optimal GES paradigms. 


\section{References}

1. Nguyen NT, Vu S, Kim E, Bodunova N, Phelan MJ. Trends in utilization of bariatric surgery, 2009-2012. Surg Endosc. 2016;30(7):2723-7.

2. Campanile FC, Boru CE, Rizzello M, Puzziello A, Copaescu C, Cavallaro G, et al. Acute complications after laparoscopic bariatric procedures: update for the general surgeon. Langenbecks Arch Surg. 2013;398(5):669-86..

3. Franco J, Ruiz P, Palermo M, Gagner M. A review of studies comparing three laparoscopic procedures in bariatric surgery: sleeve gastrectomy, Roux-en- $Y$ gastric bypass and adjustable gastric banding. Obes Surg. 2011;21(9):1458-68.

4. Cha R, Marescaux J, Diana M. Updates on gastric electrical stimulation to treat obesity: Systematic review and future perspectives. World J Gastrointest Endosc. 2014;6(9):419-31.

5. Lebovitz HE. Interventional treatment of obesity and diabetes: An interim report on gastric electrical stimulation. Rev Endocrine Metab Disord. 2016;17(1):73-80.

6. Chiu JD, Soffer E. Gastric electrical stimulation for obesity. Curr Gastroenterol Rep. 2015;17(1):424.

7. Favretti F, De Luca M, Segato G, Busetto L, Ceoloni A, Magon A, et al. Treatment of morbid obesity with the Transcend Implantable Gastric Stimulator (IGS): a prospective survey. Obes Surg. 2004;14(5):666-70.

8. Shikora SA. "What are the yanks doing?" the U.S. experience with implantable gastric stimulation (IGS) for the treatment of obesity - update on the ongoing clinical trials. Obes Surg. 2004;14 Suppl 1:8.

9. Shikora SA, Bergenstal R, Bessler M, Brody F, Foster G, Frank A, et al. Implantable gastric stimulation for the treatment of clinically severe obesity: results of the SHAPE trial. Surg Obes Relat Dis. 2009;5(1):31-7.

10. Song G-QQ, Zhu H, Lei Y, Yuan C, Starkebaum W, Yin J, et al. Gastric electrical stimulation optimized to inhibit gastric motility reduces food intake in dogs. Obes Surg. 2015;25(6):1047-55.

11. Ghoos YF, Maes BD, Geypens BJ, Mys G, Hiele MI, Rutgeerts PJ, et al. Measurement of gastric emptying rate of solids by means of a carbon-labeled octanoic acid breath test. Gastroenterology. 1993;104(6):1640-7.

12. Camilleri M, Malagelada JR, Brown ML, Becker G, Zinsmeister AR. Relation between antral motility and gastric emptying of solids and liquids in humans. Am J Physiol. 1985;249(5 Pt 1):G580-5.

13. Shikora SA. Implantable gastric stimulation for the treatment of severe obesity. Obes Surg. 2004;14(4):545-8.

14. Lebovitz HE, Ludvik B, Yaniv I, Haddad W, Schwartz T, Aviv R, et al. Fasting plasma triglycerides predict the glycaemic response to treatment of type 2 diabetes by gastric electrical stimulation. A novel lipotoxicity paradigm. Diabet Med. 2013;30(6):687-93.

15. Lebovitz HE, Ludvik B, Yaniv I, Schwartz T, Zelewski M, Gutterman DD, et al. Treatment of Patients with Obese Type 2 Diabetes with Tantalus-DIAMOND(R) Gastric Electrical Stimulation: Normal Triglycerides Predict Durable Effects for at Least 3 Years. Horm Metab Res. 2015;47(6):456-62.

16. Yao S, Ke M, Wang Z, Xu D, Zhang Y, Chen J. Visceral Sensitivity to Gastric Stimulation and its Correlation with Alterations in Gastric Emptying and Accommodation in Humans. Obes Surg. 2005;15(2):247-53.

17. Aelen P, Neshev E, Cholette M, Crisanti K, Mitchell P, Debru E, et al. Manipulation of food intake and weight dynamics using retrograde neural gastric electrical stimulation in a chronic canine model. Neurogastroenterol Motil. 2008;20(4):358-68.

18. Horbach T, Thalheimer A, Seyfried F, Eschenbacher F, Schuhmann P, Meyer G. abiliti Closed-Loop Gastric Electrical Stimulation System for Treatment of Obesity: Clinical Results with a 27-Month Follow-Up. Obes Surg. 2015;25(10):1779-87.

19. Sarr MG, Billington CJ, Brancatisano R, Brancatisano A, Toouli J, Kow L, et al. The EMPOWER study: randomized, prospective, double-blind, multicenter trial of vagal blockade to induce weight loss in morbid obesity. Obes Surg. 2012;22(11):1771-82.

20. Lammers WJ. Arrhythmias in the gut. Neurogastroenterol Motil. 2013;25(5):353-7.

21. O'Grady G, Du P, Lammers WJ, Egbuji JU, Mithraratne P, Chen JD, et al. High-resolution entrainment mapping of gastric pacing: a new analytical tool. Am J Physiol Gastrointest Liver Physiol. 2010;298(2):21. 


\section{Chapter}

The effect of 6 and 12 months duodenal-jejunal bypass liner treatment on obesity and type 2 diabetes: a cross-over cohort study

S. van Rijn, B. Betzel, C. de Jonge, D.P.J. van Dijk, I.M. Janssen, F.J. Berends, N.D. Bouvy, J.W.M. Greve Obes Surg. 2017 Nov 6. doi: 10.1007/s11695-017-2997-7 


\section{Abstract}

\section{Objective}

To study the duodenal-jejunal bypass liner (DJBL) treatment for obesity and type 2 diabetes mellitus (T2DM) in patients after dietary treatment in a cross-over design.

\section{Background}

DJBL treatment has been proven effective for treatment of obesity and T2DM. However, data on safety and efficacy of 12 month DJBL treatment is limited.

\section{Methods}

In 2014 our research group reported on a multicenter randomized clinical trial. Patients were randomized to DJBL or dietary treatment (control group). Twenty-eight patients crossed-over after their dietary treatment and received up to 12 months of DJBL treatment. Patient visits were conducted at baseline, during DJBL treatment (1 week, 1-6, 9, 12 months) and 6 months after removal of the liner. Patients underwent a standard physical examination, blood sampling, assessment of adverse events, nutritional and diabetes counseling and a standardized meal tolerance test.

\section{Results}

Of the 28 patients included in this study, 24 patients completed 6 months of treatment. Eighteen patients were extended to 12 months DJBL treatment, 13 patients completed this treatment period. After 6 months of DJBL treatment a significant increase in excess weight loss (EWL) and decrease in weight, BMI, HbA1c, fasting glucose, cholesterol, HDL and LDL was seen. After 12 months of DJBL treatment these parameters stabilized.

\section{Conclusions}

The DJBL is an effective, minimally invasive treatment option. Even after successful treatment with dietary restrictions the DJBL is still capable of significantly reducing weight and improving cardiovascular and type 2 diabetes mellitus parameters in obese patients. 


\section{Introduction}

Worldwide over 600 million people suffer from obesity (BMI $\left.\geq 30 \mathrm{~kg} / \mathrm{m}^{2}\right)^{1,2}$ The population of the USA accounts for $13 \%$ of this obese population, which is approximately one-third of the country's population. ${ }^{3}$ Indicating the magnitude of this disease, also in Europe $15-30 \%$ of the adult population is affected. ${ }^{4}$

The obese population is at high risk to develop chronic diseases, such as metabolic disorders (diabetes mellitus, fatty liver disease), cardiovascular diseases, cancer, and wear and tear of the musculoskeletal organ. ${ }^{5-8}$ Furthermore, obesity is associated with increased mortality. ${ }^{9}$ Surgery has been proven most successful in the treatment of obesity and its comorbidities. ${ }^{10-12}$ However, current surgical techniques are still accompanied by perioperative and postoperative complications. In addition, not all patients can benefit from these surgical approaches, since only patients with a BMI $\geq 35$ with comorbidities or a BMI of $\geq 40$ without comorbidities are, according to the current guidelines, considered for surgical treatment. ${ }^{12-14}$ Several endoluminal techniques have been developed with the intent to reduce perioperative and postoperative complications, while maintaining treatment success. These techniques also provide an alternative treatment option for the growing overweight and obese population (BMI between 25 to 35 ).

The duodenal-jejunal bypass liner (DJBL) is a promising endoluminal device mimicking the Roux-en-Y gastric bypass. The liner consists of an impermeable sleeve that is open at both ends to allow food passage. The liner is temporarily fixed in the duodenal bulb and extends into the jejunum. This way the pancreatic secretions and bile will only mix with the food distal to the liner, hereby creating a functional bypass of the duodenum and the proximal jejunum. Several studies investigating the DJBL have shown the procedure to be safe and effective with good results regarding weight reduction, improvement of type 2 diabetes parameters and a decrease in cardiovascular parameters. ${ }^{15-19}$

However, most studies investigated a treatment duration of 3-6 months and data on safety and efficacy of 12 months duration of treatment with the DJBL is limited.

The aim of this study was to evaluate the safety and efficacy of 12 months treatment with the DJBL in a randomized crossover study design, making the patient their own control. We hypothesize that treatment for 12 months with DJBL is safe and will accomplish a decrease in body weight accompanied by an improvement in blood glucose levels and cardiovascular parameters.

\section{Methods}

In 2014 our research group reported on a large cohort study of 77 patients that were included in a multicenter randomized clinical trial conducted in the Netherlands at the Maastricht University Medical Center, the Zuyderland Medical Center (formerly 
known as the Atrium Medical Center) Heerlen, and the Rijnstate hospital Arnhem. During this clinical trial patients were randomized either to the DJBL treatment group or to the diet control group.

In short, inclusion criteria consisted of a BMI ranging from $30-50 \mathrm{~kg} / \mathrm{m}^{2}$, type 2 diabetes for less than 10 years and a glycated hemoglobin $A_{1 c}\left(H_{b A_{1 c}}\right)$ level between 7.5\%-10\%. In addition, patients were only allowed to take metformine, sulfonylurea (SU) derivatives, and/or insulin with a maximum dose of $150 \mathrm{IU}$. Most important exclusion criteria consisted of: prior weight loss of more than $4.5 \mathrm{~kg}$; use of weight loss medication; innate insulin production failure as indicated by low C-peptide levels; Gl tract abnormalities or prior surgery of the Gl tract that could affect device placement; bleeding disorders; connective tissue disorders; and severe liver or kidney disease. $^{16}$

At baseline patients were assessed extensively. Before the procedure patient demographics and medical history were evaluated and a physical examination (including weight, BMI, and blood pressure) was performed. Further patient evaluation consisted of blood parameter outcomes (diabetes parameters and cardiovascular parameters) and a standardized 4-hour meal tolerance test using a liquid meal. Throughout the study, a diet with a maximum of $1200 \mathrm{kcal}$ for women and $1500 \mathrm{kcal}$ for men was prescribed of which the first week consisted of a liquids only regimen. Additionally, a diabetes nurse under supervision of an endocrinologist carried out the management of medical treatment of T2DM.

A total of 38 patients were randomized to the DJBL treatment group and 39 patients to the diet control group. Treatment protocol consisted of 6 months of DJBL treatment or control treatment with subsequently 6 months of follow-up. After 12 months, patients that were randomized to the diet group were offered the DJBL treatment for 6 months with an optional extension to 12 months treatment. We here describe this cross-over group.

Patient visits were conducted at baseline and during DJBL treatment at 1 week, 1-6 months and for the extended treatment also at 9 and 12 months. In addition, patients were followed until 6 months after removal of the device.

During these visits patients underwent a standard physical examination (including weight, BMI, and blood pressure), blood sampling, assessment of adverse events and nutritional and diabetes counseling. Furthermore, a standardized meal tolerance test using a liquid meal (Ensure Plus vanilla flavor, Abbott Laboratories, Abbott Park, IL; $333 \mathrm{~mL}, 500 \mathrm{kcal}, 20.8 \mathrm{~g}$ of protein, $67.3 \mathrm{~g}$ of carbohydrates, and $16.4 \mathrm{~g}$ of fat) was conducted at baseline, 3, 6 and 12 months during DJBL treatment.

The study was conducted according to the principles of the Standard ISO 14155: 2003 on clinical investigations with medical devices and the recommendations guiding physicians in biomedical research involving human patients adopted by the 18th World Medical Assembly, Helsinki, Finland, 1964 and later revisions and also in accordance with the guideline Medical Research Involving Human Subjects Act 
(WMO). The study was approved by the medical ethical committee of all 3 participating medical centers. The general principles of informed consent, ethics review and data management were in line with good clinical practice (GCP).

\section{DJBL procedure}

The DJBL was developed to mimic the duodenal bypass component of the Roux-en-Y gastric bypass. The device consists of a $60 \mathrm{~cm}$ long impermeable fluoropolymer liner and a nitinol anchor, which is used to fixate the liner in the duodenal bulb. The procedure was performed endoscopically. After positioning of the endoscope in the stomach the fluoropolymer liner was advanced into the duodenum and unfolded into the proximal jejunum. Removal of the DJBL was performed as previously described. ${ }^{15,16}$

\section{Statistical analysis}

All data are presented as median and interquartile ranges (IQR) since data were not normally distributed. Comparisons were performed using the Wilcoxon signed-rank test. The repeated measures Friedman analysis of variance was used to assess change over time. Post-hoc testing was performed using the Wilcoxon signed rank test with Bonferroni correction. $\mathrm{P}<0.05$ was regarded as significant. Missing data were not imputed. All statistical analyses were performed using commercially available computer software (IBM Corp. Released 2012. IBM SPSS Statistics for Windows, Version 21.0. Armonk, NY: IBM Corp.).

\section{Results}

\section{Patient characteristics}

Twenty-eight patients were implanted with the DJBL. Patient characteristics were compared between baseline and pre-implantation as described in Table 6.1 (17 males, median age 52 (48-56), 11 females, median age 48 (44-55)). Of these 28 patients, 18 were extended to 12 months DJBL treatment. Reasons for early removal consisted of device related adverse events (Figure 6.1). During the dietary treatment period, prior to 12 months implantation with the DJBL, patient characteristics already had significantly changed compared to baseline. This resulted in a significant difference prior to the DJBL intervention period for the following parameters: patients that were initially in the control group had a significant lower weight, BMI, systolic and diastolic blood pressure before implantation of the DJBL (Table 6.1). 


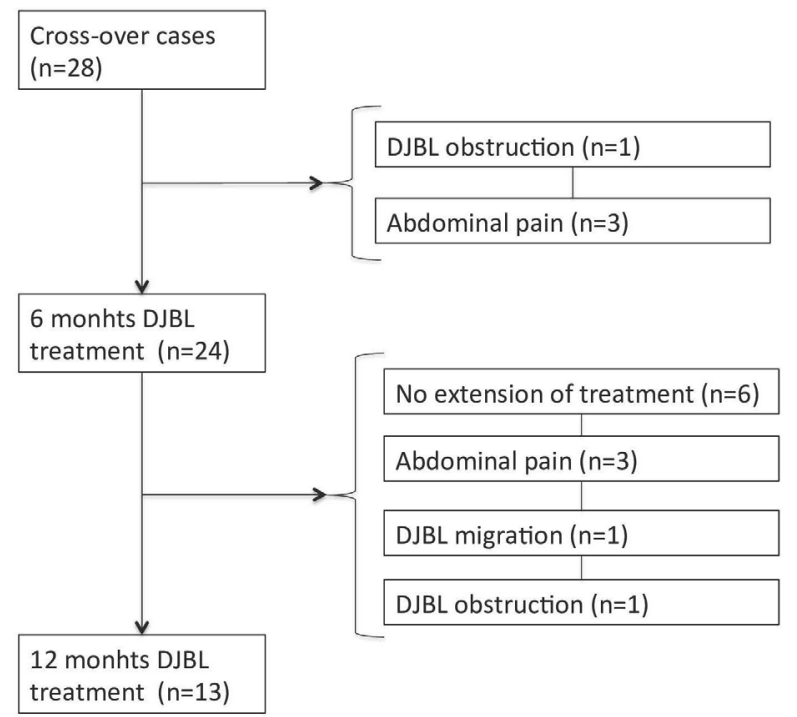

Figure 6.1 Flow-chart

Table 6.1 Comparison of weight, glucose metabolism and cardiovascular parameters between baseline and pre-implantation time point $(n=28)$

\begin{tabular}{lccc}
\hline & Baseline & $\begin{array}{c}\text { 6 months dietary treatment } \\
\text { plus } 6 \text { months FU }\end{array}$ & P-value \\
\hline Sex (male/female) & $17 / 11$ & - & - \\
Age (years) & $50(46-56)$ & - & - \\
Weight (kg) & $113.4(99.4-128.7)$ & $110.4(93.4-122.5)$ & 0.001 \\
BMI (kg/m²) & $37.0(33.0-42.9)$ & $35.2(31.7-40.0)$ & 0.001 \\
Duration of T2DM (years) & $5.0(3.3-7.8$ & - & - \\
HbA1C (\%) & $8.1(7.7-8.8)$ & $8.2(7.0-8.8)$ & $\mathrm{NS}$ \\
Fasting glucose (mmol/L) & $11.0(9.1-8.8)$ & $8.2(7.0-8.8)$ & $\mathrm{NS}$ \\
Fasting insulin (pmol/L) & $128.6(83.4-284.5)$ & $114.0(57.7-165.8)$ & $\mathrm{NS}$ \\
Systolic blood pressure (mmHg) & $152(131-159)$ & $137(121-147)$ & 0.001 \\
Diastolic blood pressure (mmHg) & $90(80-95)$ & $82(77-90)$ & 0.002 \\
Total cholesterol (mmol/L) & $4.3(3.5-5.3)$ & $4.4(3.9-5.0)$ & $\mathrm{NS}$ \\
HDL (mmol/L) & $1.2(0.9-1.3)$ & $1.2(1.9-2.9)$ & $\mathrm{NS}$ \\
LDL (mmol/L) & $2.2(1.7-2.8)$ & $2.3(1.9-2.9)$ & $\mathrm{NS}$ \\
Triglycerides (mmol/L) & $1.8(1.4-3.1)$ & $1.7(1.3-2.3)$ & $\mathrm{NS}$ \\
\hline I & &
\end{tabular}

$1 \mathrm{n}=25$ patients included for analysis 


\section{Effect of DJBL treatment on weight, cardiovascular and type 2 diabetes parameters}

At 6 months of DJBL treatment median weight was decreased from 109.7 (92.2-122.5) $\mathrm{kg}$ to $100.2(86,7-114.8) \mathrm{kg}(\mathrm{p}<0.001)$. Correspondingly, a median drop in BMI from $34.8(31.4-39.0) \mathrm{kg} / \mathrm{m}^{2}$ to $32.8(29.9-37.7) \mathrm{kg} / \mathrm{m}^{2}(\mathrm{p}<0.001)$ and an excess weight loss of $32.8(22.3-40.0) \%(p<0.001)$ was seen (Figure 6.2). As shown in Figure 6.3, $\mathrm{HbA}_{1 c}$ decreased from $8.2(7.1-9.0) \%$ to $7.6(6.7-8.3) \%(p<0.01)$. In addition, fasting glucose levels dropped from $9.7(8.8-13.3) \mathrm{mmol} / \mathrm{L}$ to 8.1 (7.1-9.8) $\mathrm{mmol} / \mathrm{L}(\mathrm{p}<0.01)$. During 6 months of treatment, also a significant decrease in total cholesterol was seen from 4.5 $(4.1-5.0) \mathrm{mmol} / \mathrm{L}$ to $3.9(3.2-4.4) \mathrm{mmol} / \mathrm{L}(\mathrm{p}<0.01)$. Simultaneously, HDL decreased from $1.2(1.0-1.5) \mathrm{mmol} / \mathrm{L}$ to $1.1(0.78-1.25) \mathrm{mmol} / \mathrm{L}(\mathrm{p}<0.001)$ and LDL from 2.3 (1.933.0) $\mathrm{mmol} / \mathrm{L}$ to $2.1(1.5-2.4) \mathrm{mmol} / \mathrm{L}(\mathrm{p}<0.01)$. After 6 months of DJBL treatment, parameters remained stable during the extended treatment period up to 12 months.

\section{Overall effect after 6 months diet plus 6 months follow-up and DJBL treatment}

Weight parameters significantly decreased after diet followed by DJBL treatment compared to baseline. An overall change in weight of $10.3(7.1-16.4) \mathrm{kg}(p<0.001)$ with an EWL of $32.7(22.3-40.0) \%(p<0.001)$ and a drop in BMI by 3.7 points $(2.5-5.0) \mathrm{kg} / \mathrm{m}^{2}$ $(p<0.001)$ was seen. Diabetes 2 parameters also significantly changed with a decrease in HbA1c $0.8(-0.1-1.7) \%(p<0.05)$, fasting glucose $3.4(1.2-4.8) \mathrm{mmol} / \mathrm{L}(p<0.001)$ and fasting insulin $69.2(27.8-190.4) \mathrm{pmol} / \mathrm{L}(\mathrm{p}<0.001)$. Cardiovascular parameters were also significantly reduced after dietary plus DJBL treatment. Total cholesterol decreased by $0.7(0.2-1.5) \mathrm{mmol} / \mathrm{L}(\mathrm{p}<0.01)$. Additionally, triglycerides and HDL reduced by $0.4(-0.4-1.0) \mathrm{mmol} / \mathrm{L}(p<0.05)$ and $0.1 \quad(0.0-0.29) \mathrm{mmol} / \mathrm{L} \quad(p<0.01)$, respectively. An overview of the results is listed in Table 6.2. 


\section{Effect of DJBL treatment on weight parameters}

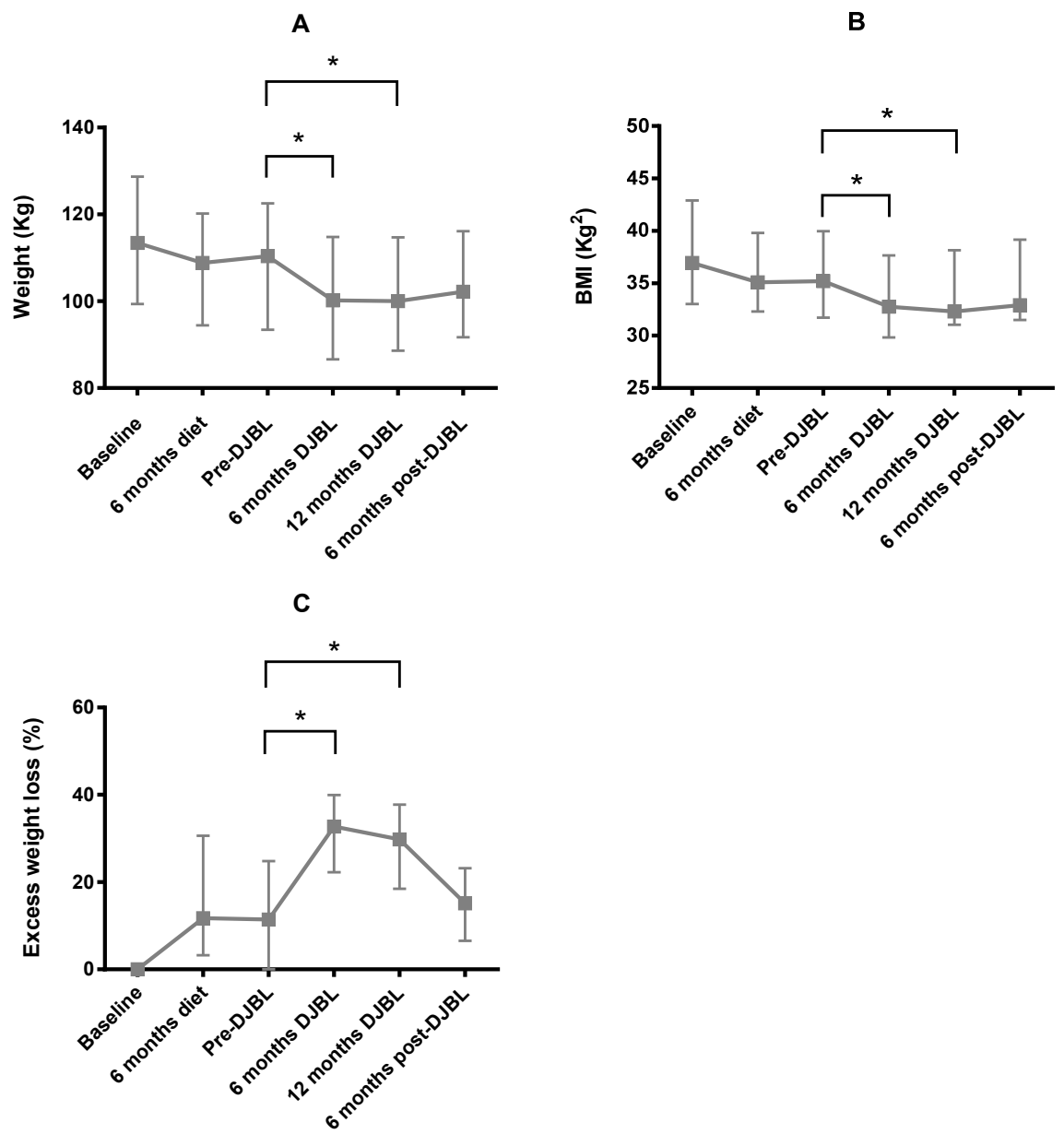

Figure 6.2 Effect of DJBL treatment on change in weight parameters over time. A, change in weight $(\mathrm{kg})$. $\mathrm{B}$, change in $\mathrm{BMI}\left(\mathrm{kg} / \mathrm{m}^{2}\right)$. C, change in $\operatorname{EWL}(\%) .{ }^{*} \mathrm{P}<0.01$ 


\section{Effect of DJBL treatment on glucose metabolism}

A

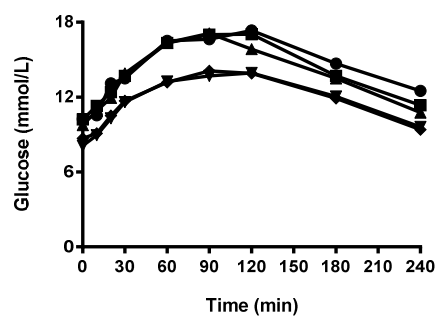

C

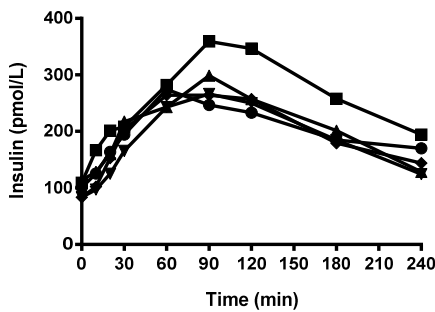

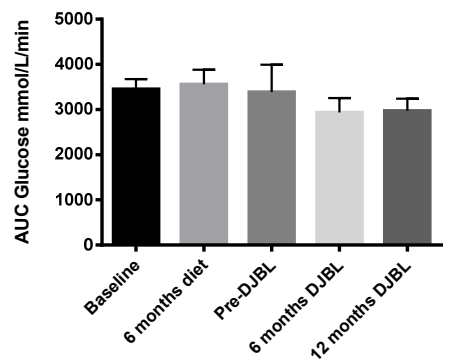

D

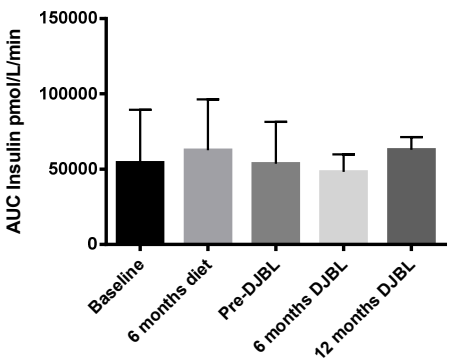

Figure 6.3 Effect of DJBL treatment on glucose metabolism parameters. A, glucose concentrations during the meal tolerance test. B, the AUC calculations for glucose. $C$, insulin concentrations during the meal tolerance test. $D$, the $A U C$ concentrations for insulin. $E$, change in $\mathrm{HbA} 1 \mathrm{C}(\%)$. $* \mathrm{P}<0.01$

Table 6.2 Change in weight, glucose metabolism parameters and cardiovascular parameters after 6 months of dietary treatment, 6 months of DJBL treatment and dietary plus DJBL treatment $(n=24)$

\begin{tabular}{|c|c|c|c|}
\hline & $\begin{array}{c}6 \text { months dietary } \\
\text { treatment plus } 6 \\
\text { months FU }\end{array}$ & $\begin{array}{c}6 \text { months DJBL } \\
\text { treatment }\end{array}$ & $\begin{array}{c}\text { Overall change after } \\
\text { dietary and DJBL } \\
\text { treatment }\end{array}$ \\
\hline Weight loss (kg) & $4.5(1.1-8.6)$ & $5.8(2.6-11.2)$ & $10.3(7.1-16.4)$ \\
\hline BMI loss $\left(\mathrm{kg} / \mathrm{m}^{2}\right)$ & $1.5(3.1-3.3)$ & $2.0(1.0-3.5)$ & $3.7(2.5-5.0)$ \\
\hline Excess weight loss (\%) & $13.3(2.1-28.4)$ & $20.9(10.0-28.8)$ & $32.7(22.3-40.0)$ \\
\hline $\mathrm{HbA1C}(\%)$ & $0.6(0.3-1.3)$ & $0.5(0.1-1.3)$ & $0.8(-0.1-1.7)$ \\
\hline Fasting glucose (mmol/L) & $1.7(1.5-4.0)$ & $1.6(0.3-3.2)$ & $3.4(1.2-4.8)^{4}$ \\
\hline Fasting insulin $(\mathrm{pmol} / \mathrm{L})^{3}$ & $23.3(32.4-118.8)$ & $27.1(6.9-104.9)$ & $69.2(27.8-190.4)^{5}$ \\
\hline Systolic blood pressure $(\mathrm{mmHg})^{1}$ & $4(3-26)$ & $6(4-12)$ & $19(5.5-28)$ \\
\hline Diastolic blood pressure $(\mathrm{mmHg})^{1}$ & $8(4-11)$ & $0(2-5)$ & $7(-3-13)$ \\
\hline Total cholesterol (mmol/L) & $0.2(0.2-0.4)$ & $0.6(0.1-1.1)$ & $0.7(0.2-1.5)$ \\
\hline $\mathrm{HDL}(\mathrm{mmol} / \mathrm{L})^{1}$ & $0.1(0.0-0.2)$ & $0.2(0.1-0.3)$ & $0.1(0.0-0.29)$ \\
\hline $\mathrm{LDL}(\mathrm{mmol} / \mathrm{L})^{2}$ & $0.0(0.2-0.3)$ & $0.3(0.0-0.8)$ & $0.2(-0.1-1.0)$ \\
\hline Triglycerides (mmol/L) & $0.1(0.3-0.8)$ & $0.2(0.1-0.3)$ & $0.4(-0.4-1.0)$ \\
\hline
\end{tabular}

${ }^{1} \mathrm{n}=23$ patients included for analysis. ${ }^{2} \mathrm{n}=22$ patients included for analysis. ${ }^{3} \mathrm{n}=18$ patients included for analysis. ${ }^{4} n=23$ patients included for analysis, ${ }^{5} n=20$ patients included for analysis 


\section{Six months after explantation of the DJBL}

After 12 months of DJBL treatment 10 patients were eligible for 6 months of follow-up after explantation of the DJBL. Six months after removal of the DJBL weight and BMI increased from 99.5 (86.1-114.2) kg to 102.8 (90.2-116.0) kg and from 31.4 (30.4-26.4) $\mathrm{kg} / \mathrm{m}^{2}$ to $32.5(31.2-37.2) \mathrm{kg} / \mathrm{m}^{2}$ (both $\mathrm{p}=0.02$ ), respectively. Also, fasting insulin levels rose from 92.2 (58.2-137.5) pmol/L to 203.5 (99.9-415.5) pmol/L ( $p=0.03)$. All other parameters remained stable during 6 months of follow-up post-explantation.

\section{Glucose lowering-medication}

During the study period usage of glucose-lowering medication was assessed. Medication usage was classified as "increased" if the dose of one or more agents was increased or an additional glucose-lowering agent was added. Medication was classified as "decreased" if the dose of one or more agents was lowered, or if one or more agents were discontinued. All patients used glucose-lowering medication prior to implantation with the DJBL. Twenty-seven (96\%) patients were taking metformin, 19 (68\%) patients SU derivatives, and 13 (46\%) patients were on insulin treatment. Alteration in glucose-lowering medication was evaluated in each of the 28 patients just prior to explantation of the DJBL. Glucose lowering-medication was decreased in $15(54 \%)$ patients, increased in $8(28 \%)$ patients and remained unchanged in 5 (18\%) patients. Additional information on the use of metformin, SU derivatives, and insulin is described in Table 6.3.

Table 6.3 Change in glucose-lowering medication. Values are given in percentages

\begin{tabular}{lc}
\hline & Change in glucose lowering medication post-explantation \\
\hline Metformin & \\
Decreased, discontinued & 14.8 \\
Unaltered & 66.7 \\
Increased & 18.5 \\
SU derivatives & \\
Decreased, discontinued & 44.4 \\
Unaltered & 33.4 \\
Increased & 22.2 \\
Insulin & \\
Decreased, discontinued & 40.0 \\
Unaltered & 20.0 \\
Increased & 40.0 \\
\hline
\end{tabular}




\section{Safety}

During DJBL treatment adverse events consisted mainly of minor gastrointestinal complaints (78.6\%). Abdominal pain and discomfort was present in $39.3 \%$ of patients and nausea and vomiting were present in $31.1 \%$ and $14.3 \%$ of the patients, respectively. In addition hypoglycemia occurred in $17.9 \%$ of patients. Complaints occurred primarily during the first two weeks of DJBL treatment after which most resolved.

During DJBL treatment, 6 adverse events required hospitalization. Four of these adverse events were device related, making early removal necessary. One patient was admitted because of complaints of upper abdominal pain due to an eversion of the liner after one month of treatment causing obstruction of the DJBL. A second patient was admitted because of abdominal pain and nausea caused by a food bolus blocking the liner after nine months of treatment. Another patient developed post procedure vomiting due to pylorospasm and in one patient a migration of the liner occurred after nine months. After removal all complaints resolved without sequelae. Additionally, during the study period 5 patients withdrew because of ongoing abdominal pain, nausea, and vomiting. In summary, 4 patients (14\%) had an early removal of the device. These patients were explanted before the 3 month treatment time point. In addition, 5 patients did not complete their extended period of DJBL treatment and were explanted between 9-11 months. No procedure related serious adverse events occurred.

\section{Discussion}

In this study we evaluated the impact of 6 and 12 months of DJBL treatment in a cross over cohort from a multicenter randomized clinical trial. This is the first study assessing the effect of DJBL treatment in a cohort of patients who first underwent dietary treatment prior to implantation of the DJBL.

In this patient group 6 months of treatment with the DJBL showed a significant decrease in weight, and improvement of cardiovascular parameters and type 2 diabetes mellitus parameters. An extension to 12 months of treatment with the DJBL showed a stabilization of these parameters. In addition, in patients who underwent 12 months of DJBL treatment, six months after removal of the device only a significant increase for weight parameters was seen.

Overall results after dietary and DJBL treatment showed an even more pronounced decrease for weight, type 2 diabetes mellitus and cardiovascular parameters than expected. Our results indicate that 6 and 12 months of DJLB treatment can even lead to a further reduction in weight, cardiovascular and diabetes parameters after a controlled diet period. 
As mentioned earlier, the effect of the DJBL is attributable to its barrier function. Pancreatic and bile secretions will only mix with food distal to the liner, creating a functional bypass of the duodenum and the proximal jejunum. As a result local absorption of micronutrients is decreased. Furthermore, it was recently shown that weight loss and improvement of obesity related comorbidities is accompanied by changes in satiety hormones. Postprandial GLP-1 and Peptide YY increased during 6 months of DJBL treatment. At the same time CCK and leptin concentrations decreased. ${ }^{20,21}$ It is known that these hormones play an important role in satiety experienced by both healthy and obese individuals. ${ }^{22,23}$ The changes in these incretins and leptin caused by implantation of the DJBL might explain the positive effects of this treatment.

Six months of treatment with the DJBL resulted in a significant excess weight loss and a decrease in weight, $\mathrm{BMI}, \mathrm{HbA}_{1 \mathrm{c}}$, fasting glucose levels, total cholesterol, $\mathrm{HDL}$ and LDL. This is in line with several other studies evaluating the effect of the DJBL that have also shown a decrease in weight, cardiovascular, and type 2 diabetes mellitus parameters. ${ }^{15-19,24-27}$ The previously published randomized clinical trial showed that DJBL treatment was superior in the reduction of these parameters compared to dietary treatment. ${ }^{16}$ In this cross-over study, as shown in Table 6.1, prior to DJBL implantation patients already had a significant decrease in weight, BMI, systolic and diastolic blood pressure. Our results show that the patients in the diet group performed exceptionally well. This might be explained by the intrinsic motivation of the patients to perform well during the diet period, since this was followed by implantation of the DJBL. This study demonstrates that after this controlled dietary treatment period, the DJLB is still capable of significantly reducing weight and improving cardiovascular and type 2 diabetes mellitus parameters.

After 12 months DJBL treatment patients seemed to reach a plateau phase. No difference was seen between 6 and 12 months of treatment with the DJBL. This is in accordance with recent literature, reporting that ongoing weight loss is diminished after approximately 6 months of DJBL treatment. ${ }^{28}$

In this study 6 serious adverse events were reported. Fourteen percent (4/28) required hospital admission because of device related adverse events. Additionally, almost all patients experienced minor adverse events. A recent study on safety experience with the DJBL showed a serious adverse event rate of $10 \%$. In this study adverse events consisted of GI bleeding, hepatic abscess, pancreatitis and perforation of the anchor. Therefore, patients need to be well instructed and have close contact with a specialized DJBL treatment center because early and quick removal might be necessary in case of device and procedure related serious adverse events. ${ }^{29}$ In the current patient population none of these serious complications occurred.

Some limitations to this study should be addressed. The design of the study is nonrandomized. In addition, the number of patients is limited; it consists of 28 patients of which only 13 extended and completed their 12 months of treatment with the DJBL. 
The strength consists of patients functioning as their own control in this cross-over designed study. This is the first study describing the effect of DJBL treatment after a controlled diet period.

In conclusion, the DJBL is an effective minimally invasive treatment option with the capability to reduce weight and improve cardiovascular and type 2 diabetes mellitus parameters in obese patients. Even after a significant reduction with dietary restrictions the DJBL is still capable of reducing these parameters even further and appears to be safe for an implantation period of 12 months. 


\section{References}

1. Yatsuya H, Li Y, Hilawe EH, Ota A, Wang C, Chiang C, et al. Global trend in overweight and obesity and its association with cardiovascular disease incidence. Circulation J. 2014;78:2807-18.

2. Ng M, Fleming T, Robinson M, Thomson B, Graetz N, Margono C, et al. Global, regional, and national prevalence of overweight and obesity in children and adults during 1980-2013: a systematic analysis for the Global Burden of Disease Study 2013. Lancet. 2014;384:766-81.

3. Ogden CL, Carroll MD, Kit BK, Flegal KM. Prevalence of obesity among adults: United States, 20112012. NCHS data brief. 2013 Oct(131):1-8.

4. von Ruesten A, Steffen A, Floegel A, van der AD, Masala G, Tjonneland A, et al. Trend in obesity prevalence in European adult cohort populations during follow-up since 1996 and their predictions to 2015. PloS One. 2011;6:e27455.

5. Arnold M, Pandeya N, Byrnes G, Renehan AG, Stevens GA, Ezzati M, et al. Global burden of cancer attributable to high body-mass index in 2012: a population-based study. Lancet Oncol. 2015;16:36-46.

6. Kannel WB, D'Agostino RB, Cobb JL. Effect of weight on cardiovascular disease. Am J Clin Nutr. 1996; 63(3 Suppl):419S-22S.

7. Guh DP, Zhang W, Bansback N, Amarsi Z, Birmingham CL, Anis AH. The incidence of co-morbidities related to obesity and overweight: a systematic review and meta-analysis. BMC Public Health. 2009;9:88.

8. Martin-Rodriguez E, Guillen-Grima F, Marti A, Brugos-Larumbe A. Comorbidity associated with obesity in a large population: The APNA study. Obesity Res Clin Pract. 2015;9:435-47.

9. Flegal KM, Kit BK, Orpana H, Graubard BI. Association of all-cause mortality with overweight and obesity using standard body mass index categories: a systematic review and meta-analysis. JAMA. 2013;309:71-82.

10. Maggard-Gibbons $M$, Maglione $M$, Livhits $M$, Ewing $B$, Maher AR, Hu J, et al. Bariatric surgery for weight loss and glycemic control in nonmorbidly obese adults with diabetes: a systematic review. JAMA. 2013;309:2250-61.

11. Courcoulas AP, Yanovski SZ, Bonds D, Eggerman TL, Horlick M, Staten MA, et al. Long-term outcomes of bariatric surgery: a National Institutes of Health symposium. JAMA Surg. 2014;149:1323-9.

12. Colquitt JL, Pickett K, Loveman E, Frampton GK. Surgery for weight loss in adults. The Cochrane database of systematic reviews. 2014;8:CD003641.

13. Piche ME, Auclair A, Harvey J, Marceau S, Poirier P. How to choose and use bariatric surgery in 2015. Can J Cardiol. 2015;31:153-66.

14. Sauerland S, Angrisani L, Belachew M, Chevallier JM, Favretti F, Finer N, et al. Obesity surgery: evidence-based guidelines of the European Association for Endoscopic Surgery (EAES). Surg Endosc. 2005;19:200-21.

15. Schouten R, Rijs CS, Bouvy ND, Hameeteman W, Koek GH, Janssen IM, et al. A multicenter, randomized efficacy study of the EndoBarrier Gastrointestinal Liner for presurgical weight loss prior to bariatric surgery. Ann Surg. 2010;251:236-43..

16. Koehestanie $P$, de Jonge $C$, Berends FJ, Janssen IM, Bouvy ND, Greve JW. The effect of the endoscopic duodenal-jejunal bypass liner on obesity and type 2 diabetes mellitus, a multicenter randomized controlled trial. Ann Surg. 2014;260:984-92.

17. Escalona A, Pimentel F, Sharp A, Becerra P, Slako M, Turiel D, et al. Weight loss and metabolic improvement in morbidly obese subjects implanted for 1 year with an endoscopic duodenal-jejunal bypass liner. Ann Surg. 2012;255:1080-5.

18. Gersin KS, Rothstein RI, Rosenthal RJ, Stefanidis D, Deal SE, Kuwada TS, et al. Open-label, shamcontrolled trial of an endoscopic duodenojejunal bypass liner for preoperative weight loss in bariatric surgery candidates. Gastrointest Endosc. 2010;71:976-82.

19. Tarnoff M, Rodriguez L, Escalona A, Ramos A, Neto M, Alamo M, et al. Open label, prospective, randomized controlled trial of an endoscopic duodenal-jejunal bypass sleeve versus low calorie diet for pre-operative weight loss in bariatric surgery. Surg Endosc. 2009;23:650-6.

20. de Jonge C, Rensen SS, Verdam FJ, Vincent RP, Bloom SR, Buurman WA, et al. Endoscopic duodenaljejunal bypass liner rapidly improves type 2 diabetes. Obesity Surg. 2013;23:1354-60. 
21. de Jonge C, Rensen SS, Verdam FJ, Vincent RP, Bloom SR, Buurman WA, et al. Impact of DuodenalJejunal Exclusion on Satiety Hormones. Obesity Surg. 2016;26:672-8.

22. Mishra AK, Dubey V, Ghosh AR. Obesity: An overview of possible role(s) of gut hormones, lipid sensing and gut microbiota. Metabolism. 2016;65:48-65.

23. Kairupan TS, Amitani H, Cheng KC, Runtuwene J, Asakawa A, Inui A. Role of gastrointestinal hormones in feeding behavior and obesity treatment. J Gastroenterol. 2016;51:93-103.

24. Koehestanie P, Dogan K, Berends F, Janssen I, Wahab P, Groenen M, et al. Duodenal-jejunal bypass liner implantation provokes rapid weight loss and improved glycemic control, accompanied by elevated fasting ghrelin levels. Endosc Int Open. 2014;2:E21-7.

25. Munoz R, Escalona A. Duodenal-jejunal bypass liner to treat type 2 diabetes mellitus in morbidly obese patients. Curr Cardiol Rep. 2014;16:454.

26. de Moura EG, Martins BC, Lopes GS, Orso IR, de Oliveira SL, Galvao Neto MP, et al. Metabolic improvements in obese type 2 diabetes subjects implanted for 1 year with an endoscopically deployed duodenal-jejunal bypass liner. Diabetes Technol Ther. 2012;14:183-9.

27. Cohen R, le Roux CW, Papamargaritis D, Salles JE, Petry T, Correa JL, et al. Role of proximal gut exclusion from food on glucose homeostasis in patients with Type 2 diabetes. Diabetic Med. 2013;30:1482-6.

28. Betzel B, Homan J, Aarts EO, Janssen IM, de Boer H, Wahab PJ, et al. Weight reduction and improvement in diabetes by the duodenal-jejunal bypass liner: a 198 patient cohort study. Surg Endosc. 2016 Nov 01.

29. Betzel B, Koehestanie P, Aarts EO, Dogan K, Homan J, Janssen IM, et al. Safety experience with the duodenal-jejunal bypass liner: an endoscopic treatment for diabetes and obesity. Gastrointest Endosc. 2015;82:845-52. 



\section{Chapter 7}

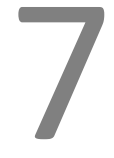

\section{Effect of the EndoBarrier Device: a 4-year follow up of a multicenter randomized clinical trial}

S. van Rijn*, Y.G.M. Roebroek*, C. de Jonge, J.W.M. Greve, N.D. Bouvy

* Both authors contributed equally 


\section{Abstract}

\section{Objective}

To evaluate the long-term effect of the duodenal jejunal bypass liner (DJBL) on weight loss and glycemic control.

\section{Background}

DJBL treatment has been proven effective for the treatment of obesity and type 2 diabetes mellitus. However, data on the long term effect of DJBL treatment is missing.

\section{Methods}

From 2010 to 2012, twenty-nine patients were treated with the DJBL at Maastricht University Medical Center and Zuyderland Medical Center Heerlen, as part of multicenter randomized controlled trial. Prior to implantation and after removal of the DJBL, all patients underwent standardized physical examination and blood sampling (HbA1c, C-peptide, total cholesterol, HDL, LDL, triglycerides). Included patients underwent standardized physical examination and blood sampling as previously performed during the initial study.

\section{Results}

Out of the 29 patients 15 patients were eligible for follow-up with a median duration of 49 months. Five patients had successfully received additional bariatric surgery and were not included in the primary analysis in this long-term evaluation of the DJBL. Four years after explantation of the DJBL median weight in these ten patents was 95.2 kg (IQR 91.7-115.2), (102.0 kg at baseline (IQR 95.0-124.4)), corresponding with a median BMI of $32.2 \mathrm{~kg} / \mathrm{m}^{2}$ (IQR 30.7-33.7), (32.6 kg/m² at baseline (IQR 31.9-34.0)). Patients had an EWL of $11.9 \%$ (IQR -39.1-0.0) compared to baseline weight. HbA1c increased from $7.2 \%$ to $7.6 \%$ (IQR 6.5-8.0). Four years after removal of the DJBL no significant changes were seen.

\section{Conclusions}

The effect of weight reduction seems to be partially maintained 4 years after DJBL treatment compared to baseline. However, to fully determine the long term effect of DJBL treatment larger prospective studies with long-term follow up need to be conducted in the future. 


\section{Introduction}

Obesity remains a complex condition concerning populations worldwide, despite innumerable initiatives to control this epidemic disease. Recent data from the UK reported a doubling of the number of adults suffering from obesity during the past two decades. ${ }^{1}$ In the USA the prevalence of obesity seems to have reached a plateau phase, still affecting roughly one third (27.0-34.9\%) of the adult population. ${ }^{2,3}$ Obesity is associated with an increased risk of developing various physical conditions, including cardiovascular disease and diabetes mellitus. ${ }^{4,5}$

In most healthcare systems, treatment of obesity consists of lifestyle interventions, pharmaceutical therapy and/or bariatric surgery. According to current guidelines, bariatric surgery is reserved for the morbidly obese, defined as a Body Mass Index (BMI) $\geq 40 \mathrm{~kg} / \mathrm{m}^{2}$ or $\geq 35 \mathrm{~kg} / \mathrm{m}^{2}$ with obesity-related comorbidity because the benefits do not outweigh the (surgical) risks in lower BMI group., ${ }^{6,7}$ Recent evidence demonstrated positive effects after metabolic surgery in patients with class I obesity (BMI $30-34.9 \mathrm{~kg} / \mathrm{m}^{2}$ ) and diabetes or metabolic syndrome, however long-term data needs to demonstrate if these benefits persist over time. ${ }^{8-10}$ At the same time, several endoluminal techniques were developed to create temporary or even structural changes of the gastrointestinal tract, aiming for weight loss and improvement of comorbidity. ${ }^{11,12}$

The EndoBarrier System ${ }^{\circledR}$ (GI Dynamics Inc., Lexington, MA) is an endoscopicallydelivered duodenal-jejunal bypass liner (DJBL) that prevents the interaction of food with digestive substances throughout the foregut. Studies evaluating the effect of the DJBL have shown that DJBL treatment results in a decrease in weight and improvement of both cardiovascular and type 2 diabetes mellitus parameters up to 1 year. ${ }^{13-18}$ Designed as a temporary device, most data on the DJBL do not exceed results more than 1 year after removal of the device. The aim of this study is to evaluate long term effects of the EndoBarrier System ${ }^{\circledR}$ on weight loss and glycemic control.

\section{Materials and methods}

From 2010 to 2012, twenty-nine patients were treated with the DJBL at Maastricht University Medical Center and Zuyderland Medical Center Heerlen, as part of a multicenter randomized controlled trial. ${ }^{13}$ Both prior to implantation and after removal of the DJBL, all patients underwent standardized physical examination and blood sampling (HbA1c, C-peptide, total cholesterol, HDL, LDL, triglycerides).

No inclusion criteria were used other than participation in and completion of the randomized controlled trial at the Maastricht University Medical Center or Zuyderland Medical Center, as described earlier. ${ }^{13}$ Exclusion criteria were as follows: patient loss 
to follow-up during the previously described RCT, or patient underwent conventional bariatric surgery after EndoBarrier treatment.

Attempts were made to contact all 29 patients once more in September 2015. Information about the study was provided via mail to the patients responsive to our attempt. Two weeks after receiving the information, the patients were contacted again and invited to visit the outpatient clinic of General Surgery of the Maastricht University Medical Center. Patients were screened for inclusion and exclusion criteria; all eligible patients signed written informed consent. Included patients underwent standardized physical examination and blood sampling as previously performed during the initial study. ${ }^{13}$

The study was conducted according to the principles of the Declaration of Helsinki $\left(64^{\text {th }}\right.$ general assembly of the WMA, Fortaleza, Brazil, Oct. 2013) and in accordance with the guideline Medical Research Involving Human Subjects Act (WMO). The medical ethical committee of the Maastricht University Medical Center approved the study. The general principles of informed consent, ethics review and data management were in line with good clinical practice (GCP).

\section{Statistical analysis}

All data are presented as median and interquartile ranges (IQR) since data were not normally distributed. The Wilcoxon signed-rank test and the Friedman repeated measures analysis of variance was used to assess change over time. A p-value $<0.05$ was regarded as statistically significant. All statistical analyses were performed using commercially available computer software (IBM Corp. Released 2012. IBM SPSS Statistics for Windows, Version 21.0. Armonk, NY: IBM Corp.).

\section{Results}

\section{Patient characteristics}

Five out of 29 patients did not respond to our request to participate in this study, 9 patients declined the request for various reasons. Fifteen patients visited our outpatient clinic for a long-term follow-up evaluation. Ten patients had not received any additional therapy after explantation of the DJBL; the remainder was treated with bariatric surgery and therefore not included in the primary analysis in this long-term evaluation of the DJBL. All included patients completed the initial trial with neither SAE nor complications. Five of the included patients underwent treatment with the DJBL for 6 months; the other half was treated with the DJBL during 12 months. Median follow-up after explant was 49 months (range 40-60 months). Figure 7.1. 


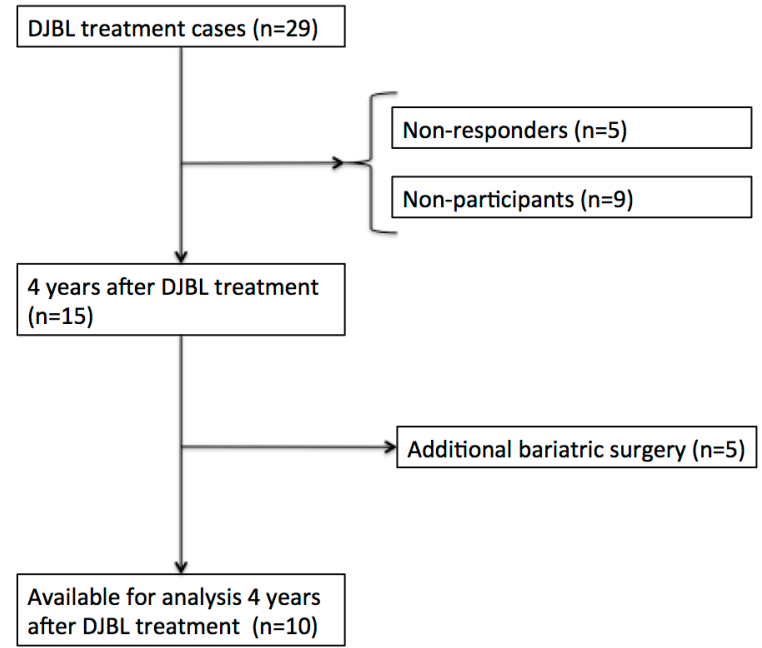

Figure 7.1 Flow chart

\section{Additional bariatric surgery}

Four years after DJBL treatment, 5 out of the 15 participating patients underwent bariatric surgery because of weight gain. Four patients underwent a laparoscopic roux-and-y gastric bypass (LRYGB) and one patient had undergone laparoscopic adjustable gastric banding (LAGB). According to the patients, no serious adverse events were reported after these additional procedures. The 4 patients who underwent LRYGB had a median weight of $111.7 \mathrm{~kg}$ (102.3-127.4) 6 months after removal of the DJBL. After treatment with $L R Y G B$, the median weight in this subgroup was decreased to $77.6 \mathrm{~kg}$ (IQR 75.2-101.8). For the patient who underwent LAGB after initial DJBL treatment, weight decreased from $100.0 \mathrm{~kg}$ to $98.4 \mathrm{~kg}$ after surgery.

\section{Short and long term outcome}

Ten patients did not receive any additional therapy after explantation of the DJBL. After DJBL treatment median weight in this patient group was significantly reduced from $102.0 \mathrm{~kg}$ at baseline (IQR 95.0-124.4) to $93.4 \mathrm{~kg}$ after treatment (IQR 87.8-115.6) $(\mathrm{P}<0.01)$. This resulted in an EWL of 24.1\% (IQR 14.7-44.2), $\mathrm{P}<0.01$. BMI dropped form $32.6 \mathrm{~kg} / \mathrm{m}^{2}$ (IQR 31.9-34.0) at baseline to $31.2 \mathrm{~kg} / \mathrm{m}^{2}$ (IQR 28.8-33.0) at explant of the device, $\mathrm{P}<0.01$. Furthermore, $\mathrm{HbA1c}$ levels decreased from $7.8 \%$ (IQR 7.5-8.8) to $7.2 \%$ (IQR 6.7-8.0), $\mathrm{P}<0.05$.

Four years after explantation of the DJBL median weight in this group was $95.2 \mathrm{~kg}$ (IQR 91.7-115.2), corresponding with a median BMI of $32.2 \mathrm{~kg} / \mathrm{m}^{2}$ (IQR 30.7-33.7). Patients still had an EWL of 11.9\% (IQR 39.1-0.0) compared to baseline weight ( $P=0.059)$. From explantation to 4 years follow-up, no significant changes were detected for weight, 
$\mathrm{BMI}$ and $\mathrm{EWL}(\mathrm{P}=0.445, \mathrm{P}=0.508, \mathrm{P}=0.508$ respectively). HbA1c slightly increased from 7.2\% to 7.6\% (IQR 6.5-8.0) during follow-up, $\mathrm{P}=0.766$. Finally, no significant change in total cholesterol, HDL and LDL was seen 4 years after explanation compared to baseline. An overview of the results is presented in Table 7.1 and Figure 7.2.

Table 7.1 Change in weight, glucose metabolism parameters and cardiovascular parameters after DJBL treatment

\begin{tabular}{lccc}
\hline & $\begin{array}{c}\text { Baseline } \\
\text { Characteristics } \\
(\mathrm{n}=10)\end{array}$ & $\begin{array}{c}\text { Directly after DJBL } \\
\text { treatment }(\mathrm{n}=10)\end{array}$ & $\begin{array}{c}4 \text { years after DJBL } \\
\text { treatment }(\mathrm{n}=10)\end{array}$ \\
\hline Weight (kg) & $102(95-124.4)$ & $93.4(87.8-115.6)$ & $95.2(91.7-115.2)$ \\
BMI (kg/m²) & $32.6(31.9-34.0)$ & $31.2(28.8-33.0)$ & $32.2(30.7-33.7)$ \\
Excess weight loss (\%) & - & $-24.1(-44.2--14.7)$ & $-11.9(-39.1-0.0)$ \\
HbA1C (\%) & $7.8(7.5-8.8)$ & $7.2(6.7-8.0)$ & $7.6(6.5-8.0)$ \\
Systolic blood pressure (mmHg) & $141(115-160)$ & $131(126-131)$ & $143(140-150)$ \\
Diastolic blood pressure (mmHg) & $90(80-101)$ & $78(74-87)$ & $90(88-90)$ \\
Total cholesterol (mmol/L) & $3.9(3.6-5.3)$ & $4.0(2.9-4.6)$ & $3.7(3.3-5.7)$ \\
HDL (mmol/L) & $0.9(0.7-1.2)$ & $1.0(0.8-1.1)$ & $0.9(0.8-1.3)$ \\
LDL (mmol/L) & $2.1(1.5-7.1)$ & $1.7(01.3-2.6)$ & $1.9(1.2-2.9)$ \\
Triglycerides (mmol/L) & $1.9(1.5-7.1)$ & $1.8(1.1-2.8)$ & $2.3(1.5-3.2)$ \\
\hline
\end{tabular}

Data is presented as median and interquartile ranges (IQR)

\section{Effect of DJBL treatment on Weight parameters and HbA1c levels}
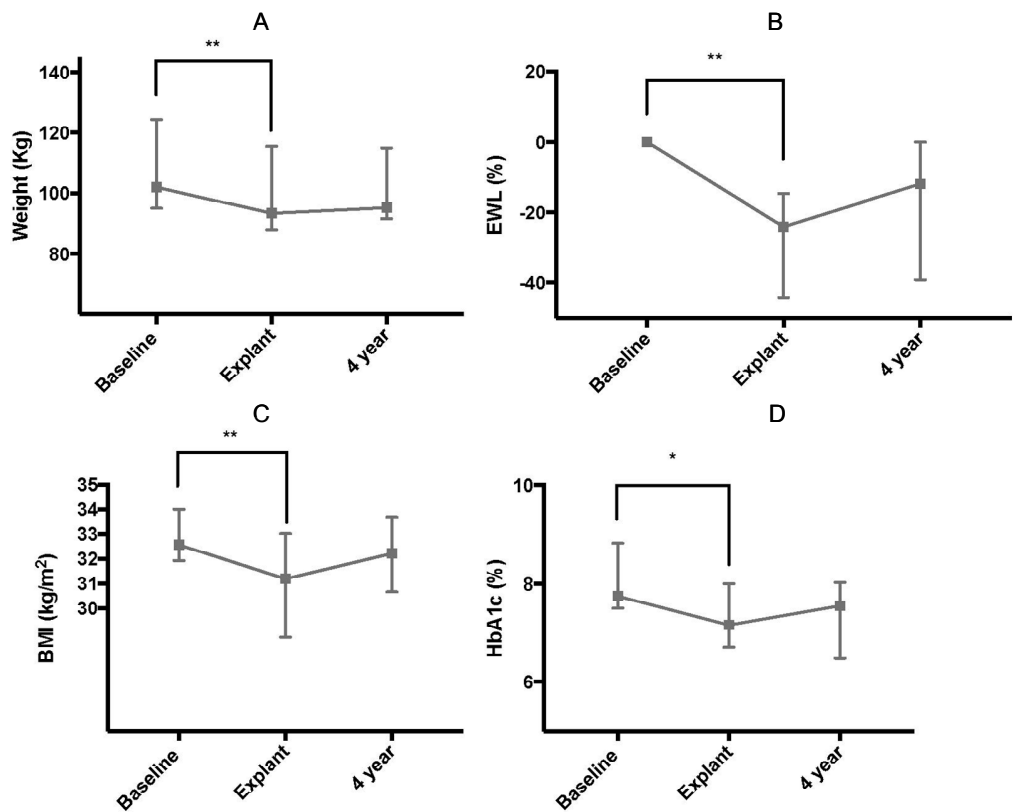

Figure 7.2 A. Change in weight (Kg), B. Change in EWL (\%), C. Change in BMI $\left(\mathrm{kg} / \mathrm{m}^{2}\right)$, D. Change in HbA1c (\%). ${ }^{*} \mathrm{P}<0.05, * * \mathrm{P}<0.01$. 


\section{Discussion}

On short term, treatment with the DJBL has proven to be both effective and relatively safe in reducing weight and improving type 2 diabetes mellitus and cardiovascular parameters compared to diet and bariatric surgery. ${ }^{13,18}$ DJBL treatment may function as a step-up approach for the severely obese population (BMI>50), who need to lose weight before they can safely undergo standard bariatric surgery or for patients with DM and a lower BMI.

The aim of this study was to evaluate the long-term effects of the DJBL on obesity and type 2 diabetes mellitus. With a median follow-up of 49 months after DJBL treatment half of the patients were available for follow up. One third of the patients initially included did not undergo additional bariatric surgery. Patients in this group did not return to their initial baseline weight 4 years after explantation of the DJBL. The median difference in weight still remained -2,5 (-9.2-0.2) kg corresponding with an excess weight loss of $11.9 \%$ (39.1-0.0). No statistical significant difference was reached for weight, EWL, type 2 diabetes mellitus parameters or cardiovascular parameters compared to the situation at explant of the device.

Standard bariatric procedures show superior long-term results with regards to reduction in weight and comorbidities associated with obesity compared to treatment with a DJBL. A recent review on the long-term effects of laparoscopic sleeve gastrectomy (LSG) showed a reduction of EWL of $>50 \%$ after more than 5 years of follow-up. ${ }^{19}$ RYGB showed similar results with a reported EBMI of $50-60 \%$ after one decade. ${ }^{20,21}$ However, as a temporary device, DJBL treatment is hard to compare to standard bariatric procedures. Despite the better results seen after bariatric surgery, a significant advantage resides in the temporary design of the DJBL procedure. Although a recent study showed that the DJBL is accompanied with adverse events in $10 \%$ of patients, removal of the device can be quickly initiated after which most adverse events resolve. ${ }^{22}$ Koehestanie et al. showed that it is feasible and safe to re-implant and explant the DJBL device resulting in significant additional weight loss. ${ }^{23}$ Such reimplantation of the DJBL should be considered. Especially in patients that show an ongoing effect in terms of weight reduction on long term as is seen in this study.

A recent systematic review assessing the long term effects of restricted diets as treatment of obesity showed a mean weight loss of $4.5 \%$ of their initial body weight after four years of follow-up $(n=5696) .{ }^{24}$ Four years after DJBL treatment a mean weight loss of $5.2 \%$ still remained. DJBL treatment may therefore have a small advantage compared to dietary treatment on the long term regarding weight control. However, we do have to take into account that there might have been a selectionbias: the primary analysis did not include the 5 patients who underwent bariatric surgery because of dissatisfaction with their weight or because of weight regain. Furthermore, approximately half of the patients were lost to follow-up, thereby 
raising the question whether the patients included in this study participated because of their positive experience with DJBL treatment.

Five of the 15 patients available for follow-up underwent bariatric surgery. No peri- or postoperative complications occurred during and after these bariatric surgical procedures. Therefore DJBL treatment does not seem to raise additional issues or complicate the performance of any form of bariatric surgery.

To our knowledge, this is the first study assessing long term follow up after DJBL treatment. The effect of weight reduction seems to be partially maintained 4 years after DJBL treatment compared to baseline. Follow-up was only available for a small group of 15 patients and as mentioned before some selection bias may have played a role in the outcome seen 4 years after DJBL treatment. To fully determine the long term effect of DJBL treatment larger prospective studies with long-term follow up need to be conducted in the future. 


\section{References}

1. Health and Social Care Information Centre LS. Statistics on Obesity, Physical Activity and Diet: England, 2013. NHS, 20139 may 2013. Report No.: 2.

2. Ogden $\mathrm{CL}$, Carroll MD, Kit BK, Flegal KM. Prevalence of childhood and adult obesity in the United States, 2011-2012. JAMA. 2014;311:806-14.

3. Schiller JS, Lucas JW, Ward BW, Peregoy JA. Summary health statistics for U.S. adults: National Health Interview Survey, 2010. Vital and health statistics Series 10, Data from the National Health Survey. 2012(252):1-207.

4. Kahn SE, Hull RL, Utzschneider KM. Mechanisms linking obesity to insulin resistance and type 2 diabetes. Nature. 2006;444:840-6.

5. Van Gaal LF, Mertens IL, De Block CE. Mechanisms linking obesity with cardiovascular disease. Nature. 2006;444:875-80.

6. Fried M, Yumuk V, Oppert JM, Scopinaro N, Torres AJ, Weiner R, et al. Interdisciplinary European Guidelines on metabolic and bariatric surgery. Obes Facts. 2013;6:449-68.

7. Mechanick JI, Youdim A, Jones DB, Garvey WT, Hurley DL, McMahon MM, et al. Clinical practice guidelines for the perioperative nutritional, metabolic, and nonsurgical support of the bariatric surgery patient--2013 update: cosponsored by American Association of Clinical Endocrinologists, The Obesity Society, and American Society for Metabolic \& Bariatric Surgery. Obesity. 2013;21 Suppl 1: S1-27.

8. Maiz C, Alvarado J, Quezada N, Salinas J, Funke R, Boza C. Bariatric surgery in 1119 patients with preoperative body mass index $<35$ (kg/m(2)): results at 1 year. Surg Obes Relat Dis. 2015;11:1127-32.

9. O'Brien PE, Dixon JB, Laurie C, Skinner S, Proietto J, McNeil J, et al. Treatment of mild to moderate obesity with laparoscopic adjustable gastric banding or an intensive medical program: a randomized trial. Ann Intern Med. 2006;144:625-33.

10. Sultan S, Parikh M, Youn H, Kurian M, Fielding G, Ren C. Early U.S. outcomes after laparoscopic adjustable gastric banding in patients with a body mass index less than $35 \mathrm{~kg} / \mathrm{m}^{2}$. Surg Endosc. 2009; 23:1569-73.

11. Mathus-Vliegen EM. Endoscopic treatment: the past, the present and the future. Best Pract Res Clin Gastroenterol. 2014;28:685-702.

12. van Rijn S, Roebroek YG, Masclee AA, van Heurn EL, Bouvy ND. Structural endoscopic techniques to treat obesity: A Review. Surg Technol Int. 2015;26:84-91.

13. Koehestanie P, de Jonge C, Berends FJ, Janssen IM, Bouvy ND, Greve JW. The effect of the endoscopic duodenal-jejunal bypass liner on and type 2 diabetes mellitus, a multicenter randomized controlled trial. Ann Surg. 2014;260:984-92.

14. Betzel B, Homan J, Aarts EO, Janssen IM, de Boer H, Wahab PJ, et al. Weight reduction and improvement in diabetes by the duodenal-jejunal bypass liner: a 198 patient cohort study. Surg Endosc. 2016 Nov 01.

15. Escalona A, Pimentel F, Sharp A, Becerra P, Slako M, Turiel D, et al. Weight loss and metabolic improvement in morbidly obese subjects implanted for 1 year with an endoscopic duodenal-jejunal bypass liner. Ann Surg. 2012;255:1080-5.

16. de Moura EG, Martins BC, Lopes GS, Orso IR, de Oliveira SL, Galvao Neto MP, et al. Metabolic improvements in obese type 2 diabetes subjects implanted for 1 year with an endoscopically deployed duodenal-jejunal bypass liner. Diabetes Technol Ther. 2012;14:183-9.

17. Gersin KS, Rothstein RI, Rosenthal RJ, Stefanidis D, Deal SE, Kuwada TS, et al. Open-label, shamcontrolled trial of an endoscopic duodenojejunal bypass liner for preoperative weight loss in bariatric surgery candidates. Gastrointest Endosc. 2010;71:976-82.

18. Schouten R, Rijs CS, Bouvy ND, Hameeteman W, Koek GH, Janssen IM, et al. A multicenter, randomized efficacy study of the EndoBarrier Gastrointestinal Liner for presurgical weight loss prior to bariatric surgery. Ann Surg. 2010;251:236-43.

19. Diamantis T, Apostolou KG, Alexandrou A, Griniatsos J, Felekouras E, Tsigris C. Review of long-term weight loss results after laparoscopic sleeve gastrectomy. Surg Obes Relat Dis. 2014;10:177-83.

20. Edholm D, Svensson F, Naslund I, Karlsson FA, Rask E, Sundbom M. Long-term results 11 years after primary gastric bypass in 384 patients. Surg Obes Relat Dis. 2013;9:708-13. 
21. Mehaffey JH, LaPar DJ, Clement KC, Turrentine FE, Miller MS, Hallowell PT, et al. 10-Year Outcomes After Roux-en-Y Gastric Bypass. Ann Surg. 2016;264:121-6.

22. Betzel B, Koehestanie P, Aarts EO, Dogan K, Homan J, Janssen IM, et al. Safety experience with the duodenal-jejunal bypass liner: an endoscopic treatment for diabetes and obesity. Gastrointest Endosc. 2015;82:845-52.

23. Koehestanie $P$, Betzel B, Aarts EO, Janssen IM, Wahab $P$, Berends FJ. Is reimplantation of the duodenal-jejunal bypass liner feasible? Surg Obes Relat Dis. 2015;11:1099-104.

24. Langeveld $\mathrm{M}, \mathrm{DeV}$ ries JH. The long-term effect of energy restricted diets for treating obesity. Obesity. 2015;23:1529-38. 


\section{Chapter 8}

Summary, discussion and future perspectives 



\section{Summary, discussion and future perspectives}

\section{Part 1: Surgical treatment of gastroesophageal reflux disease}

\section{Complications of antireflux surgery (ARS)}

ARS has proven to be a good treatment modality for GERD, both on the short and long term. $^{1-9}$ It should be taken into account that symptoms of the majority of GERD patients are well controlled by medical therapy. ${ }^{10}$ Therefore, only a strictly selected group of GERD patients should be referred for ARS. Indications for referral include: patients with persisting symptoms not sufficiently responding to medical therapy and unwillingness for maintenance medical therapy. One should realize that ARS, as other surgical procedures, may be associated with or followed by complications. ${ }^{11}$

Vagus nerve injury (VNI) is one of the most feared complications. In Chapter 2 an overview of the current literature has been presented with respect to the effect of intended and accidental VNI on the outcome of antireflux surgery. Intended VNI added to an antireflux procedure showed a higher prevalence of diarrhea, dumping syndrome and nausea after ARS. It is not known whether vagus nerve injury always leads to symptoms or whether vagus nerve injury may go clinically unnoticed in the majority of cases. Therefore we need an objective measurement or method to quantify vagus nerve injury.

In Chapter 2 we reported that up to now only two prospective studies have objectively investigated the effect of accidental VNI on the outcome of antireflux surgery. The prevalence of VNI seen after ARS was more than $10 \%$. On short term no effect of $\mathrm{VNI}$ on control of reflux symptoms, gastric emptying and 24-hour $\mathrm{pH}$ monitoring were seen after ARS. It should be taken into account that follow-up in these two studies was short and the patient cohorts were small with respect to number of patients that were studied. ${ }^{12,13}$ Therefore in Chapter 3, we investigated the short and long term effects of $\mathrm{VNI}$, objectively measured by the response of plasma pancreatic polypeptide to insulin-induced hypoglycemia (PP-test), on the outcome of antireflux surgery in a large cohort of GERD patients both before and after ARS. VNI was present in up to $20 \%$ of patients and was associated with more dissatisfaction, worse symptomatic outcome and a higher re-operation rate during long term follow up. Furthermore, gastric emptying measured by scintigraphy was significantly impaired after VNI compared to the group without vagus nerve injury. This was observed for both the rate of gastric emptying and for emptying half time.

Failure of antireflux surgery is scored by persistence of reflux symptoms and by recurrence or new onset of reflux symptoms. Standard follow-up of patients undergoing ARS consist of outpatient clinic visits where evaluation of symptoms is the first step in assessing the success of the ARS procedure. In patients with recurrent 
symptoms, the subsequent diagnostic evaluation consists of manometry, $\mathrm{pH}$ monitoring and gastric scintigraphy for emptying. As shown in Chapter $\mathbf{2}$ and 3, vagus nerve injury may present itself with recurrent reflux symptoms, nausea, vomiting, gastric stasis or dumping syndrome and diarrhea. As mentioned earlier, we were able to demonstrate that gastric emptying was more delayed in postoperative patients with VNI compared to the vagus nerve intact group. One should take into account that in patients that have undergone ARS, usually gastric emptying is more rapid or even accelerated postoperatively when compared to preoperatively. ${ }^{12,14}$

During ARS the fundus of the stomach is mobilized and wrapped around the gastro esophageal junction thereby reducing the gastric storage capacity of the fundus. This reduces the proximal gastric accommodation response and thereby enhances the propulsion of food from the proximal stomach tot the antrum. This may be one of the more prominent factors leading to an accelerated gastric emptying. ${ }^{14-16}$

Postoperative recurrence of reflux symptoms combined with impaired gastric emptying may be one the first signs indicative for the presence of VNI. As shown in Chapter 3, patients with VNI are re-operated more often. In patients with VNI who present with recurrent or new onset of reflux symptoms treatment should not consist of re-operation since this does not treat the underlying pathophysiological mechanism. Instead, treatment should consist of symptom control using a step up approach in which dietary measurements, motility reducing (for diarrhea, dumping syndrome) or motility enhancing (nausea,vomiting, stasis) drugs, gastric rest with enteral feeding, pyloric botulin toxin injections or surgical or endoscopic pyloromyotomy should be considered as treatment options depending on symptom presentation and persistence.

\section{Conclusion and future perspectives}

We have clearly shown that the prevalence of VNI is much higher than previously assumed and is associated with a worse outcome of ARS on the longer term. We emphasize that careful evaluation of patients who present with recurrent or new symptoms after ARS is of utmost importance. Here, evaluation of vagus nerve function is indicated. However, the vagus nerve integrity test is time consuming and demanding for patients. Therefore vagus nerve testing by PP response to insulininduced hypoglycemia will not become a standard procedure in routine evaluation of patients for (redo) ARS. However in patients with unsuccesfull primary ARS the presence or absence of vagus nerve injury helps to determine which steps should be taken. 


\section{Part 2: Safety and efficacy of new minimal invasive endoscopic and surgical techniques in the treatment of obesity}

The Roux-and-Y Gastric Bypass and Sleeve Gastrectomy are the most commonly used techniques in the surgical management of morbid obesity. These techniques have shown to be very effective in reducing weight and to prevent or minimize comorbidities associated with obesity on short and long term. ${ }^{17-19}$ However, these procedures remain associated with morbidity and mortality and are only available for a selected group of patients. ${ }^{20-24}$

During the last decade several new techniques to treat obesity have emerged trying to provide a less invasive and safer solution for the overweight and (morbidly) obese populations.

\section{Innovative structural surgical and endoscopic techniques}

In Chapter 4 we reviewed the efficacy and safety of endoluminal techniques that structurally change the upper gastrointestinal anatomy in the treatment of obesity. In this review we divide the different types of restrictive endoluminal procedures into two groups. One group consists of procedures that exclude the greater curvature of the stomach by using a suturing or stapling system. The second group consists of endoluminal procedures that base their restrictive effect on volume reduction by applying sutured or stapled plications. After short-to medium term follow-up we found an overall EWL ranging from 24\% to 58\%. In addition, of the 277 patients included in this review only 7 patients had post procedure complications for which only one patient required additional surgical intervention. However, only half of the studies reported on the effects of the procedures on comorbidities accompanied with obesity. Most prominent was a regression in type 2 diabetes mellitus associated factors. Although these interventions show promising results with regards to efficacy in weight loss and safety, it must be mentioned that some of these techniques suffer from procedure-related failure. In three of these techniques (TGVR, EVG and TOGA) over $50 \%$ of patients had disruptions of the applied sutures or staple lines. ${ }^{25-31}$ These disruptions might be explained by the placement of superficial sutures during these techniques thereby not reaching a full thickness bite and thus mainly approximating the mucosal lining of the stomach. The relatively rapid turnover of the mucosal lining of the stomach might cause early disruption seen after these techniques. Furthermore, these procedures owe their restrictive component to their endoscopically created gastric sleeve. High intragastric pressure build up during food ingestion with low compliance of the gastric sleeve combined with superficial staple/suture placement might also explain the reduced durability of these techniques. Further technical improvement of these techniques is warranted before they can be implemented as standard care in the treatment of morbid obesity. 
Another potentially promising laparoscopic surgical treatment preserving the anatomy and trying to treat obesity by influencing gastric function is Gastic Electrical Stimulation. The proposed mechanism of action of this new technique is to impair gastric motor function thereby inducing a delay in gastric emptying leading to an increase in satiety followed by a reduction in food intake thus resulting in weight loss. Over the past decade several GES systems have been developed. Early studies conducted on GES showed significant weight loss at 12 months follow-up. ${ }^{32,33}$ However, a double-blinded randomized trial failed to show a clear effect of GES on body weight. ${ }^{34}$ In Chapter 5, we investigated the first human experience with a new GES system. We evaluated its effect on gastric emptying rate, food intake, glucose metabolism and weight loss. Optimal pacing settings for this new GES system were extensively investigated with promising results in animal studies. ${ }^{35}$ We have shown in this first in human study that this new GES system is safe. However, we were unable to demonstrate any beneficial effect of GES on the forementioned parameters such as gastric emptying, intake, satiety or weight loss. Our data do not completely exclude a role for gastric stimulation in weight management. We strongly recommend to start more basic research with focus on electrophysiology of the stomach, an area that is practically unexplored. Future studies should focus on unraveling the pathophysiological mechanisms by which GES might affect the gastric motor and/or sensory function of the stomach and on finding optimal pacing protocols/algorithms.

\section{A temporary endoluminal device (the duodenal bypass liner) to treat obesity}

In Chapter 6 we investigated the safety and efficacy of 6 and 12 months DJBL treatment for obesity and its related comorbidities after a controlled 6 month diet period. We found that an additional DJBL treatment resulted in a further decrease in weight, and an improvement of cardiovascular and type 2 diabetes mellitus parameters. During the first 6 months of treatment the most pronounced changes were observed. These data are in line with extensive research over the past decade on 6 and 12 months of DJBL treatment. ${ }^{36-38}$

Not only the effect of this temporary in situ endoluminal technique on obesity and on its associated comorbidities is important, also safety is a relevant issue. In this thesis a low complication rate was seen after placement of the DJBL device. However a recent large study by Betzel et al., on safety of the DJBL showed a complication rate of $10 \%$. Serious adverse events consisted of GI bleeding, hepatic abscess, pancreatitis and anchor perforation. ${ }^{39}$ In case these adverse events occur, the DJBL can easily be removed. Thereafter most complaints and complications usually resolve. Patients undergoing this procedure should be under tight surveillance in centers specialized in and experienced with these type of endoluminal procedures.

Up till now no studies assessing the long term outcome of DJBL treatment on obesity are available. Therefore in Chapter 7 we evaluated and described the effect of DJBL 
treatment on obesity 4 years after explantation of the device. Four years after explantation one-third of the patients had been re-operated. In the patient group that was not re-operated no significant difference in weight, type 2 diabetes mellitus or cardiovascular parameters was seen.

When overlooking the current available data we can conclude that DJBL treatment seems to be effective in the treatment of obesity and type 2 diabetes mellitus on the short term. However, after removal of the liner its effect appears to diminish over time. Therefore its role in the treatment of obesity is under debate. This raises the question whether a place should be reserved for the DJBL in the treatment of obesity in the near future.

\section{Conclusion and future perspectives}

Innovative bariatric techniques have shown beneficial effects on obesity and its comorbidities on the short term. Techniques that structurally alter gastro-intestinal anatomy and function show the most promising results. Conventional bariatric surgery still is superior compared with novel and innovative techniques both for short and long-term treatment of obesity. However one should take into account that most of these innovative procedures are less invasive than conventional bariatric surgery. The innovative procedures mostly have lower complication rates and mortality has not been reported so far. Therefore in the future, these novel techniques may come to play a more prominent role in the treatment of the overweight and mild obese population (BMI $\leq 35 \mathrm{~kg} / \mathrm{m}^{2}$ without comorbidities) that does not directly qualify for bariatric surgical treatment. Finally, future research is warranted assessing the effect of these techniques on obesity and their comorbidities in randomized clinical trials on the short term and especially on the longer term. Such studies will provide more detailed insight which role these techniques could play in the treatment of obesity. 


\section{References}

1. Shaw JM, Bornman PC, Callanan MD, Beckingham IJ, Metz DC. Long-term outcome of laparoscopic Nissen and laparoscopic Toupet fundoplication for gastroesophageal reflux disease: a prospective, randomized trial. Surg Endosc. 2010;24:924-32.

2. Simorov A, Ranade A, Jones R, Tadaki C, Shostrom V, Boilesen E, et al. Long-term patient outcomes after laparoscopic anti-reflux procedures. J Gastrointest Surg. 2014;18:157-62; discussion 62-3.

3. Mardani J, Lundell L, Engstrom C. Total or posterior partial fundoplication in the treatment of GERD: results of a randomized trial after 2 decades of follow-up. Ann Surg. 2011;253:875-8.

4. Kamolz T, Granderath FA, Bammer T, Wykypiel H, Jr., Pointner R. "Floppy" Nissen vs. Toupet laparoscopic fundoplication: quality of life assessment in a 5-year follow-up (part 2). Endoscopy. 2002;34:917-22.

5. Hagedorn C, Lonroth H, Rydberg L, Ruth M, Lundell L. Long-term efficacy of total (Nissen-Rossetti) and posterior partial (Toupet) fundoplication: results of a randomized clinical trial. J Gastrointest Surg. 2002;6:540-5.

6. Engstrom C, Cai W, Irvine T, Devitt PG, Thompson SK, Game PA, et al. Twenty years of experience with laparoscopic antireflux surgery. Br J Surg. 2012;99:1415-21.

7. Fein M, Bueter M, Thalheimer A, Pachmayr V, Heimbucher J, Freys SM, et al. Ten-year outcome of laparoscopic antireflux surgery. J Gastrointest Surg. 2008;12:1893-9.

8. Blazejczyk K, Hoene A, Glitsch A, Busemann A, Heidecke CD, Patrzyk M. Evaluation of short-term and long-term results after laparoscopic antireflux surgery: esophageal manometry and 24-h $\mathrm{pH}$ monitoring versus quality of life index. Langenbecks Arch Surg. 2013;398:1107-14.

9. Dallemagne B, Perretta S. Twenty years of laparoscopic fundoplication for GERD. World J Surg. 2011; 35:1428-35.

10. Grant AM, Boachie C, Cotton SC, Faria R, Bojke L, Epstein DM, et al. Clinical and economic evaluation of laparoscopic surgery compared with medical management for gastro-oesophageal reflux disease: 5-year follow-up of multicentre randomised trial (the REFLUX trial). Health Technol Assess. 2013;17: 1-167.

11. Watson DI, de Beaux AC. Complications of laparoscopic antireflux surgery. Surg Endosc. 2001;15: 344-52.

12. Lindeboom MY, Ringers J, van Rijn PJ, Neijenhuis P, Stokkel MP, Masclee AA. Gastric emptying and vagus nerve function after laparoscopic partial fundoplication. Ann Surg. 2004;240:785-90.

13. DeVault KR, Swain JM, Wentling GK, Floch NR, Achem SR, Hinder RA. Evaluation of vagus nerve function before and after antireflux surgery. Journal of gastrointestinal surgery : official journal of the Society for Surgery of the Aliment Tract. 2004;8:883-8; discussion 8-9.

14. Vu MK, Straathof JW, v d Schaar PJ, Arndt JW, Ringers J, Lamers CB, et al. Motor and sensory function of the proximal stomach in reflux disease and after laparoscopic Nissen fundoplication. Am J Gastroenterol. 1999;94:1481-9.

15. Vu MK, Ringers J, Arndt JW, Lamers CB, Masclee AA. Prospective study of the effect of laparoscopic hemifundoplication on motor and sensory function of the proximal stomach. Br J Surg. 2000;87: 338-43.

16. Lindeboom MY, Vu MK, Ringers J, van Rijn PJ, Neijenhuis P, Masclee AA. Function of the proximal stomach after partial versus complete laparoscopic fundoplication. Am J Gastroenterol. 2003;98: 284-90.

17. Arman GA, Himpens J, Dhaenens J, Ballet T, Vilallonga R, Leman G. Long-term (11+years) outcomes in weight, patient satisfaction, comorbidities, and gastroesophageal reflux treatment after laparoscopic sleeve gastrectomy. Surg Obes Relat Dis. 2016;12:1778-86.

18. Mehaffey JH, LaPar DJ, Clement KC, Turrentine FE, Miller MS, Hallowell PT, et al. 10-Year Outcomes After Roux-en-Y Gastric Bypass. Ann Surg. 2016;264:121-6.

19. Colquitt JL, Pickett K, Loveman E, Frampton GK. Surgery for weight loss in adults. The Cochrane database of systematic reviews. 2014 Aug 08(8):CD003641.

20. Rausa E, Bonavina L, Asti E, Gaeta M, Ricci C. Rate of Death and Complications in Laparoscopic and Open Roux-en-Y Gastric Bypass. A Meta-analysis and Meta-regression Analysis on 69,494 Patients. Obes Surg. 2016;26:1956-63. 
21. Chang SH, Stoll CR, Song J, Varela JE, Eagon CJ, Colditz GA. The effectiveness and risks of bariatric surgery: an updated systematic review and meta-analysis, 2003-2012. JAMA Surg. 2014;149:275-87.

22. Rosenthal RJ, International Sleeve Gastrectomy Expert P, Diaz AA, Arvidsson D, Baker RS, Basso N, et al. International Sleeve Gastrectomy Expert Panel Consensus Statement: best practice guidelines based on experience of $>12,000$ cases. Surg Obes Relat Dis. 2012;8:8-19.

23. Longitudinal Assessment of Bariatric Surgery C, Flum DR, Belle SH, King WC, Wahed AS, Berk P, et al. Perioperative safety in the longitudinal assessment of bariatric surgery. N Engl J Med. 2009;361: 445-54.

24. Smith MD, Adeniji A, Wahed AS, Patterson E, Chapman W, Courcoulas AP, et al. Technical factors associated with anastomotic leak after Roux-en-Y gastric bypass. Surg Obes Relat Dis. 2015;11:313-20.

25. Fogel R, De Fogel J, Bonilla Y, De La Fuente R. Clinical experience of transoral suturing for an endoluminal vertical gastroplasty: 1-year follow-up in 64 patients. Gastrointest Endosc. 2008;68:51-8.

26. Brethauer SA, Chand B, Schauer PR, Thompson CC. Transoral gastric volume reduction for weight management: technique and feasibility in 18 patients. Surg Obes Relat Dis. 2010;6:689-94.

27. Brethauer SA, Chand B, Schauer PR, Thompson CC. Transoral gastric volume reduction as intervention for weight management: 12-month follow-up of TRIM trial. Surg Obes Relat Dis. 2012;8:296-303.

28. Moreno C, Closset J, Dugardeyn S, Barea M, Mehdi A, Collignon L, et al. Transoral gastroplasty is safe, feasible, and induces significant weight loss in morbidly obese patients: results of the second human pilot study. Endoscopy. 2008;40(5):406-13.

29. Familiari P, Costamagna G, Blero D, Le Moine O, Perri V, Boskoski I, et al. Transoral gastroplasty for morbid obesity: a multicenter trial with a 1-year outcome. Gastrointest Endosc. 2011;74:1248-58.

30. Leccesi L, Panunzi S, De Gaetano A, Familiari P, laconelli A, Guidone C, et al. Effects of transoral gastroplasty on glucose homeostasis in obese subjects. J Clin Endocrinol Metab. 2013;98:1901-10.

31. Deviere J, Ojeda Valdes G, Cuevas Herrera L, Closset J, Le Moine O, Eisendrath P, et al. Safety, feasibility and weight loss after transoral gastroplasty: First human multicenter study. Surg Endosc. 2008;22:589-98.

32. Bohdjalian A, Prager G, Aviv R, Policker S, Schindler K, Kretschmer S, et al. One-year experience with Tantalus: a new surgical approach to treat morbid obesity. Obes Surg. 2006;16:627-34.

33. Camilleri M, Toouli J, Herrera MF, Kulseng B, Kow L, Pantoja JP, et al. Intra-abdominal vagal blocking (VBLOC therapy): clinical results with a new implantable medical device. Surgery. 2008;143:723-31.

34. Shikora SA, Bergenstal R, Bessler M, Brody F, Foster G, Frank A, et al. Implantable gastric stimulation for the treatment of clinically severe obesity: results of the SHAPE trial. Surg Obes Relat Dis. 2009;5:31-7.

35. Song GQ, Zhu H, Lei Y, Yuan C, Starkebaum W, Yin J, et al. Gastric electrical stimulation optimized to inhibit gastric motility reduces food intake in dogs. Obes Surg. 2015;25:1047-55.

36. Betzel B, Homan J, Aarts EO, Janssen IM, de Boer $\mathrm{H}$, Wahab PJ, et al. Weight reduction and improvement in diabetes by the duodenal-jejunal bypass liner: a 198 patient cohort study. Surg Endosc. 2016 Nov 01.

37. Koehestanie P, de Jonge C, Berends FJ, Janssen IM, Bouvy ND, Greve JW. The effect of the endoscopic duodenal-jejunal bypass liner on obesity and type 2 diabetes mellitus, a multicenter randomized controlled trial. Ann Surg. 2014;260:984-92.

38. Schouten R, Rijs CS, Bouvy ND, Hameeteman W, Koek GH, Janssen IM, et al. A multicenter, randomized efficacy study of the EndoBarrier Gastrointestinal Liner for presurgical weight loss prior to bariatric surgery. Ann Surg. 2010;251:236-43.

39. Betzel B, Koehestanie P, Aarts EO, Dogan K, Homan J, Janssen IM, et al. Safety experience with the duodenal-jejunal bypass liner: an endoscopic treatment for diabetes and obesity. Gastrointest Endosc. 2015;82:845-52. 



\section{Part III}

Addendum 



\section{Valorisation addendum}





\section{Valorisation addendum}

This thesis focuses on two major socio-economic and health burdens; gastroesophageal reflux disease (GERD) and morbidly obesity. The aim was to provide new insight in complications of anti-reflux surgery (ARS) and to provide new treatment options for people with morbidly obesity.

\section{Gastroesophageal reflux disease (GERD)}

The prevalence of GERD has increased over the last decades and is still increasing. Prevalence varies world wide from 18\%-28\% in North America, 9\%-26\% in Europe, 3\%-8\% in East Asia, 9\%-33\% in the Middle East, 11.6\% in Australia and 23.0\% in South America. With the numbers of patients suffering from GERD rising, the disease has become a serious global socio-economic burden. GERD is the number one given gastrointestinal diagnosis in the US. The costs in the US of proton pump inhibitor usage for acid related disorders are estimated to be 10 billion dollars yearly. PPI use is considered a safe treatment, however risk of pneumonia, intestinal infections, hip fractures and deficiency of vitamin B12, iron and other micronutrients have been reported in long term PPI users.

Surgery as treatment for GERD has proven to be effective and also seems to be a more cost effective alternative over a longer period of time than medical therapy. However, surgery is accompanied by peri- and postoperative complications. In the first part of this thesis we have addressed one of the feared perioperative complications (vagus nerve injury) of ARS and the effect of this complication on the outcome of ARS. We have shown in chapter $\mathbf{2}$ and $\mathbf{3}$ that the occurrence of vagus nerve injury (VNI) resulting from anti reflux surgery is much higher than previously assumed in literature. We have also demonstrated that VNI leads to a higher recurrence rate of symptoms of GERD and subsequently leads to a higher re-operation rate on long term. As previously described in chapter 3, treatment of patients with VNI who present with recurrent or new onset of reflux symptoms treatment should not consist of re-operation because of poor efficacy and other pathophysiological mechanisms that are involved, such as delayed gastric emptying. Our observations and findings are relevant for decision making in clinical practice. Patients with persistent or new complaints after ARS will more frequently consult the gastroenterologist or surgeon, will use more medication, will undergo mores tests or surgical re-interventions which results in a higher burden on healthcare costs. It is therefore of importance to investigate these causes and consequences of these complications and provide better solutions or alternative treatment options. With these complications in mind, new techniques have emerged as an alternative to current standard surgical procedures (Nissen and Toupet fundoplication). Although early results are promising, longer term efficacy and safety need improvement. These techniques have not yet been able to reach the same level of success rate as the 
current standard surgical procedures. Hopefully, future development and research will provide us with safer and more effective treatment options. Awareness for occurrence of vagal nerve injury due to antireflux surgery should increase as well as the clinical consequences with poorer outcome, serious side effects and lower efficacy of redo surgery.

\section{Overweight and Obesity}

Overweight (BMI $25-30 \mathrm{~kg} / \mathrm{m}^{2}$ ) and obesity $\left(\mathrm{BMI}>30 \mathrm{~kg} / \mathrm{m}^{2}\right.$ ) have become pandemic. Approximately 1.9 billion adults are overweight or obese, while 462 million are underweight. Obesity does not only have a large social impact but is also responsible for a tremendous economic burden. USA national medical care costs related to obesity have been estimated to be around 210 billion USD, which accounts for approximately $20 \%$ of the total annual US healthcare expenditures. More important obesity is associated with a higher risk of developing metabolic disorders (Diabetes Mellitus), cardiovascular disorders, sleep apnea, arthrosis, degradation of musculoskeletal organs and cancer all adding up to the socio-economic burden.

Bariatric surgery (sleeve gastrectomy, roux-y gastric bypass) has proven to be most effective and cost beneficial in the treatment of obesity compared to non-surgical techniques. Although these procedures are highly effective in decreasing weight and reducing obesity associated comorbidities they are still accompanied with complications. More importantly, according to current guidelines on bariatric surgery only patients with a $B M I \geq 35 \mathrm{~kg} / \mathrm{m}^{2}$ with comorbidities or patients with a $\mathrm{BMI} \geq 40 \mathrm{~kg} / \mathrm{m}^{2}$ are considered eligible for surgery leaving a considerable large group of patients untreated. Therefore, to broaden the therapeutic range and further minimize complications new bariatric techniques that are less invasive have been developed. In the second part of this thesis (chapter 4-7) we focus on several of these new minimal invasive techniques and investigated both their safety and effectiveness. Most of the investigated new bariatric techniques in this thesis have shown beneficial effects on obesity and its comorbidities on short term and show lower complication rates. However, current standard bariatric techniques are still superior in the treatment of obesity. Further development and investigation of these less invasive new techniques is of high importance to be able to provide a solution for the ever growing overweight population and the accompanying socio-economic burden. 
Samenvatting 



\section{Samenvatting}

Dit proefschrift bestaat uit twee delen. Het eerste deel richt zich op een complicatie na antireflux chirurgie (vagusletsel) en het tweede deel richt zich op nieuwe technieken voor de behandeling van obesitas.

\section{Chirurgische ingrepen voor behandeling van gastro-oesofageale refluxziekte (GORZ)}

GORZ is een veelvoorkomend ziektebeeld. Dit ziektebeeld wordt gekenmerkt door symptomen als zuurbranden, regurgitatie en retrosternale pijn. Dit komt doordat maagzuur terug komt in de slokdarm (reflux).

De eerst keus voor behandeling van refluxziekte is het remmen van het zuur door het geven van zuurremmers (protonpomp remmers, PPI's). Deze behandeling blijkt echter niet bij iedereen effectief te zijn en sommige mensen blijven klachten houden ondanks het gebruik van een hoge dosis PPI's. Daarnaast moeten sommige mensen hun hele leven PPI's blijven gebruiken. Voor deze patiënten kan een chirurgische ingreep een goede oplossing bieden. De meest gebruikte chirurgische technieken zijn de laparoscopische Nissen fundoplicatie (LNF) en de laparoscopische Toupet fundoplicatie (LTF). Bij deze technieken wordt de hiatus oesophagei (de opening in het middenrif waardoor de slokdarm de buik in gaat) verkleind tot zijn normale doorsnede en wordt de fundus van de maag gedeeltelijk (180-270 graden; Toupet) of geheel (360 graden; Nissen) om het onderste gedeelte van de slokdarm gewikkeld. Hierdoor wordt de mechanische barrière van de onderste slokdarm sfincter versterkt.

Het is bewezen dat antireflux chirurgie (ARC) effectief is voor de behandeling van GORZ op korte en lange termijn.

Ondanks deze goede resultaten kan ARC gepaard gaan met peri- en postoperatieve complicaties. Het risico op postoperatieve complicaties moet daarom altijd per patiënt worden afgewogen ten opzichte van de voordelen van de operatie. Postoperatieve complicaties bestaan uit dysphagie, diarree, gas bloating syndroom, overgeven of niet kunnen boeren en andere gas gerelateerde symptomen en zuurbranden. Specifieke peri-operatieve complicaties voor LNF and LTF bestaan uit bloedingen, vagusletsel, pneumothorax, pneumomediastinum en perforaties van de bovenste tractus digestivus. Een gevreesde peri-operatieve complicatie is vagusletsel. In hoofdstuk 2 van dit proefschrift geven we een overzicht van de huidige literatuur met betrekking tot bewust (vagotomie) en onbewust aangebrachte schade aan de nervus vagus tijdens ARC en het effect hiervan op de resultaten van ARC. Wanneer de nervus vagus bewust was beschadigd als extra ingreep bij ARC dan werd een hogere prevalentie van diarree, dumpingklachten en misselijkheid gezien. Het is echter niet bekend of vagusletsel altijd leidt tot uiting van deze symptomen of dat deze in de meerderheid van de gevallen onopgemerkt blijven. Om dit uit te zoeken is een objectieve meting nodig om vagusletsel vast te kunnen stellen. In hoofdstuk 2 hebben 
we alle huidige literatuur die bekend is over vagusletsel na ARC op een rij gezet. We zien dat er tot nu toe slechts twee prospectieve studies zijn gedaan die met een objectieve meting vagusletsel hebben vastgesteld. We hebben gekeken naar de uitkomsten hiervan op ARC. In deze studies is de prevalentie van vagusletsel na ARC meer dan $10 \%$. Het voorkomen van vagusletsel had geen effect op de uitkomsten van de chirurgische behandeling. Wel moet hierbij worden meegenomen dat de follow-up in deze studies kort was en dat het een klein aantal patiënten betrof. Daarom hebben we in hoofdstuk $\mathbf{3}$ de korte en lange termijneffecten van vagusletsel na ARC in een groot cohort door middel van een objectieve test, de PP-test, onderzocht en het effect hiervan op de uitkomsten van ARC. De PP-test houdt in: de plasma respons van pancreas polipeptide op insuline-geïnduceerde hypoglycemie .

In deze studie kwam vagusletsel voor bij $20 \%$ van de patiënten en was op de lange termijn geassocieerd met meer ontevredenheid, het terugkeren van klachten en een hoger percentage her-operaties. Daarnaast was de maagontledigingssnelheid aanzienlijk verminderd in patiënten met vagusletsel.

Onze conclusie is dat de prevalentie van vagusletsel veel hoger is dan aanvankelijk werd gedacht en dat vagusletsel geassocieerd is met een slechtere uitkomst van ARC op lange termijn. We benadrukken dat zorgvuldige evaluatie van patiënten die zich presenteren met terugkerende of nieuwe klachten na ARC van groot belang is. Bij deze patiënten is onderzoek naar de aanwezigheid van vagusletsel geïndiceerd omdat hiermee duidelijk wordt welke vervolgstappen bij de behandeling genomen moeten worden. De objectieve evaluatie van vagusletsel kost echter veel tijd en is belastend voor de patiënt. Daarom zal het objectief testen van vagusletsel door middel van de PP-test geen routine onderzoek kunnen worden bij patiënten die ARC ondergingen.

\section{Nieuwe technieken ter behandeling van morbide obesitas}

Obesitas is wereldwijd een groot probleem. Op dit moment hebben 1.9 miljard mensen overgewicht en 600 miljoen mensen hiervan lijden aan obesitas. Dit is $13 \%$ van de totale wereldbevolking. lemand heeft obesitas wanneer hij een BMI van 30 of hoger heeft. Obesitas kan worden onderverdeeld in 3 klassen:

Klasse 1 BMI $30-35 \mathrm{~kg} / \mathrm{m}^{2}$, klasse $2 \mathrm{BMI} 35-40 \mathrm{~kg} / \mathrm{m}^{2}$, klasse $3 \mathrm{BMI} \geq 40 \mathrm{~kg} / \mathrm{m}^{2}$. Obesitas is geassocieerd met een verhoogd risico op het ontwikkelen van metabole stoornissen (diabetes mellitus type 2), cardiovasculaire aandoeningen, slaap apneu, artrose, snellere degeneratie van het bewegingsapparaat en zelfs een hogere kans op het ontwikkelen van kanker. Het is bewezen dat chirurgische behandelingen effectiever zijn dan niet chirurgische behandelingen voor het verlagen van het gewicht en daardoor voor het verminderen van deze geassocieerde comorbiditeiten. De meest uitgevoerde chirurgische behandelingen zijn de Roux en Y Gastric Bypass (RYGB) en de Sleeve Gastrectomie (SG). De SG is een restrictieve procedure terwijl de RYGB restrictie met malabsorptie combineert. Beide technieken bleken zeer effectief te zijn voor het verminderen van gewicht en comorbiditeiten zowel op korte als op lange 
termijn, maar gaan nog steeds gepaard met morbiditeit en mortaliteit. Daarnaast komen volgens de huidige richtlijnen alleen patiënten met $\mathrm{BMI} \geq 35 \mathrm{~kg} / \mathrm{m}^{2}$ in combinatie met comorbiditeiten of patiënten met een $\mathrm{BMI} \geq 40 \mathrm{~kg} / \mathrm{m}^{2}$ in aanmerking voor chirurgische behandeling. Daarom zijn de afgelopen decennia nieuwe technieken ontwikkeld die veiliger en minder invasief zijn om zo een oplossing te bieden voor de groeiende populatie patiënten met obesitas.

In het tweede gedeelte van dit proefschrift onderzoeken we verschillende nieuwe technieken en hun effectiviteit en veiligheid.

In hoofdstuk 4 geven we een overzicht van endoluminale technieken (technieken die via de slokdarm worden uitgevoerd), die structureel een verandering teweeg brengen in het bovenste gedeelte van het maagdarmstelstel en de resultaten hiervan met betrekking tot de behandeling van obesitas. Deze technieken verkleinen de maag van binnenuit met behulp van hechtingen of nietjes. Op korte termijn raakten patiënten met deze technieken $24 \%$ tot $58 \%$ van hun overtollige gewicht kwijt. Daarnaast hadden slechts 7 van de 277 patiënten postoperatieve complicaties waarvoor slechts één patiënt opnieuw geopereerd moest worden. Ondanks deze veelbelovende resultaten was er ook sprake van falen van deze technieken. Bij drie van deze technieken lieten de nietjes en hechtingen los waardoor het initiële effect van de behandeling teniet werd gedaan.

In hoofdstuk $\mathbf{5}$ onderzochten we elektrische stimulatie therapie van de maag (EST) ter behandeling van obesitas. De hypothese is dat door elektrische pulsen af te geven aan de maag de motoriek van de maag wordt verminderd, waardoor een vertraagde ontlediging van de maag optreedt. Dit zou dan leiden tot een sneller vol gevoel en dus tot vermindering van voedselinname. Deze elektrische stimulatie therapie bleek veilig te zijn. We konden echter helaas geen meetbaar effect aantonen op de eerder beschreven parameters, zoals maagontlediging, gewichtsverlies, hongergevoel en voedselinname.

In hoofdstuk 6 en 7 onderzochten we het effect van de duodenal-jejunal bypass liner (DJBL) op obesitas op korte en lange termijn. De DJBL bestaat uit een $60 \mathrm{~cm}$ lange niet permeabele fluorpolymeer liner. Door middel van een anker wordt deze bevestigd in de twaalfvingerige darm. De liner is aan beide kanten open zodat de voeding kan passeren. Op deze manier kunnen er geen voedingstoffen worden opgenomen in de twaalfvingerige darm. Na 6 tot 12 maanden werd de liner weer verwijderd. In dit proefschrift hebben we aangetoond dat de DJBL effectief bleek te zijn voor het verlagen van gewicht en cardiovasculaire en diabetes mellitus type 2 geassocieerde parameters op korte termijn. Zelfs na een succesvolle dieetperiode is de DJBL in staat om deze parameters nog verder te verlagen. Echter, op lange termijn onderging $1 / 3$ van de patiënten een operatie. Bij de patiënten die niet geopereerd werden, werd geen verschil gezien ten opzichte van de situatie vóór de behandeling met de DJBL.

Concluderend kunnen we stellen dat innovatieve nieuwe technieken voor de behandeling van obesitas op korte termijn veelbelovende resultaten laten zien; met name die technieken die structurele veranderingen teweegbrengen. De huidige 
chirurgische technieken zijn echter nog steeds superieur in vergelijking met deze nieuwe technieken. Maar deze nieuwe innovatieve technieken gaan wel gepaard met minder complicaties en hierbij is nog geen mortaliteit beschreven. Daarnaast is er een groot aantal patiënten (met overgewicht en klasse 1 obesitas) dat niet in aanmerking komt voor de huidige chirurgische technieken. Deze nieuwe technieken zouden voor deze groep wellicht een belangrijke rol kunnen gaan spelen. 
List of publications 



\section{List of publications}

\section{Published articles}

van Rijn S*, Roebroek YG*, Masclee AA, van Heurn LE, Bouvy ND. * Both authors contributed equally. Structural Endoscopic techniques to treat obesity: a review. Surg Technol Int. 2015;26:84-91.

Vogels R, Bosmans JW, van Barneveld KW, Verdoold V, van Rijn S, Gijbels MJ, Penders J, Breukink SO, Grijpma DW, Bouvy ND. A new Poly (1, 3-trimethylene carbonate) film provides safe and effective adhesion reduction after major abdominal surgery in a rat model. Surgery. 2015;157(6):1113-20.

van Rijn S, Roebroek YG, Bouvy ND, Conchillo JM, Masclee AA. The effect of vagus nerve injury on the outcome of antireflux surgery: a review. Dig Surg. 2016;33(3): 230-9.

van Rijn S, Rinsma NF, Ringers J, Gooszen $H$, van Rijn PJ, Veenendaal RA, van Herwaarden-Lindeboom MY, Conchillo JM, Bouvy ND, Masclee AA. Effect of Vagus Nerve integrity on short and long term efficacy of antireflux surgery. Am J of Gastroenterol. 2016;111(4):508-15.

Bosmans JW, Jongen AC, Boonen BT, van Rijn S, Scognamiglio F, Stucchi L, Gijbels MJ, Marsich E, Bouvy ND. Comparison of three different application routes of butyrate to improve colonic anastomotic strength in rats. Int J Colorectal Dis. 2017;32(3):305-313.

van Rijn S, de Jonge $C$, Betzel B, van Dijk DP, Janssen IM, Berends FJ, Bouvy ND, Greve JW. The effect of 6 and 12 months duodenal-jejunal bypass liner treatment on obesity and type 2 diabetes: a cross-over cohort study. Obes Surg. 2017 Nov 6. doi: 10.1007/s11695-017-2997-7.

\section{Submitted manuscripts}

Paulus GF*, van Avesaat M*, van Rijn S, Swain JM, Abell TL, Williams B, Bouvy ND, Masclee AA. * Both authors contributed equally. Multicenter, phase 1, open prospective trial in gastric electrical stimulation for the treatment of obesity: first in human results with the Exilis system.

van Rijn S*, Roebroek YG*, de Jonge C, Greve JW, Bouvy ND. * Both authors contributed equally. Effect of the EndoBarrier Device: a 4-year follow up of a multicenter randomized clinical trial. 

About the author 



\section{About the author}

Selwyn van Rijn was born on the $14^{\text {th }}$ of January 1986 in Zoeterwoude, The Netherlands. After graduating from high school in 2004 (Atheneum, Erasmus College, Zoetermeer), he studied pharmacy for one year before he got accepted into medical school at the university of Amsterdam in 2005. During medical school he finished a scientific traineeship at Maastricht University where he investigated the "Long-term outcome of laparoscopic antireflux surgery". This research was led by prof. dr. N.D. Bouvy and prof. dr. A.A.M. Masclee and became the foundation for the work presented in this thesis. After obtaining his medical degree in 2013, Selwyn started as a PHD-fellow affiliated to the division of General Surgery and the division of Gastroenterology of Maastricht University Medical Center (MUMC+) under supervision of prof. dr. N.D. Bouvy and prof. dr. A.A.M. Masclee.

Selwyn continued his medical career as a resident not in training in 2016, first the department of General Surgery at MUMC+ and from January 2017 onwards at the Catharina Hospital in Eindhoven.

In January 2018 Selwyn was accepted as a surgical resident and started his training at the Catharina Hospital in Eindhoven under supervision of dr. S.W. Nienhuijs. 

Dankwoord 



\section{Dankwoord}

Tijdens mijn studie geneeskunde in het AMC ben ik gestart met wetenschappelijk onderzoek naar antirefluxchirurgie in het MUMC. Deze wetenschappelijke stage heeft de basis gelegd voor dit proefschrift. De vuurdoop was het onderzoek naar complicaties van antirefluxchirurgie in samenwerking met de afdeling maag-, darmen leverziekten in het LUMC. Dit leidde tot een eerste mooie publicatie. Tijdens mijn onderzoeksperiode heb ik hierover mogen spreken op congressen in binnen- en buitenland.

De afgelopen vier jaar heb ik met medepromovendi en diverse instanties samengewerkt aan de verschillende artikelen, hetgeen heeft bijgedragen aan het tot stand komen van dit proefschrift. Graag wil ik dan ook de mensen bedanken die dit alles mogelijk hebben gemaakt, om te beginnen natuurlijk mijn beide promotoren.

Prof. dr. Bouvy, beste Nicole, tijdens het vierde jaar van mijn studie kwam ik via via bij jou terecht voor mijn wetenschappelijke stage over antirefluxchirurgie en vervolgens voor mijn semi-arts stage Heelkunde in Maastricht. Je enthousiasme en gedrevenheid voor het vak hebben mij gemotiveerd om onderzoek bij jou te gaan doen. Ik kon altijd bij je terecht, alles was mogelijk, je zag altijd wel weer oplossingen en had creatieve ideeën om het onderzoek en mij verder te brengen. Je hebt me veel vrijheid en vertrouwen gegeven, waardoor ik een fantastische promotietijd heb gehad. Van meet af aan was duidelijk dat ik chirurg wilde worden en daarin heb je me al die jaren heel erg gesteund. Waarvoor dank!

Prof. dr. Masclee, beste Ad, vrijwel direct werd je door Nicole bij mijn onderzoek betrokken. Je had meteen een heldere visie op mijn promotietraject, terwijl dat voor mij aanvankelijk nog helemaal niet zo duidelijk was. Je hebt me gemotiveerd om door te zetten en daardoor mijn grenzen te verleggen, ook als bijvoorbeeld een van de vele deadlines niet meer haalbaar leek. Bij de DDW heb je me uit de brand geholpen toen bleek dat door mijn onervarenheid bij de aanmelding voor een presentatie, er ineens allerlei voorwaarden rond het artikel op tafel kwamen. Je kritische blik en scherpzinnige commentaar hielpen mij telkens weer verder. Het overleg met jou duurde meestal niet lang maar was uiterst effectief. Dank voor alles wat je me hebt geleerd.

Mijn dank gaat uit naar de leden van de promotiecommissie, Prof. dr. Blaak, Prof. dr. Cuesta, Prof. dr. Smout, Prof. dr. Stassen en Dr. Straathof voor de kritische beoordeling van mijn proefschrift en de bereidheid om in de promotiecommissie zitting te nemen. 
Dr. Greve, beste Jan Willem, bij de laatste twee hoofdstukken van dit proefschrift over de EndoBarrier hebben we intensief samengewerkt. We hebben menig avond bij jou thuis gezeten om te discussiëren over de uitkomsten van het onderzoek. Jouw wetenschappelijke ervaring en kritische blik hebben ervoor gezorgd dat de inhoud naar een hoger niveau is getild.

Dr. Veenendaal, graag wil ik $u$ hartelijk bedanken dat $u$ mij de mogelijkheid hebt geboden om de data voor het vagusletselonderzoek bij antirefluxchirurgie bij $u$ in het LUMC te verzamelen.

Beste paranimfen, wat hebben we veel samengewerkt en mooie momenten tijdens onze promotietijd beleefd. En wat heb ik veel aan jullie te danken. Het was voor mij dan ook vanzelfsprekend om jullie te vragen om naast mij te staan tijdens de verdediging van dit proefschrift.

Beste Mark, toen ik mijn wetenschappelijke stage begon werd ik aan jou gekoppeld. Jij was al onderzoeker bij Prof. Masclee. Als echte Limburger vroeg jij je meteen af wat deze Hollander in Maastricht kwam doen. Het ijs was echter snel gebroken. Naast onze samenwerking op wetenschappelijk gebied werd ik door jou ingewijd in het Limburgse bourgondische leven. Ook was er altijd plek voor mij om te logeren in Casa Avesaat. Twee keer heb ik Club Moustache mogen meemaken en gelukkig was er beide keren voldoende mascara om mijn snor aan te dikken. Mark, mijn promotietijd met jou was zeer zeer "bruut"!

Beste Fedde, als refluxman van de MDL kon samenwerking met jou niet uitblijven; al snel was het refluxteam geboren. Je hebt me enorm geholpen om de weg te vinden in het wetenschappelijk onderzoek doen. Met ons artikel gingen we naar de DDW in Washington en wie schetste onze verbazing dat het een praatje werd op de presidential plenary session. Dat was een van de hoogtepunten van mijn promotietraject. Met jou had ik een hotline, een rode knop op mijn telefoon.

Het wordt weer tijd om een volgend hiphopconcert in te plannen.

Beste Yvonne, tijdens de afgelopen vier jaar hebben wij veel samengewerkt. De twee reviews die we samen hebben geschreven stonden onder grote tijdsdruk. Zo kwam het regelmatig voor dat ik jou ook in de weekenden daarover belde, zelfs zondagmorgen vroeg. Je kan gerust zijn, dat is nu voorbij.

Naast onze gesprekken over het wetenschappelijk gedeelte hebben we ook diepgaande gesprekken gevoerd onder het genot van een kop koffie en speciaal voor jou een stuk carrotcake. Je had altijd een luisterend oor.

Beste Charlotte, het was een eer om jouw studie over de EndoBarrier te mogen voortzetten. Hartelijk dank voor de samenwerking bij dit project. 
Door de inhoud van mijn onderzoek maakte ik deel uit van twee promotiegroepen, de groep van de MDL en die van de Heelkunde. Dit heeft mij veel contacten en inspiratie opgeleverd. De vrijdagmiddagborrels, feestjes, lab-uitjes en congressen vormden een welkome afwisseling naast al het serieuze werk. Onderzoekers van de chirurgie en in het bijzonder Anne Claire, Audrey, Briete, David, Frans, Givan, Kiran, Lori, Marissa, Martine, Ruben en Victor, graag wil ik jullie hartelijk bedanken voor jullie bijdragen en de vele gezellige momenten.

Het was bijzonder om als enige onderzoeker van de chirurgie samen met alleen maar MDL-promovendi naar de DDW in Washington af te reizen en in deze groep te worden opgenomen. Ankie, Bauke, Bram, Chantal, Ellen, Kirsten en Steven en natuurlijk ook Fedde en Mark, het was een geweldige reis.

Victor, roomy, we hebben als kamergenoten veel tijd met elkaar doorgebracht. Ons kamernummer Juicy van Notorious B.I.G. schalde regelmatig door de speakers. Dank voor alle goede gesprekken en je droge humor.

Graag wil ik alle overige medeauteurs bedanken voor de samenwerking en het tot stand komen van de publicaties. De afgelopen vier jaar heb ik met veel mensen samengewerkt, meer dan hierboven zijn genoemd. Graag wil ik ook hen bedanken voor hun bijdrage aan deze bijzondere periode.

Mijn bijzondere waardering gaat ook uit naar Tiny Wouters en Stefan Habets voor de mooie lay-out van dit boekje.

Tot slot

Lieve Carine, ondanks dat je verreweg de kleinste van ons tweeën bent, ben je altijd mijn grote zus geweest. Je ging me voor in de geneeskunde en bent al anesthesioloog. Dat vind ik soms best gek; mijn "kleine" zusje, al klaar met de opleiding en baas. Van kleins af aan stond je altijd voor me klaar en ging je als het nodig was voor me door het vuur. De enige die aan jouw broertje mocht komen was jijzelf en de rest moest het niet proberen; dat is nog steeds zo. Ook de afgelopen jaren ben je weer een grote steun voor mij geweest. Ik vind het fijn dat we altijd goede gesprekken kunnen voeren en dat we dit nu vaak doen, 's morgens in de auto als we allebei naar het ziekenhuis rijden.

Lieve Roosje en Pieter, Mama en Papa, wat hebben we toch een bijzondere band met elkaar in ons gezin. Mama, je zegt vaak als enige niet medicus, dat je "de enige normale" bent. Ik denk dat je daar gelijk in hebt! Jij bent de rots in de branding. Bij jou kan ik altijd terecht voor een wijs en weloverwogen advies. Ik vind het bijzonder hoe 
genuanceerd je bent, je mensen weet te motiveren en altijd het goede in iedereen weet te zien. Daar kan ik nog veel van leren.

Papa, vanaf kleins af aan probeerde ik al op je te lijken. Voordat ik naar school ging probeerde ik mijn haar net zoals jij in een scheiding te kammen, maar door alle krullen bleef het nooit zitten. Ik ben meermaals in je voetsporen getreden (skiën, tennissen, klimmen) en toen ik acht was beklommen we onze eerste berg in Zwitserland. Tijdens mijn studie geneeskunde stonden we samen op OK; voor ons beiden een bijzondere gebeurtenis. Ook nu kruipt het bloed waar het niet kan gaan en ben ik je weer gevolgd, ditmaal in de chirurgie. Je bent altijd een groot voorbeeld voor me geweest.

Carine, Roosje en Pieter, dank voor al jullie steun tijdens de afgelopen turbulente jaren! 